\title{
Proposta de Integração entre Bases de Dados e Recuperação de Informação Através de Linguagem Natural
}

\author{
Alida Maria Salimon \\ Orientação \\ Maria Carolina Monard
}

\begin{abstract}
Disscrlaçâo aprescnlada ao Instilulo de Ciências Malemáticas de São Carlos, Universidade de São Paulo para obtenção do Título de Mestre na área de Ciências da Computação e Matemática Computacional.
\end{abstract}

USP - São Carlos

Março de 1993 
A.

Maria Thereza,

Lafayete $e$

Jefter 


\section{Agradecimentos}

à Profa. Maria Carolina Monard, pela orientação;

à Profa. Lucia Helena Machado Rino, pelas críticas construtivas;

a Lafayete, Maria Thereza e Jefter, pelo apoio e incentivo;

a Jayme, pelo auxílio na implementação;

aos meus irmãos;

às Roselis, Ana Paula e Karen, pela amizade.

Este trabalho contou com o apoio financeiro da CAPES e FAPESP. 


\section{Resumo}

Embora a atual tecnologia não possa lidar com a complexidade e tamanho da linguagem humana, podem ser desenvolvidos sistemas úteis, apesar de mais limitados, em linguagem "natural".

Se o sistema considera uma declaração por vez e os assuntos sobre os quais o sistema pode dialogar são limitados, a gramática é menos complexa e pode ser mantida pequena. Assim, com uma área de interesse bem definida, é possível escolher um número limitado de estruturas sintáticas para suprir a maioria das necessidades do usuário.

Neste trabalho, é discutido o projeto e a implementação de uma interface simples para bases de dados. A interface oferece ao usuário a capacidade de obter informações da base através de requisições em linguagem natural.

Para isto, foram realizados estudos sobre alguns aspectos de sistemas de processamento de linguagem natural e o uso destes sistemas para interfaces a bases de dados. Alguns sistemas com interfaces em linguagem natural para consultar bases de dados foram pesquisados. Foran discutidas algumas considerações sobre a adequação do uso de linguagem natural para realizar esta tarefa.

O sistema foi desenvolvido para testar a possibilidade de se construir uma interface em linguagem natural que possa ser adaptada, por um especialista em processamento de linguagem natural, a novas bases de dados. 


\begin{abstract}
Even though the size and complexity of human languages cannot be handled by the current technology, useful but more limited "natural" language systems can be developed.

If the system considers one statement at a time and the topics about which the system can converse are limited, the grammar is less complex and can be kept small. Furthermore, within a well-defined subject area, it is possible to choose a limited number of sentence structures to handle most of user's needs.

In this work we discuss the design and implementation of a simple natural language interface to a computer database. The interface provides the user with the capability of obtaining information by querying the system in natural language.

The system has been constructed to test the feasibily of building a natural language interface that could be adapted, by an expert in natural language processing, as an interface to new databases.
\end{abstract}




\section{Conteúdo}

1 Introdução 1

1.1 Considerações Gerais . . . . . . . . . . . . . . . . . 1

1.2 Objetivos do Trabalho ................. 3

1.3 Organização do Trabalho . . . . . . . . . . . . . 3

2 Interfaces em Linguagem Natural 5

2.1 Considerações Iniciais . . . . . . . . . . . . . . 5

2.2 Tipos de Sistemas de Processamento de Linguagen Natural . . . 6

2.3 Aspectos do Processamento de Linguagem Natural . . . . . . . 8

2.3.1 Análise Léxica . . . . . . . . . . . . . . . 9

2.3.2 Análise Sintática ................. 9

2.3.3 Análise Semântica e Pragmática . . . . . . . . . . 9

2.4 Alguns Critérios para Avaliar Sistemas e Interfaces em Linguagem Natural . . . . . . . . . . . . . . . . 10

2.5 Considerações Finais . . . . . . . . . . . . . . . 16

3 Interfaces em Linguagem Natural para Bases de Dados 17

3.1 Considerações Iniciais . . . . . . . . . . . . . . . . . 17

3.2 Bases de Dados: um Ambiente para Pesquisa em Linguagem Natural 17 
3.3 Arquitetura Típica de um Sistema de Processamento de LN para Acesso à Base de Dados . . . . . . . . . . . . . . . . . 19

3.3.1 Análise de Sentenças ............... . 19

3.3.2 Acesso ao Conhecimento Específico . . . . . . . . . 22

3.3.3 Geração de Respostas . . . . . . . . . . . . . 23

3.3.4 Interação com o Usuário . . . . . . . . . . . . 23

3.4 Alguns Sistemas Existentes . . . . . . . . . . . . 23

3.5 Considerações Finais . . . . . . . . . . . . . . . . 26

4 Processamento de Linguagem Natural em Prolog 27

4.1 Considerações Iniciais . . . . . . . . . . . . . . . . 27

4.2 Gramática de Cláusulas Definidas . . . . . . . . . . . . . 28

4.3 Construção da Árvore Sintática . . . . . . . . . . . . . . 31

4.4 Entrelaçamento entre Sintaxe e Semântica . . . . . . . . . . 33

4.5 Consideraçồes Finais . . . . . . . . . . . . . . 36

5 Proposta de Integração entre Base de Dados e Interfaces em $\begin{array}{ll}\text { Linguagem Natural } & \mathbf{3 7}\end{array}$

5.1 Considerações Iniciais . . . . . . . . . . . . . . . . 37

5.2 Arquitetura do Sistema Proposto . . . . . . . . . . . 39

5.2.1 Base de Dados do SGBD . . . . . . . . . . . 39

5.2 .2 Tradutor para Prolog . . . . . . . . . . . 39

5.2.3 Base de Dados em Prolog . . . . . . . . . . . . 40

5.2.4 Interface em Linguagem Natural . . . . . . . . . . 40

5.3 Modelo de Dados . . . . . . . . . . . . . . . 42

5.4 Conteúdo da Base de Dados . . . . . . . . . . . . . 44

5.4 .1 Colegiados e Comissões . . . . . . . . . . . . . 44 
5.4.2 Composição dos Colegiados e Comissões . . . . . . . . 45

5.5 Descrição da Base de Dados . . . . . . . . . . . . . . . 47

5.5 .1 Professores ..................... 49

5.5 .2 Alunos .......................... 51

5.5 .3 Servidores ....................... 51

5.5.4 Prolessores Externos . . . . . . . . . . . . 52

5.5.5 Elementos da Comunidade . . . . . . . . . . 52

5.5 .6 Colegiados e Comissões . . . . . . . . . . . 53

5.6 Tipos de Consultas do SCC ................... 54

5.7 Considerações Finais . . . . . . . . . . . . . . 55

6 Descrição dos Módulos do SGBD do Sistema SCC 56

6.1 O Módulo Principal $(\mathrm{SCC}) \ldots \ldots \ldots \ldots$

6.2 Módulo de Manipulação de Dados dos Professores (ModPro) . . . 59

6.3 Módulo de Gerenciamento de Dados dos Servidores (ModSer) . . 62

6.4 Módulo de Manipulação de Dados dos Alunos, Professores Externos e Elementos da Comunidade (ModOut) . . . . . . . . 64

6.5 Módulo de Comissões e Colegiados (ModCol) . . . . . . . . . . 66

6.6 Módulo de Relatórios (ModRel) . . . . . . . . . . . . 66

6.7 Módulo de Utilitários (ModUti) . . . . . . . . . . . 66

7 Descrição da Interface em Linguagem Natural 68

7.1 Considerações Iniciais . . . . . . . . . . . . . . . . 68

7.2 Análise de Sentenças . . . . . . . . . . . . . . . 69

7.2 .1 Representação do Vocabulário . . . . . . . . . 69

7.2 .2 Análise Léxica . . . . . . . . . . . . . 77

7.2 .3 Análise Sintática . . . . . . . . . . . 77 
7.2.4 Análise Semântica _ . . . . . . . . . . . . . . . 79

7.2 .5 Análise Pragmática . . . . . . . . . . . . . . . 84

7.3 Acesso ao Conhecimento Específico . . . . . . . . . . . 84

7.4 Geração de Respostas . . . . . . . . . . . . . . . . . . . 88

7.5 Interação com Usuário $\ldots \ldots \ldots \ldots \ldots \ldots$

7.6 Adaptação do Sistema Proposto a Novos Domínios de Aplicação . 91

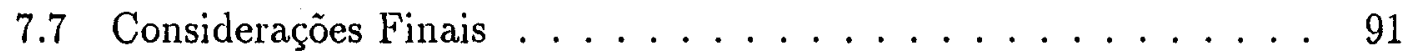

8 Conclusões $\quad 92$

$\begin{array}{ll}\text { Bibliografia } & 96\end{array}$ 


\section{Lista de Figuras}

2.1 Processo de Reconhecimento de uma Sentença . . . . . . . . . 8

3.1 Arquitetura Típica do Processamento de LN . . . . . . . . . . 20

5.1 Arquitetura do Sistema Proposto . . . . . . . . . . . 38

5.2 Diagrama E-R do SCC . . . . . . . . . . . . . 48

6.1 Tela Inicial do Sistema . . . . . . . . . . . . . . 57

6.2 Tela do Módulo Principal _... . . . . . . . . . . 57

6.3 Diagrama do Módulo Principal SCC . . . . . . . . . 58

6.4 Tela de Finalização do Sistema . . . . . . . . . . . . . . . . 59

6.5 Diagrama do Módulo ModPro . . . . . . . . . . . . . 60

6.6 Tela do Módulo ModPro . . . . . . . . . . . . . . . 60

6.7 Tela de Inclusão de Dados do Módulo ModPpes . . . . . . . . . . 61

6.8 Diagrama do Módulo ModSer . . . . . . . . . . . . . . . 62

6.9 Tela do Módulo ModSer . . . . . . . . . . . . . 62

6.10 Tela de Alteração de Dados do Módulo ModScat . . . . . . . . . . 63

6.11 Diagrama do Módulo ModOut . . . . . . . . . . . . . . 64

6.12 Tela do Módulo ModOut . . . . . . . . . . . . . . 65

6.13 Tela do Módulo ModCol . . . . . . . . . . . . . 66

6.14 Tela de Inclusão de Dados do Módulo ModCol . . . . . . . . . . 67 
6.15 Tela do Módulo ModRel . . . . . . . . . . . . . . . . 67

7.1 Representação Conceitual de uma Árvore-B . . . . . . . . . . . 72

7.2 Exemplo de Utilização da Interface em Linguagem Natural . . . 89

7.3 Exemplo de Utilização da Interface em Linguagem Natural . . . . 89

7.4 Exemplo de Utilização da Interface em Linguagem Natural . . . . 90 


\section{Lista de Tabelas}

4.1 Parte de uma Gramática para Língua Portuguesa . . . . . . . . . 29

4.2 Inclusão de Argumentos Extra na GCD . . . . . . . . . . . . 31

5.1 Representação do Modelo Relacional . . . . . . . . . . . 43

5.2 Casos de Duplicação de Dados no SCC . . . . . . . . . . . . 46

6.1 Tabela de Opções e Submódulos do Módulo Principal . . . . . . . 58

6.2 Tabela de Opções e Submódulos do Módulo ModPro . . . . . . . 59

6.3 Tabela de Opções e Submódulos do Módulo ModSer . . . . . . . . 63

6.4 Tabela de Opções e Submódulos do Módulo ModOut . . . . . . 65

7.1 Conteúdo dos Arquivos Manipulados pelo Sistema GBC . . . . . . 71 


\section{Capítulo 1}

\section{Introdução}

\subsection{Considerações Gerais}

A linguagem é um elo de comunicação entre o computador e o meio exterior. Esta interação faz parte das características operacionais, cujo desenvolvimento está estreitamente relacionado ao desenvolvimento físico do computador. Corn as melhorias que foram realizadas na máquina, aumentou a necessidade de se estudar maneiras mais fáceis e expressivas de comunicação. No início, eram utilizadas linguagens de baixo nível e com a evolução das pesquisas foram desenvolvidas então as linguagens de alto nível.

Qual seria o limite da capacidade de expressão e facilidade de uso que estas linguagens poderiam atingir? A linguagem utilizada pelas pessoas para se comunicarem - a linguagem natural - seria o mais alto nível de linguagem de programação, o que evidentemente é considerado uma meta muito ambiciosa.

A Lingǘstica Computacional é uma área interdisciplinar, que se originou de pesquisas em Inteligência Artificial, e diz respeito à aplicação de um paradigma computacional para o estudo científico da linguagem humana e a construção de sistemas que processem ou analisem a linguagem escrita ou falada [Ballard 87]. Duas razões principais motivaram este estudo [Allen 88 ]:

- a motivação tecnológica é construir sistemas computacionais inteligentes, tais como interfaces em linguagem natural para bases de dados, sistemas de análise de textos, sistemas de compreensão da fala, etc;

- a motivação lingüística, ou ciência cognitiva, é obter um conhecimento melhor sobre a comunicação humana através de linguagem natural. 
Os computadores não podem lidar com todas as capacidades do ser humano envolvidas na comunicação através da linguagem - memória, raciocínio, formulação de hipóteses, conhecimento social, etc. - e ninguém jamais ousou dizer que desenvolveu um sistema computacional de compreensão real da linguagem natural [Wallace 84]. Na verdade, a maioria dos grupos de pesquisas trabalham com subconjuntos da linguagem natural. Os usuários da linguagem adaptam conscientemente sua maneira de falar aos seus companheiros, e o subconjunto da linguagem natural poderia ser suficientemente "denso", de maneira que o usuário a usasse sem esforço consciente.

Um sistema de processamento de linguagem natural pode ser utilizado em vários tipos de sistemas e, para reconhecer e manipular uma linguagem, ele deve ser capaz de aceitar entradas em linguagem natural, armazenar conhecimentos relacionados ao domínio de aplicação, realizar inferências a partir destes conhecimentos e, baseado neste conhecimento, gerar respostas às solicitações dos usuários. Não ë fácil desenvolver um sistema que execute todas estas tarefas, uma possibilidade é desenvolver um sistema que realize um conjunto delas.

Uma possível abordagem é a construção de um sistema capaz de entender, interpretar e responder requisições em linguagem natural de um grupo de usuários, sobre um assunto bem determinado, cujo conhecimento já está armazenado no sistema. A abordagem em um domínio de conhecimento limitado viabiliza a implementação deste tipo de sistema, pois cria uma expectativa do tipo de conversação que o usuário terá com o sistema, permite a definição básica do vocabulário, que é restrito ao domínio de aplicação, e os conhecimentos que devem estar contidos no sistema podem constituir um mundo fechado, considerando falsas as informações que não estiverem contidas na base de conhecimento [Miranda 86].

Os sistemas de Perguntas e Respostas possuem uma abordagem semelhante à descrita, e têm sido os mais populares e de implementação menos complexa, pois utilizam uma base de conhecimento para um domínio de aplicação limitado, o que restringe os tipos de perguntas e o vocabulário de interação. Uma das aplicações deste tipo de sistemas é a interface em linguagem natural para acesso a bases de dados, que substitui as linguagens formais de acesso aos dados de um sistema gerenciador de bases de dados - SGBD.

As bases de dados fornecem um domínio explicitamente limitado, o que torna as interfaces em linguagem natural uma possibilidade prática de aplicação. Entretanto, é necessário cuidado para que as técnicas - resultantes das tentativas de exploração desta característica - sejam suficientemente gerais para possibilitar sua aplicação a novos domínios.

A adaptação de uma interface em linguagem natural para novos domínios é uma questão importante. Mesmo no caso de interfaces de propósito geral, é necessária 
uma interface intermediária que incorpore o conhecimento específico do domínio em uma base de conhecimento. Por este motivo, existe uma relação entre portabilidade e abrangência, pois uma interface desenvolvida para uma base de dados específica - que incorpore muitos "atalhos" específicos da base de dados - provavelmente não seria capaz de enfrentar usos ou evoluções da base de dados não previstos pelos projetistas.

\subsection{Objetivos do Trabalho}

Em todo sistema que manipula grande quantidade de informações, uma das preocupações é armazenar e recuperar estas informações de maneira rápida e eficiente. Os sistemas de gerenciamento de bases de dados podem ser incluídos neste tipo de sistema. O SGBD oferece, além de outras, a facilidade de programação de uma interação com o usuário através de várias funções para realização de operações básicas de manipulação de dados. Entretanto, as linguagens formais de acesso aos dados apresentam, em geral, uma estrutura rígida. As interfaces em linguagem natural por sua vez, permitem a obtenção das informações sem a necessidade de conhecer a linguagem formal de acesso aos dados ou como e onde eles estão armazenados.

O objetivo deste trabalho foi estudar uma maneira de integrar os dois tipos de sistemas - SGBD e interface em linguagem natural. Com base neste estudo foi proposta uma arquitetura e desenvolvida uma aplicação do sistema, cujas informações se referem à composição dos colegiados e comissões do Instituto de Ciências Matemáticas de São Carlos - ICMSC/USP.

Além de extrair e aproveitar de cada um destes sistemas suas características mais favoráveis, um outro objetivo do sistema proposto foi facilitar sua adaptação a novos dominios, desenvolvendo-o em módulos independentes, que realizam tarefas específicas e apresentando, através da aplicação desenvolvida, um modelo para as modificações necessárias nos módulos que sejam dependentes do domínio.

\subsection{Organização do Trabalho}

O trabalho está organizado da seguinte forma:

No Capítulo 2, são apresentadas algumas classificações dos sistemas de processamento de linguagem natural segundo alguns critérios e os casos em que eles são mais apropriados, bem como aspectos do processamento de linguagem natural e alguns critérios para avaliação destes sistemas. 
O Capítulo 3 aborda interfaces em lingagem natural para acesso a bases de dados. São apresentadas razões para se pesquisar linguagem natural para esta tarefa, a arquitetura típica de um sistema de processamento de linguagem natural para acesso a bases de dados e a descrição de alguns sistemas existentes.

No Capítulo 4, são abordados alguns aspectos do processamento de linguagem natural com a utilização da linguagem de programação lógica Prolog. São apresentadas a utilização da Gramática de Cláusulas Definidas, a construção da árvore sintática e o entrelaçamento entre sintaxe e semântica.

No Capítulo 5, é apresentada a arquitetura do sistema proposto que integra um SGBD com uma interface em linguagem natural para recuperação de conhecimento, bem como a base de dados que foi desenvolvida como aplicação desta proposta.

No Capítulo 6, são descritos os módulos de manipulação dos dados do sistema SCC na base de dados do SGBD.

No Capitulo 7, são descritos os módulos que compõem a Interface em LN do sistema, bem como algumas estruturas e procedimentos utilizados nestes módulos. São apresentadas também as ações necessárias para a adaptação do sistema a um novo domínio de aplicação.

Finalmente, o Capítulo 8 contém as conclusões sobre o trabalho desenvolvido e sugestões para trabalhos futuros. 


\section{Capítulo 2}

\section{Interfaces em Linguagem Natural}

\subsection{Considerações Iniciais}

A Linguagem Natural - LN - é uma das formas de manifestação externa da atividade mental humana. Outras formas, como posturas, gestos, ações, podem exprimir emoções e raciocínio, mas é na linguagem que mais se vê a marca da humanidade, ao menos na expressão do raciocínio. Em particular, a linguagem é um meio muito rico de comunicação entre pessoas. Esta comunicação pode ser de idéias, emoções, desejos, experiências e outras atividades mentais [Savadovsky 88].

Como por muito tempo os únicos a usarem linguagem "natural" foram os humanos, fica difícil separar as capacidades lingüísticas dos parceiros de conversação de outras capacidades tais como memória, raciocínio, solução de problemas, formulação de hipóteses, classificação, planejamento, conhecimento social, aprendizagem, compartilhamento de informações, modelagem de conhecimentos e capacidades do outro, processamento de grandes quantidades de informações bem como atualização destas estruturas durante a conversação.

Com relação a um computador, não se espera que ele possụa todas estas capacidades e, por isso, existern limitações no que se pode esperar de uma interface em LN. Entretanto, o que se encontra é um preocupante grau de superestimação das capacidades de um sistema de LN e uma subestimação da complexidade da linguagem humana, como por exemplo achar que a interface faz com que as pessoas usem uma linguagem livre e significativa, quando na verdade são forçadas a usar o vocabulário e conceitos estabelecidos pelo projetista da interface. Felizmente, um conjunto limitado destas capacidades de linguagem será suficiente para a maioria 
das aplicações, e o usuário pode facilmente adaptar alguns dos aspectos de sua linguagem baseado no conhecimento de seu parceiro, no caso o computador.

\subsection{Tipos de Sistemas de Processamento de Linguagem Natural}

Segundo Kaplan em [Kaplan 82b], desde o primeiro programa escrito, o custo do desenvolvimento e manutenção de um software tem aumentado, e esta foi uma das razões para se procurar melhores maneiras de comunicação com os computadores. Para exemplificar, pode-se verificar a evolução das linguagens de programação, que começou com o código de máquina, passando por assembler, linguagens de alto nível e geradores de relatórios, observando-se o crescente desejo de se utilizar LN. Contudo, é razoável questionar a existência de um limite para este desenvolvimento, ou quão expressivas e fáceis de usar tais linguagens possam ser.

Uma das primeiras áreas de pesquisa em processamento de LN foi o desenvolvimento de interfaces para bases de dados, porque seu sucesso não dependia da resolução de todos os problemas de linguagem e conlıecimento, e mesmo assim oferecia um sólido ambiente de teste e a experiência ganha seria valiosa para o estudo de tarefas mais complexas. Entretanto, alguns pesquisadores defendem a idéia de que consulta a bases de dados não é mais uma boa área de pesquisa e sugerem outras áreas, como interfaces para sistemas operacionais, para sistemas especialistas, de suporte à decisão e interfaces para integrar várias funções ou sistemas.

Alguns produtores de software, para alcançar a popularidade das interfaces em $\mathrm{LN}$, fizeram pequenas modificações em seus sistemas para que eles usassem palavras, parecendo entender a língua nativa. Entretanto, fazendo algumas comparações com a língua permitida pela interface, percebe-se que elas não são muito próximas e que pouco processamento de LN está sendo realizado. Como exemplo, a entrada

\section{LISTE OS GERENTES QUE SÃO HOMENS}

pode funcionar em um destes sistemas, porém suas variações

QUAIS OS GLRENTLS QUE SÃO HOMLNS

ou 


\section{DÊ-ME O NOME DOS GERENTES HOMENS}

não funcionam.

Os sistemas de processamento de linguagem natural - PLN - podem ser separados em diversos tipos segundo alguns critérios adotados, por exemplo Bates em [Bates 87] separa os sistemas pela maneira de comunicação que eles podem apresentar:

- comunicação em LN;

- comunicação natural, que pode ou não usar linguagem, e não requer aprendizagem;

- ou possuir uma interface amigável, que geralmente não usa linguagem e é fácil de aprender, mas não é necessariamente natural.

Kaplan distingue os sistemas pela maneira que eles reagem a uma entrada razoável que é mal interpretada [Kaplan $82 \mathrm{~b}$ ], por exemplo:

- o projetista de um sistema em LN (que visa processar qualquer expressão aceitável) provavelmente voltará à mesa de projetos;

- o projetista de um sistema "English-like" (que lida apenas com alguns termos e formas) dirá "Você tem que se expressar desta maneira."

Outra distinção que se pode fazer é entre sistemas de propósito geral ou específico:

- sistemas de propósito geral: o conhecimento dependente do domínio é claramente separado do conhecimento geral semântico e sintático; oferecem a promessa de fácil portabilidade para novos domínios, e têm como desvantagem o longo tempo necessário para clesenvolver os componentes independentes do domínio;

- sistemas de propósito específico: possuem o conhecimento do domínio particular em baixos níveis de processamento e as regras de inferência são formuladas apenas para este domínio particular; têm como vantagem atingir excelente performance para seu domínio, mas é difícil para alguém, exceto seu projetista, modificá-los. Além disto, para adaptá-los a um novo domínio, eles têm que ser praticamente reescritos. 


\subsection{Aspectos do Processamento de Linguagem Natural}

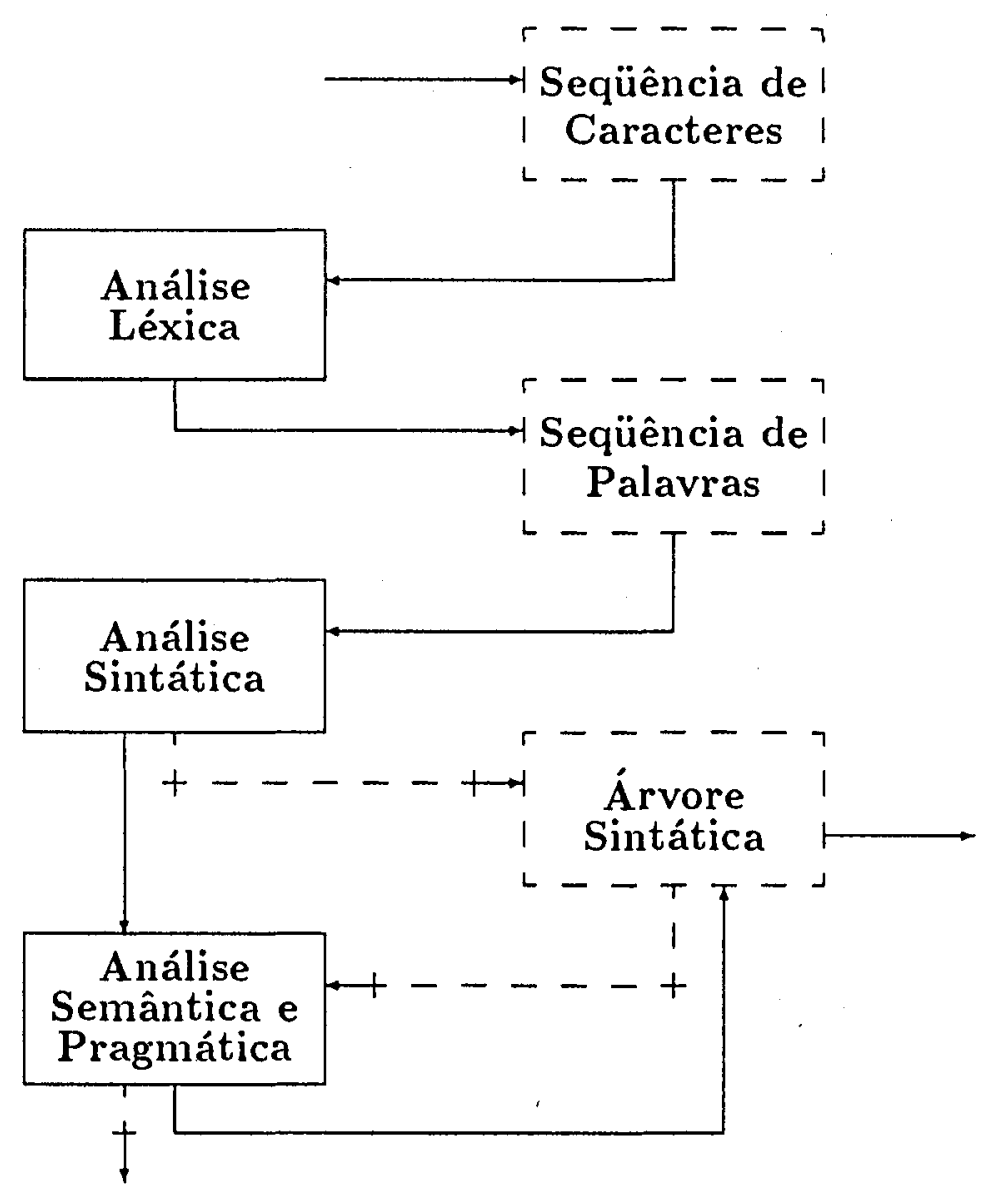

Figura 2.1: Processo de Reconhecimento de uma Sentença

O processo automático de reconhecimento de uma certa linguagem, quer natural ou artificial, requer os mesmos passos. No caso das linguagens computacionais, os compiladores, interpretadores ou processadores de comandos são responsáveis por organizar seqüências de letras em palavras, seqüências de palavras em frases, etc, aplicando regras para reconhecer as construções válidas da linguagem, através de métodos específicos de análise. Estes métodos envolvem a análise léxica, a análise sintática e a análise semântica. No caso de processamento de linguagem natural, existe também a análise pragmática, que consiste do estudo do uso da linguagem e sua correlação com a realidade [Miranda 86]. A Figura 2.1 mostra as entradas e os resultados de cada um dos passos citados anteriormente. 


\subsubsection{Análise Léxica}

A função da análise léxica é delimitar e separar as palavras de um texto através dos caracteres que o compóem, reconhecendo os constituintes do texto, ou frase, como ítens léxicos. Mesmo em sistemas que possuam uma gramática independente do domínio, o vocabulário é dependente de alguma maneira, pois existem palavras de classes fechadas, tais como determinantes, preposições, conjunções e verbos auxiliares, que são independentes do domínio, mas existem palavras que são especificas do domínio, que devem ser incluídas quando o sistema for transportado para domínios específicos.

É possivel que várias palavras representem um único ítem léxico, como "João Roberto". Neste caso, é função do analisador léxico agrupar as palavras "João" e "Roberto" de forma que elas representem o indivíduo cujo nome é "João Roberto" de forma única.

O resultado da análise léxica é usado nos próximos passos de análise e devem ser guardados em uma estrutura conveniente.

\subsubsection{Análise Sintática}

A sintaxe de uma linguagem compreende suas regras gramaticais, que devem ser aplicadas para verificar se uma dada sentença está escrita corretamente em termos sintáticos. Desse modo, estabelecem-se relacionamentos entre os itens léxicos fornecidos pela fase de análise anterior, a fim de extrair a estrutura sintática da sentença, quando esta for válida. Existem vários formalismos gramaticais que podem ser utilizados nesta fase de análise para descrever a estrutura das sentenças e caracterizar todas as estruturas legais de uma linguagem. Alguns desses formalismos são as gramáticas livres de contexto, as redes de transição simples, as redes de transição recursivas, as redes de transição ampliadas, etc.

Esta fase da análise será tratada de forma mais detalhada no Capítulo 4.

\subsubsection{Análise Semântica e Pragmática}

A nível de processamento semântico e pragmático, o computador se diferencia do ser humano como interlocutor, pois a extração do significado computacional limita-se aos problemas de representação do conhecimento e a relacionamento entre constituintes de frases. Lingüisticamente, este processamento diz respeito a características, tais como ironia, gestos, expressões, que, ao menos por enquanto, não se consegue representar computacionalmente. 
Uma sentença pode estar gramaticalmente correta, mas sem significado, como na sentença

\section{O peixe dirigiu a 300 palavras por minuto.}

que é gramaticalmente correta, mas é de conhecimento geral que peixes não dirigem e que a velocidade de dirigir não é medida em palavras por minuto, o que é detectado durante a análise semântica.

Os processamentos semântico e pragmático dizem respeito ao significado, mas não existe um limite preciso entre eles. O conhecimento pragmático diz respeito a maneira como as sentenças são usadas em diferentes contextos e como o contexto afeta a interpretação das sentenças [Allen 88]. Do ponto de vista computacional, pode-se definir a semântica como a produção de uma representação do significado que seja compreensivel para o computador, e a pragmática como um processamento que faça uso desta representação. O esquema apresentado a seguir resume as fases de análise de uma sentença, do ponto de vista computacional.

\begin{tabular}{|rcccc|}
\hline forma & $<->$ & sintaxe & $<->$ & lingüisticamente correta \\
significado & $<->$ & semântica & $<->$ & psicologicamente real \\
uso & $<->$ & pragmática & $<->$ & computacionalmente realizável \\
\hline
\end{tabular}

Nota-se que existe uma interdependência entre as três fases de análise apresentadas. A sintaxe e a semântica dependem da aquisição precisa do vocabulário por parte do léxico, que garante o conhecimento das palavras, que serão agrupadas em estruturas, às quais se pode associar um significado. Com relação à interpretação, a interdependência cutre a sintaxe e a semântica se acentua, pois as regras semânticas são delimitadoras das possibilidades de interpretação sugeridas pela sintaxe, eliminando certas construções sintáticas que, embora corretas, não correspondem a significados corretos no domínio.

\subsection{Alguns Critérios para Avaliar Sistemas e Interfaces em Linguagem Natural}

É muito difícil avaliar um sistema de PLN, pois pouco foi publicado sobre testes práticos de interfaces em linguagem natural. $O$ resultado de experimentos em ambientes particulares não pode ser amplamente aplicável devido aos fatores contextuais envolvidos. Um outro problema é que variações no domínio ou padrões de uso dificultam a extrapolação de uma aplicação para outra e também a comparação entre diferentes interfaces [Copestake 90]. 
Embora exista esta dificuldade, existem alguns tópicos que ajudam na avaliação de um sistema ou interface em $\mathrm{LN}$, e é importante observar que nesta avaliação a questão apropriada seria

Com que profundidade o sistema em avaliação lida com certo aspecto, e qual a importância deste aspecto para a aplicação em questão? [Bates 87]

Alguns destes aspectos são apresentados a seguir, entretanto deve-se observar que alguns critérios não são exclusivos de interfaces de linguagern natural.

- Adaptabilidade. Mede qual a rapidez e o conforto de um usuário no reconhecimento e adaptação às limitações do sistema.

- Abrangência. É a caracterização da competência lingüística do sistema. Pode ser categorizada em dimensões, tais como abrangência léxica, que diz respeito ao conteúdo do vocabulário; abrangência sintática, que avalia o conjunto de fenômenos sintáticos com os quais o sistema lida; abrangência semânlica, que diz respeito ao conhecimento do domínio. O vocabulário e a gramática têm que ser suficientemente ricos para abranger os tipos de consultas que podem ser feitas, e de maneira natural, mas uma abrangência muito grande pode aumentar, entre outros, os problemas de ambigüidade.

- Inferência. É a capacidade de obter conclusões lógicas baseadas nos dados da base e/ou conhecimento geral do assunto e não apenas de dados explicitamente armazenados. Por exemplo: supondo que uma base de dados contém registros sobre empregados, que contêm um campo sobre serviços nos quais ele trabalhou e registros sobre serviços prestados a clientes pela companhia, que contêm um campo com o nome do cliente, uma consulta natural seria determinar se um empregado já trabalhou com determinada empresa. Para isso o sistema tem que ser capaz de concluir, procurando na base de dados, se o empregado trabalhou em um serviço que tenha a empresa como cliente, ainda que nenhum serviço esteja explícito na consulta e nenhuma relação trabalhar exista na base.

- Controle da Interpretação pelo Usuário. É a possibilidade do usuário estabelecer una ordem padrão nos casos onde o sistema tem várias possibilidades de interpretação. Se o usuário pergunta

QUAL O MAIOR DEPAR'TAMENTO NA COMPANHIA?

neste caso, maior poderia ser em termos de número de empregados, número de empregados de certo tipo, total de vendas, ou outra métrica e, então, 
o usuário poderia determinar uma métrica padrão, temporária ou permanente, para evitar ter que ser questionado todas as vezes que sua consulta envolver alguma métrica.

- Elipses. Na conversação, algumas partes das sentenças não são ditas e se assume que as partes omitidas podem ser preenchidas pelo ouvinte que compartilha o contexto da discussão. Um exemplo disto é a seguinte seqüência de perguntas:

\section{QUANTAS PESSOAS FORAM CONTRATADAS NO MÊS PASSADO? \\ E NO MÊS ANTERIOR?}

É enganador pensar que um sistema lida com qualquer tipo de elipse. $\mathrm{Na}$ verdade, ele pode lidar com un subconjunto destes tipos, que seja o mais interessante para a aplicação.

- Referências Anafóricas. O uso de pronomes é extremamente complexo, e por isso é preciso cuidado ao avaliar a capacidade de um sistema em lidar com eles. Os pronomes podem se referir a objetos explicitamente mencionados no discurso anterior, ou a objetos que ainda serão mencionados, por exemplo:

Depois que o TRANSFERIRam do Departamento 22, Joño TRABALIIOU NA DIVISÃO $6 ?$

Ou ainda, o pronome rêfere-se a ações, ou pode referir-se a objetos da resposta anterior:

P: QUANTOS PROJETOS ESTÃo ADIANTAdOS NO CRONOGRAMA?

R: UM.

P: QUEM É RESPONSÁVEL POR ELE?

- Quantificação. O uso de palavras como algum, todo e qualquer pode complicar o entendimento da linguagem natural, porque sua interpretação depende de conhecimento geral ou talvez do conhecimento detalhado do domínio particular. Por exemplo, as consultas:

TODAS AS PESSOAS DO DEPARTAMENTO 5 APRESENTARAM SEU RELÁTÓRIO DE VIAGEM?

TODAS AS PESSOAS DO DEPARTAMENTO 5 CONSULTARAM SEU GERENTE DE DEPARTAMENTO? 
são estruturalmente equivalentes, mas o primeiro caso diz respeito a vários relatórios e o segundo caso a um único gerente.

- Negação. A negação é particularmente enganadora quando combinada com quantificação. A sentença

TOdOS OS PROJETOS NÃO FORAM COMPLETADOS A TEMPO.

pode significar, em linguagem corrente, que nenhum projeto foi completado ou que alguns foram completados a tempo e outros não.

- Relações Temporais. Ainda não existem mecanismos para representar efetiva e eficientemente eventos ou objetos que mudam com o tempo. Felizmente, a maioria das aplicações de bases de dados contém dados históricos limitados que não apresentam relações complexas de tempo.

- Conjunção e Disjunção. Geralmente as palavras e e ou agregam unidades completas (o livro e o autor), mas às vezes agregam segmentos descontínuos, por exemplo:

\section{EU ENCAPEI E GUARDEI O LIVRO NOVO.}

A manipulação de conjunções simples já é parte dos sistemas atuajs, mas a combinação de conjunções com elipses e outros fenômenos ainda é um problema em aberto.

- Entrada Telegráfica. Em um sistema usado freqüentemente, o usuário pode querer abreviar a entrada deixando de escrever algumas palavras. Por exemplo,

\section{DÊ-ME OS PROFESSORES MS1.}

que também pode ser escrita como

\section{DÊ-ME OS NOMES DOS PROFESSORES CUJA CATEGORIA É MS1.}

Embora seja interessante que o sistema entenda tais entradas, isto pode causar equivocos ou diminuição da habilidade em usar pontos refinados da estrutura gramatical.

- Portabilidade. Existem alguns tipos de portabilidade, mas o mais importante na prática é o que se refere à mudança do sistema para novos domínios. Outro tipo de portabilidade é o uso do sistema com diferentes sisternas gerenciadores de bases de dados. Nenhum sistema, por mais sofisticado que seja, é adaptado a novos domínios sem alguma intervenção humana, uma questão importante é quanto treinamento e experiência é necessária para 
esta intervenção. Se a adaptação é feita por uma pessoa que não seja o projetista do sistema, é necessário que o sistema possua ferramentas para auxiliar nesta tarefa.

- Robustez e Respostas a Entradas Problemáticas. Pode-se discernir as entradas problemáticas entre os erros reais, como erros de ortografia; os enganos, onde o usuário não está avisado sobre a natureza do domínio e faz uma consulta inadequada; ou as falhas do sistema, onde as questões do usuário são corretas mas o sistema não pode interpretá-las. Uma solução para este problema poderia ser descrever no sistema todo o domínio da base de dados detalhadamente, o que não é possível, a menos que ele seja trivialmente simples.

- Auxílio a Usuários Inexperientes. Algumas facilidades podem ser oferecidas pela interface para facilitar e otimizar seu uso por usuários inexperientes. Alguns exemplos são oferecer uma estimativa do custo de uma consulta antes de executá-la, principalmente em grandes bases de dados, e apresentar as respostas de mancira apropriada e informativa (por exemplo, apresentar um gráfico ao invés de uma lista de tuplas em alguns casos).

- Ambigüidade. As várias origens da ambigüidade e as maneiras de tratar este problema é uma questão importante em qualquer sistema de linguagem natural. Pode-se distinguir duas classes principais de ambigüidade: estrutural e léxica. Por exemplo

\section{DÊ-ME UMA LISTA DE ESTUDANTES E UMA DE PROFESSORES COM SALÁRIO MENOR QUE DEZ SALÁRIOS MÍNIMOS.}

é estruturalmente ambígua, pois pode ser interpretada como estudantes e professores com salário menor que dez salários minímimos ou apenas o salário dos professores é especificado. Neste caso, o conhecimento geral não resolve esta ambigüidade, mas pode existir um domínio onde apenas a segunda interpretação seja considerada válida, por não existir na base informação sobre salário de estudantes. Um exemplo de ambigüidade léxica seria a palavra curso, pois pole significar cursos de golfe, de culinária, curso do rio, mas em um domínio que contenha apenas informações de cursos com conferencistas, a consulta

\section{QUANTOS CURSOS EXISTEM?}

não é ambígua.

Percebe-se que a questão é como determinar e representar as restrições do domínio, e como aplicá-las na resolução de uma consulta ambígua. Em [Copestake 90], as autoras consideram três classes de restrições: aquelas que estão explicitamente armazenadas no SGBD, as que estão implícitas no 
esquema da base de dados e aquelas que podem fazer parte do conhecimento de um usuário especialista mas não são deriváveis do SGBD. A seguir são apresentados alguns exemplos e considerações sobre suas restrições.

No exemplo anterior, se for considerado que apenas os professores possuem salário, esta restrição pode ser determinada diretamente do esquema da base de dados, mas outras restrições podem ser mais sutis. Por exemplo:

QUE CURSOS TODOS OS PROFESSORES LECIONAM?

pode ser ambígua entre

LISTE OS CURSOS TAL QUE TODOS OS PROFESSORES LECIONAM EM CADA CURSO.

$\mathrm{e}$

PARA TODOS OS PROFESSORES LISTE OS CURSOS QUE ELES LECIONAM.

No domínio em questão pode estar incluída a restrição de que existe apenas um professor por curso, e se o usuário souber disto, a questão não é ambígua. Se no domínio existe a restrição de que ninguém pode matricular-se em um curso sem ter cursado seus pré-requisitos, a questão

LISTE OS ESTUDANTES QUE ASSISTEM $A O$ CURSO DE SISTEMAS OPERACIONAIS E OS QUE ASSISTEM AO CURSO DE BASES DE DADOS QUE NÃO CURSARAM OS PRÉ-REQUISITOS DE SISTEMAS OPERACIONAIS.

não é ambígua. Se existe a informação de que a linguagem $\mathrm{C}$ é um prérequisito para o curso de sistemas operacionais mas que o curso de bases de dados não é, então a questão abaixo é ambígua.

LISTE OS ESTUDANTES QUE ASSISTEM AO CURSO DE SISTEMAS OPERACIONAIS E AQUELES QUE ASSISTEM AO CURSO DE BASES DE DADOS E NÃO CURSARAM OS PRÉ-REQUISISTTOS DE PROGRAMAÇÃo EM LINGUAGEM C.

Neste caso a informação é um dado e não conhecimento, e a ambigüidade não pode ser resolvida sem uma consulta à base de dados. Na questão

QUAIS CURSOS TODO ESTUDANTE CURSA?

é estruturalmente ambígua, e esta ambigüidade não pode ser resolvida pelo conhecimento do domínio. 


\subsection{Considerações Finais}

A comunicação entre parceiros humanos possui características que, ao menos por enquanto, não se consegue reproduzir computacionalmente em interfaces homemmáquina, mesmo que elas sejam realizadas através de linguagem natural. Ainda assim, é possível considerar interfaces em LN para domínios de conhecimento restritos.

As interfaces em LN são adequadas para aplicações nas quais os custos, pessoais ou financeiros, para a aprendizagem de uma linguagern formal e especifica pode: exceder o valor da informação obtida. Entretanto, existem alguns casos em que a linguagem natural não é a opção mais adequada, como por exemplo quando o domínio envolve identificação de objetos ou controles físicos, tais como jogar video game ou dirigir um carro, ou ocorrem situações que requerem a apresentação de uma figura ou alguma forma de apontar elementos de uma imagem, com mouse ou uma tela sensivel ao toque por exemplo, ou ainda se o conteúdo das interações é muito limitado e a brevidade de urna linguagem artificial é desejável.

Não existe ainda um critério único para avaliar as interfaces em linguagem natural, mas existem características que são mais importantes para cada domínio e que podem auxiliar nesta avaliação. 


\section{Capítulo 3}

\section{Interfaces em Linguagem Natural para Bases de Dados}

\subsection{Considerações Iniciais}

Surgem, com freqüência, novas áreas de aplicações para bases de dados e seu uso aumenta rapidamente. Um passo importante para a melhoria das interfaces homem-máquina é poder isolar o usuário de detalhes da base de dados como e onde estão os dados, por exemplo - e assim evitar a dependência de programadores e analistas que conhecem estes detalhes.

A interface para bases de dados foi uma das primeiras aplicações de processamento de linguagem natural. Embora seja fácil desenvolver uma interface para um conjunto limitado de questões, uma linguagem natural restrita não funciona como bom substituto para uma linguagem formal, pois é muito difícil estabelecer um subconjunto da linguagem que seja suficientemente expressivo, evite ambigüidades e pareça razoavelmente natural. Entretanto, uma interface que manipule una linguagem natural irrestrita e a interprete apropriadamente, que auxilie un usuário inceperiente e possa ser facilmente adlaptada a novas bases de dados está um tanto quanto distante do atual estado da arte [Wallace 84].

\subsection{Bases de Dados: um Ambiente para Pes- quisa em Linguagem Natural}

Os pesquisadores escolheram as consultas às bases de dados como um dos primeiros ambientes de testes para processamento de linguagem natural. Fista escolha 
foi feita porque os pesquisadores acreditavam que a tarefa era restrita o suficiente para tornar possível bons resultados, que seria muito útil e que a experiência ganha seria uma boa base para tentativas de processamentos mais complexos de linguagem. Muitos sistemas foram pesquisados e sistemas comerciais estiveram disponíveis - uns dos primeiros foram BASEBALL e LUNAR, que influenciaram trabalhos posteriores - mas o uso prático das interfaces em linguagem natural ainda não é muito difundido. A construção de interfaces reais provou ser um desafio ainda maior do que os primeiros pesquisadores esperavam [Copestake 90].

Características que para alguns pesquisadores determinam que bases de dados não são mais ambientes atrativos para pesquisas em linguagem natural, justificam para outros a continuidade das mesmas. Algumas destas características serão citadas a seguir.

- A tarefa é relativamente restrita, e o sucesso do desenvolvimento da interface não depende da solução de todos os problemas de processamento da linguagem e conhecimento. Segundo Bates, é melhor escolher uma área limitada, exigindo que cada aspecto do domínio seja integrado com os outros, produzindo um todo coerente [Jones 84].

- A tarefa fornece um sólido ambiente de teste para o processador de linguagem, pois sua eficiência é avaliada de forma independente da consulta formal obtida.

- Os sistemas de bases de dados atuais não possibilitam o uso de algumas capacidades importantes do processamento de linguagem, tais como negação, algumas variedades de quantificadores e diferentes relações semânticas.

- As características autônomas dos sistemas de bases de dados impõem restrições idiossincráticas ao processador, como por exemplo a interpretação específica de quantificadores, a determinação de quantidade, os procedimentos para mapear atributos compostos e técnicas para decompor consultas complexas.

Nesta discussão sobre a continuidade da pesquisa em interfaces para bases de dados, os pesquisadores sugerem novas áreas de aplicação, tais como interfaces para sistemas especialistas ou sistemas operacionais, e sugercm também alguns critérios para a escolha destas aplicações [Jones 84] :

- ser mais "central" em relação à compreensão de linguagem do que bases de dados;

- ser mais consistente, sem oprimir pela dificuldade; 
- ser possível utilizar o conhecimento obtido com a aplicação em bases de dados;

- possuir um critério próprio desenvolvido de avaliação da atuação do processador de linguagem;

- ser computacionalmente tratável e baseado em um teste de validação externo;

- deve motivar a investigação de fenômenos da linguagem de reconhecida importância teórica;

- ter importância prática, ou ser um passo importante para uma tarefa com tal característica.

\subsection{Arquitetura Típica de um Sistema de Pro- cessamento de LN para Acesso à Base de Dados}

Nesta seção é apresentada uma divisão em módulos de um sistema de PLN para acesso a bases de dados. Deve ser ressaltado que esta divisão pode variar entre os sistemas, principalmente se eles se destinam a outras tarefas que não sejam acesso a bases de dados, como por exemplo geradores ou tradutores de textos ou interpretadores de histórias.

Os módulos nos quais se dividem os sistemas de PLN executam tarefas específicas, que são:

- Análise de Sentenças;

- Acesso ao Conhecimento Específico;

- Geração de Respostas;

- Interação com o Usuário.

Nas seções seguintes são leitas algumas considerações sobré cada um dos módulos.

\subsubsection{Análise de Sentenças}

A função básica de um sistema de PLN para acesso a bases de dados é a interpretação de uma requisição em $L N$ que seja lingüisticamente correta e apropriada 
ao domínio, gerando uma consulta à base. Esta interpretação abrange as análises léxica, sintática, semântica e pragmática, como descrito na Seção 2.3.

Podem ser citadas duas técnicas para realizar esta análise. A primcira, mais aplicada a sistemas de propósito específico, é aquela em que a semântica e os ítens léxicos podem ser diretamente definidos em termos das consultas à base de dados. As gramáticas que utilizam esta técnica podem ser chamadas Gramáticas Semânticas. As interfaces mais sofisticadas, entretanto, fazem uso de uma representação intermediária, que não é limitada a uma base de dados particular e não é especifica para acesso a bases de dados. As gramáticas desenvolvidas de acordo com a primeira técnica não são portáteis, além de ser muito grande o esforço de prover uma gramática com grande abrangência, e ser desejável fazer uso de informações o mais genéricas possível. Assim, a escolha da técnica a ser utilizada está relacionada com a abrangência do sistema [Sgall 89].

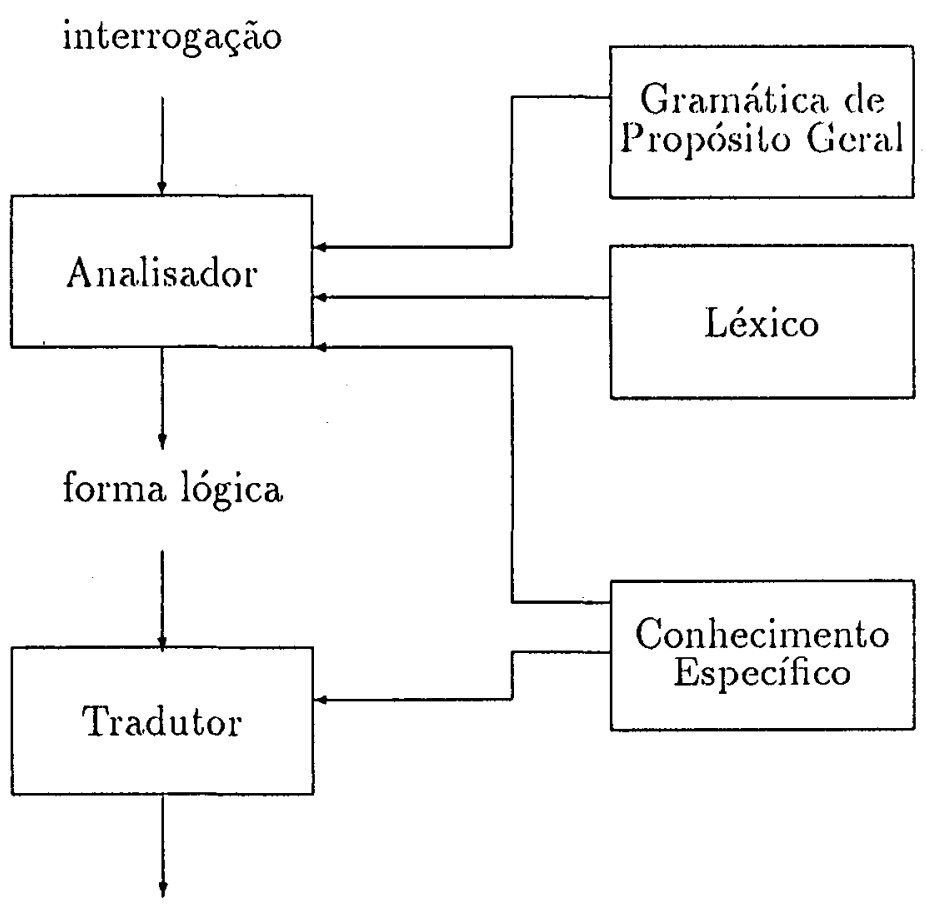

consulta à base

Figura 3.1: Arquitetura Típica do Processamento de LN

A Figura 3.1 ilustra a arquitctura de un sistema que produz uma representação intermediária. O analisador realiza o processamento sintático e semântico, embora o processamento semântico não seja necessariamente completamente realizado. O tradulor é responsável pela produção da consulta à base de dados na 
linguagem formal do SGBD, ou seja, traduzir uma representação formal, a intermediária, para uma outra mais limitada.

A representação produzida pela fase de análise varia entre os sistemas. Algumas interfaces fazem uso de uma representação intermediária mais poderosa do que o necessário para consultas a bases de dados, e por isso, sua transformação em uma consulta na linguagem do SGBD vai envolver uma certa simplificação, mas mesmo neste caso o poder extra, para lidar com fatores temporais por exemplo, pode ser necessário para o diálogo.

\section{Exemplo de Tradução de uma Questão em LN para uma Consulta à Base de Dados}

O exemplo apresentado nesta seção, semelhante ao citado em [Copestake 90], demonstra a tradução de uma questão em LN para uma consulta expressa em SQL ${ }^{1}$.

Este exemplo diz respeito a uma base de dados relacional, que contém dados sobre estudantes, professores e cursos oferecidos por um departamento de uma universidade. As relações PESSOA, ESTUDANTE e PROFESSOR descrevem o pessoal; cada pessoa tem um identificador único, que não tem significado fora da base. A relação CURSO contém informações sobre qual professor leciona cada curso; assume-se que cada curso possui apenas um professor, isto significa que a relação é um-para-um. Em contraste, a relação entre alunos e cursos, armazenada em ASSISTE, é muitos-para-muitos. A relação REQUER armazena informação sobre os cursos que possuem outros cursos como pré-requisito. Abaixo é apresentado o esquema da base de dados descrita, onde as chaves são sublinladas e as chaves externas estão em negrito.

\begin{tabular}{|l|l|}
\hline PESSOA & $\underline{\text { Id Nome Endereco }}$ \\
ESTUDANTE & $\underline{\text { IdEstudante }}$ \\
PROFESSOR & $\underline{\text { IdProfessor Salario }}$ \\
CURSO & $\underline{\text { IdCurso NomeCurso IdProfessor }}$ \\
ASSISTE & $\underline{\text { IdEstudante IdCurso Nota }}$ \\
REQUER & IdCurso IdCursoReq \\
\hline
\end{tabular}

\footnotetext{
${ }^{1} \mathrm{O}$ modelo SQL - Structured Query Language - é um tipo de linguagein para bases de dados relacional. Uma descrição completa da SQL pode ser encontrada em [Date 84]. A SQL define um conjunto de comandos "english-like" que permitem ao usuário se comunicar com a base de dados. Estes comandos podem criar ou alterar tabelas no dicionário de dados, bem como adicionar ou retornar informações da base de dados en forma de tabclas.
} 
Considerando a questão

QUem LECIONA Matemática Para FERnando?

uma possivel consulta na base de dados descrita, expressa em SQL, pode ser:

SELECT PPESSOA.NOME

FROM PESSOA PPESSOA, PESSOA EPESSOA, ASSISTE, CURSO

WHERE PPESSOA.ID = CURSO.IDPROFESSOR

AND (CURSO.NOMECURSO = "Matematica Basica"

OR CURSO.NOMECURSO = "Algebra")

AND CURSO.IDCURSO $=$ ASSISTE.IDCURSO

AND ASSISTE.IDESTUDANTE = EPESSOA.ID

AND EPESSOA.NOME LIKE ‘\% Fernando';

A definição de "lecionar" em termos de duas relações básicas entre um professor e um curso e entre um curso e um estudante tem que estar disponível para a interface de alguma mancira, bem como a informação de que "Matemática Básica" e "Álgebra" são cursos de matemática.

\subsubsection{Acesso ao Conhecimento Específico}

O objetivo da análise de sentenças é obter seu significado para possibilitar a busca das possíveis respostas, que é satisfeita quando o sisterna consegue localizar as informações pertinentes na sua base de conhecimento.

Em geral, após obtida a representação conceitual da sentença introduzida, que é voltada à estrutura interna de representação do conhecimento, pode-se ter acesso a esta estrutura com o objetivo de obter elementos de informação que preencham conceitualmente os requisitos embutidos na representação. Assim, são completadas informações das sentenças com o objetivo de responder ao usuário, ou de acrescentar novos conhecimentos ao sistema. 


\subsubsection{Geração de Respostas}

O objetivo deste módulo é buscar informações de conhecimento específico na base de dados para elaborar a resposta ao usuário. A mesma gramática utilizada na análise poderia funcionar como geradora de mensagens, porém este não é o procedimento adotado pelos sistemas de PLN para consultas a bases de dados, pois uma vez que o sistema possua os elementos de resposta, basta apresentá-los ao usuário através de mecanismos diretos de representação. Desse modo, simplificase o processo de geração de respostas, através de construções de sentenças nas quais não se exige esforço lingüístico, e sim um arranjo das informaçôes obtidas em resposta às solicitações do usuário.

\subsubsection{Interação com o Usuário}

Em um sistema natural de conversação, não se deseja que um dos interlocutores esteja sempre alerta para fornecer a seu companheiro informações sobre o que eles podem conversar, o que tornaria a comunicação entediante e mesmo confusa. Porém, em sistemas computacionais, não é possível que a interação seja tão natural. Existem várias maneiras de resolver este problema, algumas delas são que o sistema seja robusto no sentido de dispender o máximo esforço na tentativa de compreender as mensagens do usuário, que o sistema recuse as mensagens quando não conseguir identificá-las e que a interação seja dirigida por menus.

Para que se tenha um processo de diálogo ou consulta entre homem e máquina, é necessário que o sistema forneça subsídios para a construção de sentenças, apresentando as informações que ele possui na base de dados a que se possa ter acesso através da interação em LN. Um dos modos de fornecer estes subsídios é através de menus [Tennant 87], ou restringindo o vocabulário, ou ainda permitindo o uso de sinônimos. Neste último caso o sistema é mais robusto, porém mais lento.

\subsection{Alguns Sistemas Existentes}

Nesta seção são apresentados alguns dos sistemas de LN para acesso a bases de dados. Estes sistemas estão relacionados a seguir, listadós em ordem histórica. As referências são, em geral, aos artigos que melhor descrevem os sistemas bem como trabalhos mais recentes. Deve ser ressaltado que alguns dos artigos originais que descrevem os sistemas - aqueles com asterisco (") - não foram encontrados nas bibliotecas consultadas. São descritos o domínio de aplicação - Dom nos casos em que se encontrou referência ao domínio na bibliografia consultada, e algumas observações - Obs - referentes a cada sistema. 
BASEBALL [Green 61] *

Dom: Baseball

Obs: Un dos primeiros sistemas desenvolvidos.

LUNAR [Woods 72] *

Dom: NASA Manned Spacecraft Center

Obs: Primeiro marco das Interfaces em LN.

RENDEZVOUS [Cood 74] *

Obs: Modelo relacional de dados; utiliza menus como forma de diálogo; uso de paráfrase para confirmar interpretação.

ROBOT [Harris 77] *, [Harris 80], [Harris 84] *

Obs: Deu origem ao INTELLECT; independente do domínio; gramática semântica.

PLANES [Waltz 78]

Dom: Manutenção e vôos de Aeronaves

Obs: Modelo Relacional de dados; gramática semântica; redes de transição ampliada; uso de estatística para otimizar a ordem de busca; uso de paráfrase; uso de diálogo para chegar à interpretação correta.

LADDER [Hendrix 78]

Dom: Frota Naval

Obs: Independente do domínio e do tipo de base de dados; testado com Datacomputer; uso do pacote LIFER como componente de linguagem natural, que usa árvores de transição (uma simplificação de redes de transição ampliadas); gramática semântica; uso de paráfrase.

EUFID [Templeton 79] *

Obs: Independente do domínio e do tipo de base de dados; gramática semântica.

PHLIQA1 [Bronnenberg 80] *, [Scha 83] *

Obs: Moclelo de rede (CODASYL); independente do domíno.

CO-OP [Kaplan 82a]

Dom: National Center for Atmospheric Researcl

Obs: Modelo de rede (CODASYL); independente do domínio; uso de respostas cooperativas. 
Q \& A [Haas 83] *, [Byte S6]

Obs: Derivado do LADDER e do NONAKLAUS; gramática limitada a questões cujo verbo principal (em inglês) é be ou have; suporta interfaces para dBase II e III, Lotus 1-2-3, Symphony, etc.

DATATALKER [Ginsparg 83] *

Dom: Bell Labs Company Directory

Obs: Independente do domínio e do tipo de base de dados, somente com modelo relacional.

INTELLECT [Harris 84]

Obs: Primeiro sistema comercial de propósito geral; mais de quatrocentas instalações comerciais; derivado do ROBOT; utiliza a base de dados como parte principal do léxico.

IRUS [Bates 86] *

Obs: Independente do domínio e do tipo da base de dados.

TELI [Ballard 86] *

Obs: Independente do domínio.

TEAM [Grosz 87]

Obs: Independente do domínio e do tipo da base de dados; testado com modelo relacional; gramática semântica.

\section{LOKI [Binot 88] *}

Obs: Independente do domínio.

\section{JANUS [Weiscliedel S9] *}

Obs: Independente do domínio.

Com o objetivo de separar os sistemas de LN que ficaram "no papel" daqueles efetivamente em uso, Sap e McGregor realizaram um levantamento apresentado em [Sap 92]. Em uma primeira fase eles requisitaram informações sobre interfaces em LN e uma comparação entre elas e as linguagens formais de consultas através da Internet News Groups. Da pequena quantidade de respostas recebida, os autores concluiram que, apesar da existência de atividade comercial dos fornecedores, as interfaces em $\mathrm{LN}$ estão distantes do uso diário. $\mathrm{Na}$ segunda fase eles consultaram especialistas em LN sobre a possibilidade de clesenvolvimento de uma nova linguagem de consulta às bases de dados. Desta fase eles concluíram que as interfaces atuais em LN para bases de dados ainda são limitadas quanto a capacidade de lidar com ambigüidade e na sua abrangência e é difícil adaptá-las a novas bases de dados. 


\subsection{Considerações Finais}

Com o objetivo de fornecer uma visão das bases de dados como um ambiente para pesquisas em linguagem natural, foram apresentadas neste capitulo características e razões para se pesquisar LN para acesso a bases de dados, sugestões de novas áreas de aplicação e suas características, a arquitetura típica de um sistema de PLN para acesso a bases de dados e a descrição de alguns sistemas existentes. 


\section{Capítulo 4}

\section{Processamento de Linguagem Natural em Prolog}

\subsection{Considerações Iniciais}

A linguagem de programação lógica Prolog tem uma especial aplicabilidade no processamento de linguagem natural por três razões principais, que são [Geetha 90]:

- as gramáticas para linguagem natural podem ser escritas quase diretamente como programa Prolog, de forma que a análise da sintaxe da linguagem natural pode ser realizada eficientemente através da execução do Prolog;

- as representações lógicas da semântica de frases em linguagem natural são produzidas mais naturalmente com Prolog devido à proximidade entre Pro$\log$ e a lógica;

- a inferência com estas representações lógicas - para respostas a consultas - sempre pode ser realizada pelo motor de inferência do Prolog, ou por procedinentos de inferência construídos em Prolog.

Segundo McCord [McCord 87], estas características foram percebidas por Alain Colmerauer, no início da década de 70, com algum auxílio de Robert Kowalski, e foi uma grande motivação para Colmerauer desenvolver esta linguagem. 


\subsection{Gramática de Cláusulas Definidas}

Uma técnica para implementação de gramáticas, que é incluída em muitas versões do Prolog, é a Gramática de Cláusulas Definidas [Pereira 83] - GCD - que é uma extensão das Gramáticas Livres de Contexto - GLCs.

A principal característica das GLCs é que cada constituinte de uma sentença é independente do outro, ou seja, o seu reconhecimento não depende do contexto onde ele se insere. Entretanto, sabemos que nas sentenças em linguagem natural os constituintes não são totalmente livres do contexto. Por exemplo, o tempo e a pessoa de verbos, ou o gênero de substantivos, influenciam as construções de outros constituintes, para que a sentença esteja gramaticalmente correta.

Nas GLCs, cada elemento da linguagem, do mais complexo ao mais simples, deve ser definido separadamente. Estas definições compreendem a definição de terminais e de não terminais. Um não terminal pode ser definido em termos de outros elementos da linguagem; por exemplo, uma sentença pode ser constituida por um sintagma nominal e um sintagma verbal. Um sintagma nominal é um não terminal porque é constituido de um determinante seguido por um substantivo. Um sintagma verbal é também um não terminal, porque pode ser constituído por um verbo e um sintagma nominal. Um terminal só pode ser definido em termos dele mesmo; por exemplo, um determinante é definido pelos terminais $a, o, a s, o s$, um, uma, uns, umas, que correspondem diretamente aos símbolos do vocabulário.

Embora a notação GCD possa definir as GLCs, devido a suas características, ela estende estas gramáticas em dois aspectos. Primeiro, a GCD pode passar informações entre as partes das sentenças como argumentos, permitindo que a gramática verifique a concordância entre diferentes partes da sentença, como tempo, pessoa e gênero. Segundo, a GCD pode conter metas executáveis, que não são parte da gramática propriamente dita, mas são executadas quando uma sentença da linguagem é analisada, permitindo que a gramática produza resultados, como árvores sintáticas, por exemplo ou uma interpretação da sentença.

Na Tabela 4.1 é aprescntado un exemplo muito simples de una parte de uma gramática para a língua portuguesa a fim de ilustrar as características das GCDs. A esquerda a gramática é apresentada com a notação na forma de Backus-Naur - BNF, usada para descrever GLCs - e à direita, na notação GCD. Pode-se observar que existe uma correspondência direta entre as duas notações.

Em Prolog, GCD se refere apenas a uma notação. O símbolo --> é um operador Prolog, que é definido para converter as regras GCD para cláusulas do Prolog. Por exemplo, as regras GCD apresentadas na Tabela 4.1 serão traduzidas para as seguintes cláusulas Prolog: 


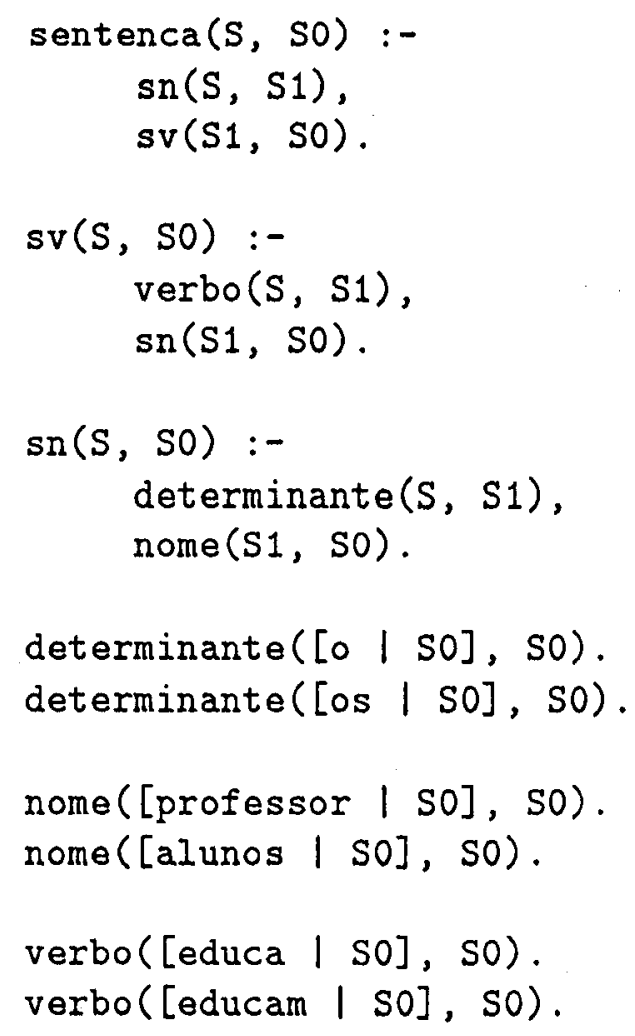

Tabela 4.1: Parte de uma Gramática para Lingua Portuguesa

Este programa pode ser usado tanto para verificar se uma sentença é gramaticalmente correta, por exemplo:

?- sentenca([0,professor, educa, os, alunos $],[])$. yes

?- sentenca ([um, professor, educam, um, aluno], []).

no 
bem como para gerar todas as sentenças definidas por esta gramática ${ }^{1}$, por exemplo:

?- sentenca(Sentenca, []).

Sentenca $=[0$, professor, educa, 0, professor $]$

Sentenca $=[0$, professor, educa, 0, aluno $]$

Sentenca $=[0$, professor, educa, os, professor $]$

Sentenca $=[$ os, aluno, educam, 0 , professor $]$

Sentenca $=[0 s$, aluno, educam, 0 , aluno $]$

Sentenca $=[o s$, aluno, educam, os, professor $]$

Sentenca $=[$ os, aluno, educam, os, aluno $]$

Pode-se notar, no programa Prolog explicitado na notação da GCD, que são incluídos argumentos extras em cada predicado que reconhece uma parte da sentença, para expressar como cada parte "usa" algumas palavras da seqüência que representa a sentença e deixa o resto. Estes argumentos - que são dois - são chamados listas de diferenças. $O$ primeiro argumento $-\mathrm{S}$, no predicado sentenca do programa acima, por exemplo - é a seqüência de palavras que vai ser analisada. O predicado consome algumas palavras desta seqüência, sobrando outra sequência que não foi reconhecida - o scgundo argumento, que no programa acima é representado por So no predicado sentenca. Por exemplo, o predicado sentenca pode receber a seguinte interpretação:

Existe uma frase entre $\mathrm{S}$ e $\mathrm{S} 0$ se existe um sintagma nominal entre $\mathrm{S}$ $e \mathrm{~S} 1$ e existe um sintagma verbal entre $\mathrm{S} 1$ e S0.

Quando introduzidos argumentos extras na GCD a gramática pode deixar de ser livre de contexto. Por exemplo, se a gramática definida acima fosse modificada como demonstrado na Tabela 4.2, a frase:

\section{O PROFESSOR EDUCAM OS ALUNOS.}

que seria válida pcla gramática definida pela BNF, não scria validada pela GCD. Neste caso, a dependência de contexto diz respeito à concordância de número entre sujeito e verbo da frase, que é verificada através do argumento Numero introduzido nos predicados sentenca, sn e sv, e pelos valores sing e plural nos símbolos terminais.

\footnotetext{
${ }^{1}$ A resposta Prolog foi reformatada, pois o número de sentenças geradas é elevado.
} 


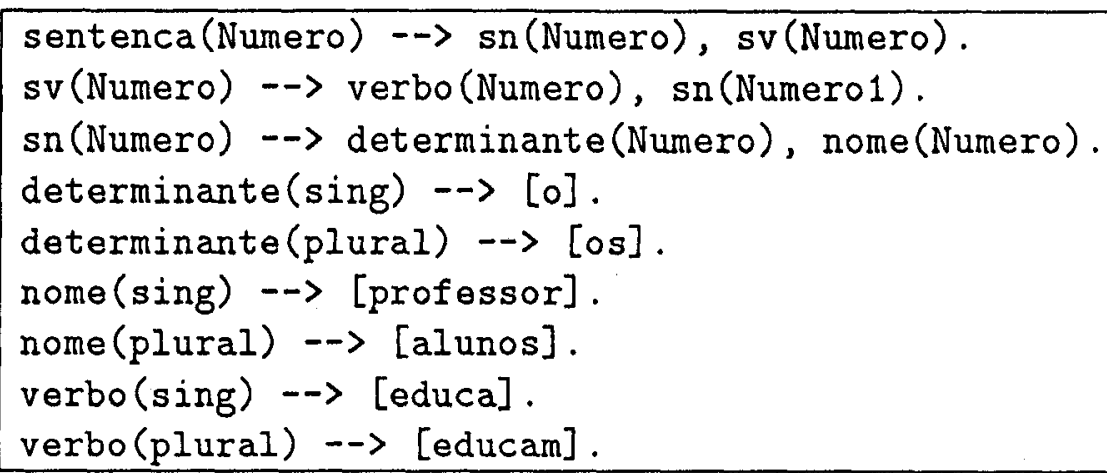

Tabela 4.2: Inclusão de Argumentos Extra na GCD

\subsection{Construção da Árvore Sintática}

Além de realizar a análise sintática, a notação GCD torna possivel incorporar a extração do significado, através do uso de parâmetros extras ${ }^{2}$, permitindo a análise semântica dos constituintes de uma sentença ao mesmo tempo em que verifica sua validade sintática. Assim, passo a passo, é realizada uma análise semântica que permite assegurar a continuidade da análise, ou a necessidade de se retroceder tentando encontrar uma alternativa mais provável de análise na busca da interpretação.

Nas GCDs podem ser adicionados argumentos que expressam informações importantes, como por exemplo concordância entre constituintes de sentenças. Além disto, os argumentos podem ser usados para manter um registro dos constituintes que aparecem fora da ordem normal; ou registrar itens com significado semântico, para dizer como o significado semântico é composto do significado de seus constituintes. Um importante uso de argumentos extras é a formação de uma árvore sintática como resultado do processo, que mostra o relacionamento entre os elementos da sentença. Esta possui as seguintes propriedades:

- todas as folhas da árvore contêm símbolos terminais da gramática;

- todos os nós internos da árvore contêm símbolos não terminajs da gramática;

- a raiz da árvore contém o símbolo inicial da gramática;

- a relação pai-fillio na árvore é como especificado pelas regras da gramática.

\footnotetext{
${ }^{2} \hat{E}$ importante ressaltar que os lingüistas afirmam que com a inclusão de argumentos extras, não se pode mais garantir que a linguagem definida pela gramática é livre de contexto, embora quase sempre elas continuem sendo.[Clocksin 81]
} 
A existência de uma árvore sintática explicitamente representada pode ser útil para realizar alguma computação sobre ela - por exemplo, extrair o significado de uma sentença. A árvore sintática pode ser representada por um termo Prolog cujo funtor é a raiz da árvore e cujos argumentos são suas subárvores.

O exemplo apresentado na Tabela 4.2 teria sua gramática modificada como demonstrado a seguir, onde a árvore sintática tem a forma sentenca(SN, SV).

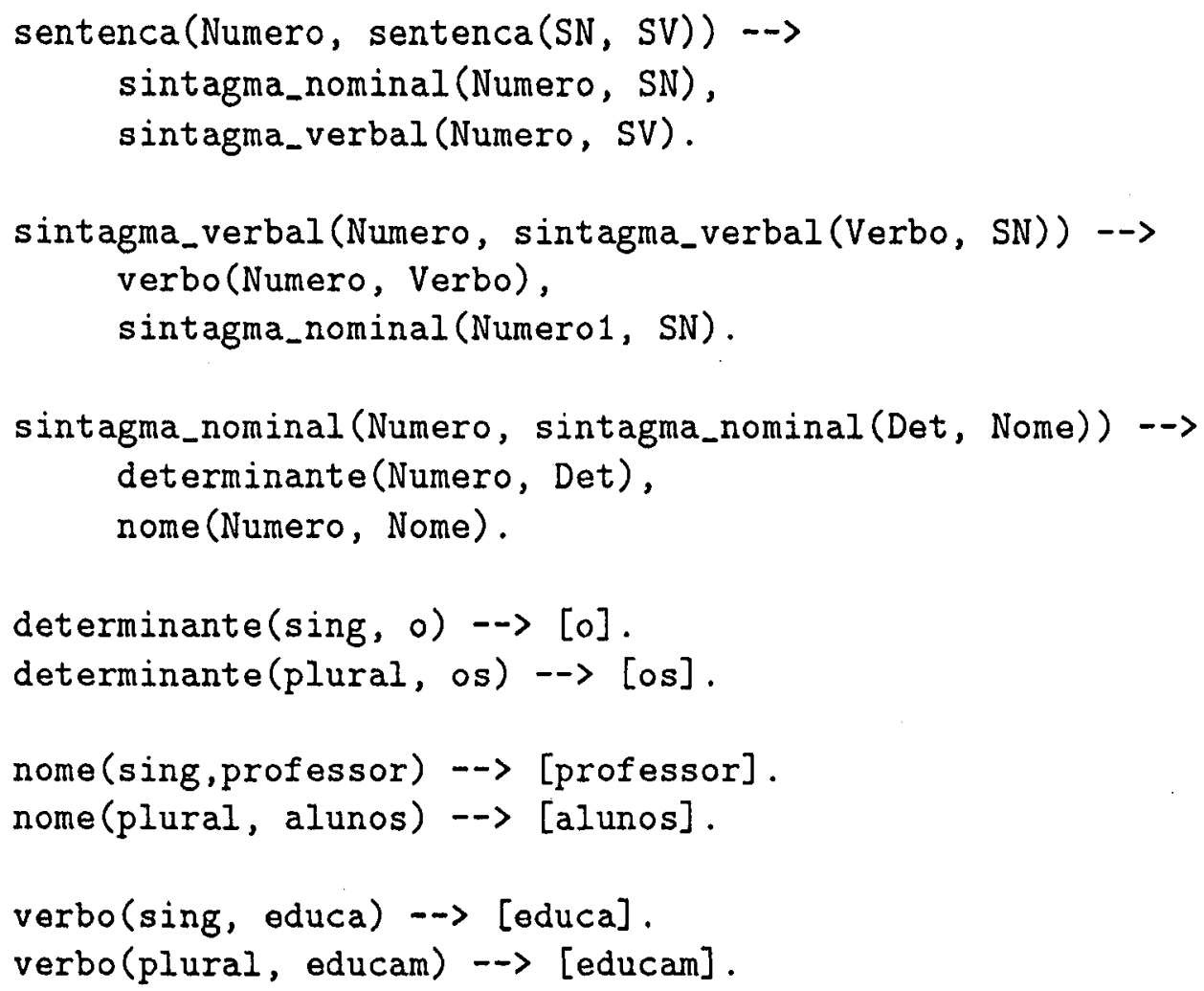

A árvore sintática produzida para a sentença

O PROFESSOR EDUCA OS ALUNOS.

é a que corresponde à seguinte interrogação Prolog ${ }^{3}$

?- sentenca (Numero, sentenca (SN, SV),

$[0$, professor, educa, os, alunos],[]$)$.

Numero $=$ sing

$\mathrm{SN}=$ sintagma_nominal (o,professor)

$\mathrm{SV}=$ sintagma_verbal (educa, sintagma_nominal (os, alunos))

\footnotetext{
${ }^{3} \mathrm{~A}$ resposta foi reformatada de maneira a fornecer uma melhor compreensão.
} 


\subsection{Entrelaçamento entre Sintaxe e Semântica}

Existem várias maneiras de se organizar a interpretação semântica, com diferentes níveis de interação entre o processamento sintático e o semântico. Ter estágios de processamento sintático e semântico separados tem como vantagem permitir modelos mais sofisticados de análise, porque a porção sintática do sistema é relativamente independente do domínio. Por outro lado, um único estágio combinando os dois processamentos é capaz de usar informação semântica mais cedo para eliminar muitas interpretações sintáticas que sejam semanticamente anômalas.

Uma técnica usada em alguns sistemas comerciais, como visto na Seção 3.4, é a Gramática Semântica, na qual a informação semântica é completamente codificada em uma gramática sintática. Nela, os processamentos sintático e semântico são separados, mas em estruturas uniformes. Assim, a gramática semântica se parece com uma gramática comum mas usa categorias semânticas para símbolos terminais. Algumas outras técnicas que apresentam níveis diferentes de interação entre sintática e semântica são a interpretação semântica baseada em preferências, a interpretação semântica regra por regra e técnicas em que o analisador realiza. a interpretação semântica primeiro e usa a informação sintática apenas quando necessário.

Algumas perguntas que surgem ao definir o significado de uma linguagem são:

Como o significado será representado?

Para que será utilizado o significado extraído?

A lógica tem sido aceita como uma boa candidata para representar o significado de sentenças da linguagem natural. Estudar a semântica para LN usando sistemas formais lógicos significa considerar a interpretação das sentenças como o seu valor de verdade [Branco 87].

Em toda sentença existe, no mínimo, uma ação semântica a ser realizada - a verificação da possibilidade de se utilizar os complementos do verbo principal. Um exemplo desta verificação são as regras livres de contexto apresentadas a seguir na notação GCD `.

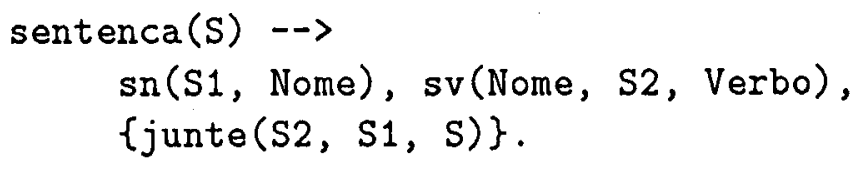

\footnotetext{
${ }^{4}$ A notação GCD permite inserir metas Prolog nas regras gramaticais, sendo estas metas delimitadas pelos símbolos " $\{$ " e " $\}$ ".
} 


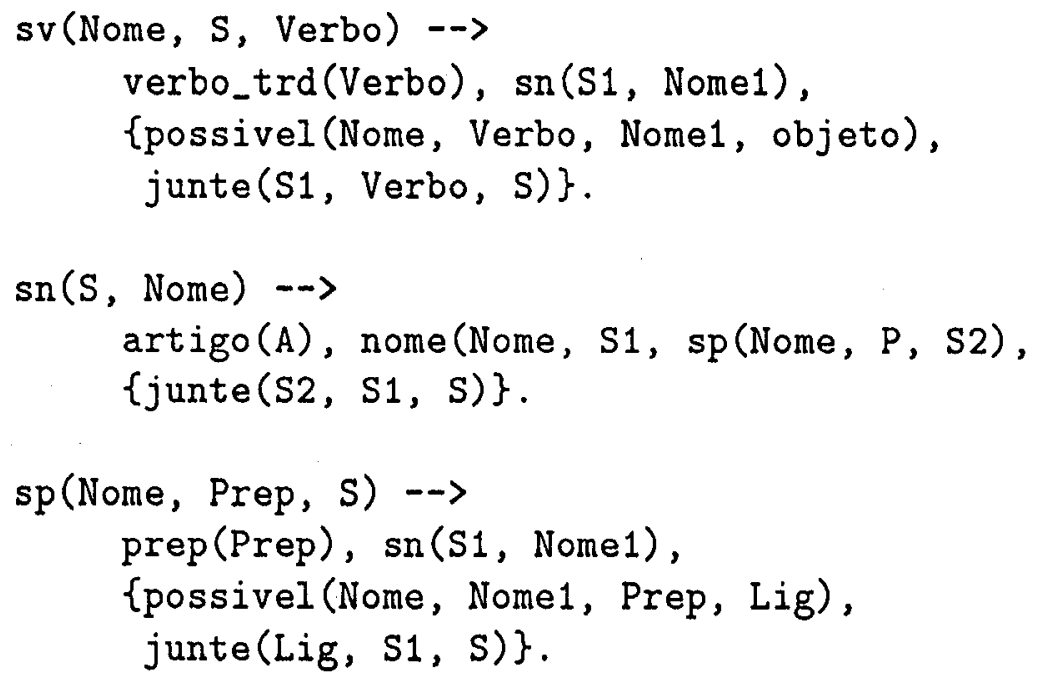

Neste exemplo, a ação semântica corresponde à verificação da validade do relacionamento entre Nome - que é o núcleo do sintagma nominal - e Nome1 - que ć o objeto do sintagma verbal - através do verbo Verbo, dada pela verificaşão da condição

$$
\text { possivel(Nome, Verbo, Nome1, objeto). }
$$

na regra correspondente ao não terminal sv. Caso seja válida a condição, é possível obter a representação $S$ do sintagma verbal na mesma regra.

No caso das preposições, a ação semântica corresponde à verificação da validade da ocorrência de dois nomes ligados por uma preposição, que é representada pela última regra do exemplo acima.

Nas interrogações, através da análise semântica, é associado ao pronome - qual, por exemplo - a idéia de que se procura um certọ número de objetos que satisfaçam a especificação da mensagem.

Como exemplo, na frase

\section{QUal É a CATEGoria de José?}

temos a idéia de buscar elementos para satisfazer a especificação, e a preposição introduzida relaciona o indivíduo "José" como possuidor de um atributo - a categoria. Pode-se representar esta associação de idéias pela seguinte asserção Prolog:

eh([possuidor, individuo(jose), masc, sing, nome-proprio], 


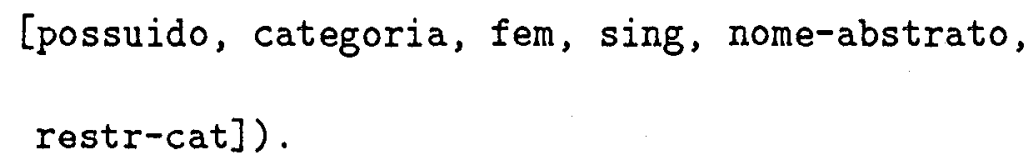

que em termos de requisição, poderia ser traduzida como:

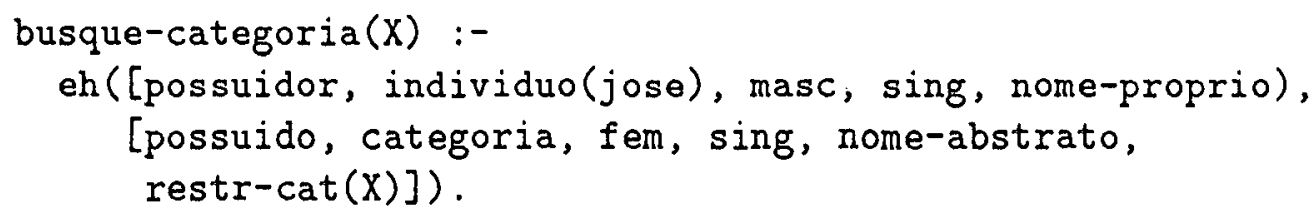

onde restr-cat $(X)$ seria um procedimento semântico responsável por verificar a restrição do valor de $X$, por exemplo:

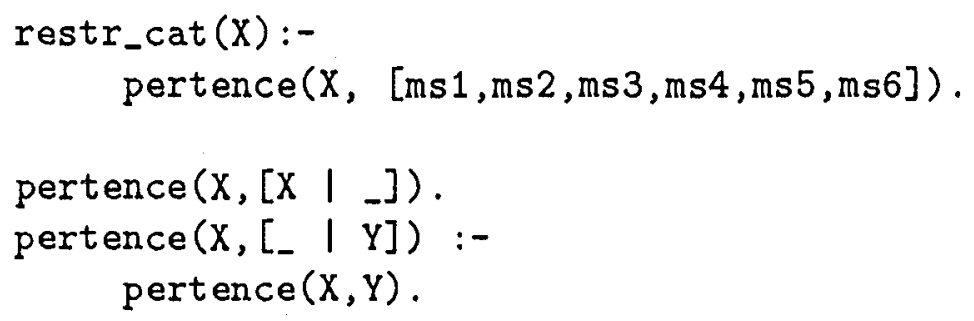

As sentenças que contêm determinantes apresentam alguma dificuldade extra. Seria um erro grosseiro, por exemplo, representar a sentença

\section{UM HOMEM PINTA.}

por pinta(homem). Na verdade, a sentença diz que existe um homem que pinta, e seria melhor representada por

$$
\operatorname{existe}(X, \operatorname{homem}(X) \text { e pinta(X)). }
$$

Generalizando esta idéia, o significado do determinante um pode ser representado pelo termo Prolog

$$
\text { existe(X, Propriedade e Afirmacao). }
$$


que indica que existe algum $X$ tal que $X$ possui alguma propriedade e que alguma afirmação pode ser feita sobre $X$. Uma possível regra GCD para o determinante um pode ser:

determinante(X, Prop, Afirm, existe(X, Prop e Afirm)) $\rightarrow->$ [um].

De maneira análoga, o determinante todo pode ser representado por

$$
\text { todo (X, Propriedade } \Rightarrow \text { Afirmacao). }
$$

que indica que todo $X$ tal que $X$ possui alguma propriedade, então alguma afirmação é válida sobre $X$, e sua regra GCD pode ser:

determinante(X, Prop, Afirm, todo (X, Prop $\Rightarrow$ Afirm)) $\rightarrow$ [todo].

\subsection{Considerações Finais}

Neste capítulo foram abordados alguns aspectos do processamento de linguagem natural, com a utilização da linguagem de programação lógica Prolog. Prolog é uma linguagem apropriada para escrever sistemas de LN devido ao seu poder em programação lógica e processamento simbólico [Bratko 90], [Marcus 87]. Outra característica favorável é a existência, em muitos interpretadores Prolog, da notação GCD, pois Prolog converte automaticamente as regras gramaticais em cláusulas normais, ou seja, en um programa para reconhecer as sentenças geradas pela gramática.

Neste trabalho será utilizada a linguagem Prolog - especificamente Arity Prolog [Arity 90 ] - para implementar uma interface em linguagem natural para realizar o acesso a uma base de dados. 


\section{Capítulo 5}

\section{Proposta de Integração entre Base de Dados e Interfaces em Linguagem Natural}

\subsection{Considerações Iniciais}

Como já mencionado, alguns dos objetivos de um SGBD são armazenar e recuperar informações de uma maneira eficaz e rápida. Embora existam linguagens de consulta para estes sistemas convencionais, elas apresentam, em geral, uma estrutura rígida e artificial [Date 88 ].

Com o objetivo de utilizar de cada sistema suas facilidades e características favoráveis, surge o interesse em se integrar um SGBD convencional com uma interface em $L N$. Do $S G B D$, a característica interessante é a facilidade de programação de uma interação com o usuário para realização de operações básicas de manipulação de dados, através da facilidade de gerenciamento de janelas e menus, de gerenciamento de índices, impressão de relatórios, etc. Da interface em LN, a possibilidade de obter informações da base de dados sem a necessidade de conhecer a linguagem formal de acesso aos dados, permitindo que as consultas sejam realizadas através de requisições em $L N$.

O sistema proposto neste trabalho é una experiência de integraçào destes interesses. Cada parte do sistema possui suas características próprias, como linguagem de programação, representação e manipulação de dados. Para permitir o relacionamento entre estas partes e, portanto, possibilitar a integraşão proposta, foi elaborada uma arquitetura que será descrita nas próximas seções. 


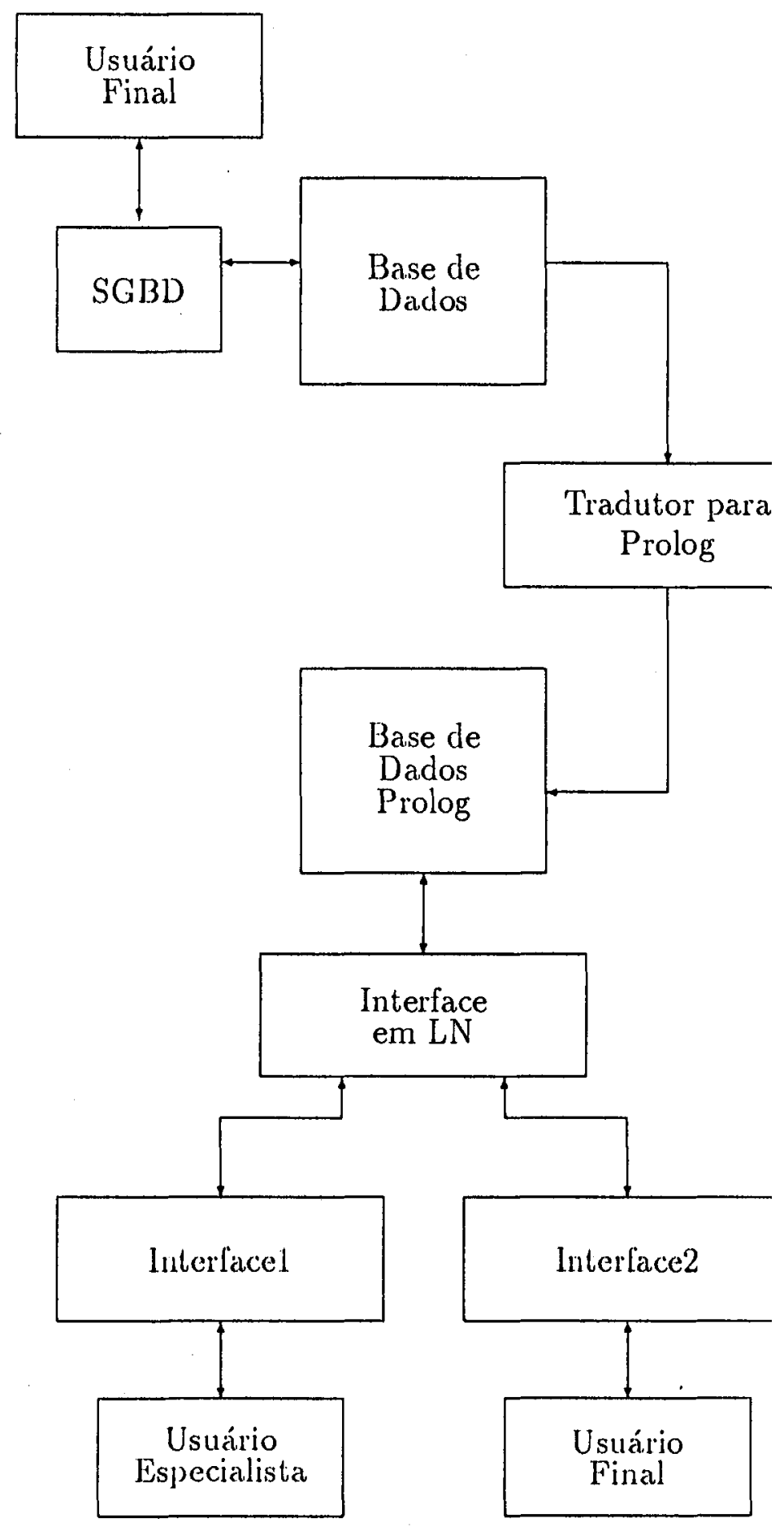

Figura 5.1: Arquitetura do Sistema Proposto 
O sistema é projetado para interagir com dois tipos de usuários: um usuário especialista (em geral o construtor da base de dados) e um usuário final. O usuário especialista é responsável por fornecer a informação necessária para adaptar o sistema a um novo domínio ou expandi-lo. Depois que o usuário especialista supriu o sistema com as informações de que ele necessita, qualquer usuário final pode usá-lo para fazer consultas à base de dados.

\subsection{Arquitetura do Sistema Proposto}

A arquitetura do sistema proposto é apresentada na Figura 5.1, sendo descritas a seguir cada uma de suas partes.

\subsubsection{Base de Dados do SGBD}

Esta base de dados é construída através de um SGBD que utiliza o modelo relacional - neste trabalho, devido à sua disponibilidade, foi utilizado especificamente - CLIPPER [Vidal 90]. Nesta base de dados são realizadas as operaçóes de inserção, alteração e remoção dos dados do sistema, e também de consultas padrão à base de dados e geração de relatórios, pelo usuário final.

As operações realizadas nesta base de dados são independentes dos outros módulos do sistema. Entretanto, as tarefas realizadas pelos outros módulos utilizam parte dos dados armazenados nesta base de dados.

\subsubsection{Tradutor para Prolog}

A Interface em LN utiliza os mesmos dados armazenados na Base de Dados do SGBD. Entretanto, nem todas as informações são utilizadas pela Interface em LN, uma vez que apenas consultas sobre dados atuais são realizadas através desta interface. Deve ser observado que a base de dados possui informações atuais bem como sobre fatos passados.

Para que o sistema seja totahnente livre de uma linguagen formal de acesso à base de dados e para que sejam selecionadas apenas as informaçòes que serão utilizadas - informações atuais - escolheu-se obter uma base de dados em Prolog, a partir da base de dados acima mencionada. Por serem ulilizadas linguagens de programação distintas em cada uma destas bases e portanto métodos diferentes de armazenamento de informações, é necessário que se tenha uma interface entre elas. 
Esta interface - Tradutor para Prolog na Figura 5.1 - obtém, a partir da base de dados a representação das informações contidas no SGBD de maneira que possam ser armazenadas e manipuladas pelo Prolog. Apenas as informações que dizem respeito a fatos atuais são incluidas na Base de Dados em Prolog. Esta interface é também responsável pela atualização da Base de Dados em Prolog, sendo ativada cada vez que um usuário desejar utilizar a Interface em $L N$ e a Base de Dados do SGBD tiver sido atualizada.

O Tradutor é um programa implementado em Clipper e sua função é transformar os registros de cada arquivo da base de dados do SGBD em fatos Prolog. Por exemplo, para o arquivo cacongr, descrito na Seção 5.5.6, o Tradutor cria um arquivo contendo as informações como apresentadas a seguir, onde a última informação é a data da última atualização, utilizada para verificar se os dados da base de dados do SGBD foram atualizados após a última ativação do Tradutor.

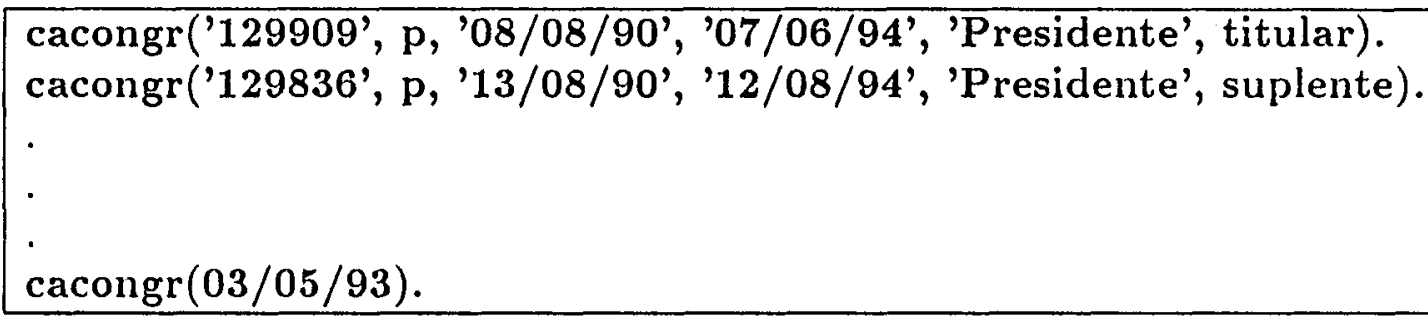

Pela existência do Tradutor, esta arquitetura é mais adequada a sistermas onde ocorram poucas atualizações e que não possuam grande quantidade de dados armazenados.

\subsubsection{Base de Dados em Prolog}

A Base de Dados em Prolog é o resultado obtido pela ativação do Tradutor para Prolog. Ela contém as informações armazenadas na Base de Dados do SGBD que foram selecionadas pelo Tradutor, e é sobre esta base em Prolog que são feitas as consultas para obtenção das respostas às requisições feitas pelo usuário final através da Interface em LN.

\subsubsection{Interface em Linguagem Natural}

Esta interface é usada para realizar requisiçôes à base de dados mais complexas que as realizadas pela Base de Dados do SGBD, ou que não são previstas na fase de definição do sistema. As interrogações são realizadas em linguagem natural, permitindo maior facilidade de uso e aumentando a utilidade do sistema. 
Um dos interesses do sistema proposto é que ele seja o mais genérico possível bem como de fácil adaptação para novos domínios. Para isto, esta interface é dividida em duas partes - a Interfacel e a Interface2.

$\mathrm{Na}$ construção de sistemas que possam ser transportados a novos domínios, é importante fornecer uma maneira de adquirir as informações específicas do domínio. Este é o objetivo da Interfacel, que é utilizada por um usuário especialista, usualmente o construtor da base de dados. Sua função é incluir informaçóns semânticas - os relacionamentos entre os constituintes das sentenças - ou seja, alterações no módulo de tratamento semântico bem como complementar e alterar o léxico, com a inclusão de palavras específicas do domínio. Esta última tarefa é realizada pelo Sistema GBC (Gerenciador de Bases de Conhecimentos).

Além destas informações, que são utilizadas pela interface para obtenção de uma interpretação da requisição, o usuário especialista é responsável por definir a forma de acesso aos dados a partir desta interpretação. Assim, esta interface é responsável por adquirir as informações que variam de acordo com o domínio, ou para adaptar o sistema a um novo domínio além de estender sua capacidade de compreensão das requisições de um domínio existente.

A Interface2 contém a parte fixa da Interface em LN. Ela contém as regras gramaticais de um subconjunto da língua portuguesa, um módulo de interação para consultas em LN através de requisições do tipo Qu (quem, qual, quando, etc) e as palavras de classe fechada, ou seja, a parte que não muda de acordo com o domínio de aplicação da base de dados.

A Interface2 possui uma arquitetura semelhante à descrita na Seção 3.3, e é também semelhante ao sistema proposto cm [Rino 87]. Entretanto, a diferença no sistema proposto neste trabalho é a consulta obtida a partir da interpretação da requisição em LN. No sistema descrito na Seção 3.3, a interrogação introduzida pelo usuário é traduzida para a linguagem formal de consulta do SGBD. Em contraste, no sistema proposto neste trabalho a interrogação é traduzida para uma representação na mesma linguagem - Prolog - utilizada para armazenar os dados nesta base.

Como se pode perceber, as informações adquiridas através da Interfacel e as contidas na Interface 2 se complementam para produzir a Interface em LN. Utilizando o módulo de interação e a gramática - que estão contidos na Interface2 - juntamente com o léxico e as informações semânticas - que são obtidos pela Interface1 - a Interface em LN realiza o processamento de linguagem natural. Através do módulo de acesso à base de dados - que faz parte da Interface1 a Interface em LN busca na Base de Dados em Prolog - obtida pelo Tradutor - as respostas às requisições do usuário final do sistema e estas respostas são apresentadas utilizando-se o módulo de interação. 


\subsection{Modelo de Dados}

No sistema proposto, as informações são armazenadas em duas bases de dados. Não é necessário que os modelos destas bases sejam iguais. Entretanto, se o mesmo modelo de dados for utilizado em ambas as bases, a tarefa de traduzir os dados para cláusulas Prolog - modelo relacional - é simplificada. O SGBD utilizado - CLIPPER - também utiliza o modelo relacional, descrito resumidamente a seguir.

Uni dos objetivos de se organizar os clados, com o uso de algum modelo, é permitir maior flexibilidade e extensibilidade. O modelo relacional foi proposto pelo cientista computacional E.F. Codd, usando a álgebra relacional para resolver o problema de representar dados eficientemente. Segundo Garavaglia em [Garavaglia 87], no artigo original de Codd, ele também propunha que uma linguagem baseada no cálculo de predicado de primeira ordem seria uma ferramenta poderosa para representar e manipular bases de dados relacionais e, embora não tenha sido mencionado Prolog - sua pesquisa era provavelmente contemporânea com os primeiros desenvolvimentos do Prolog - suas idéias podem ser traduzidas para Prolog de uma maneira natural [Kasik 90].

O modelo relacional é baseado no conceito de relação no escopo matemático, que por sua vez é baseado na teoria dos conjuntos. Dada uma coleção de conjuntos $D_{1}, D_{2}, \ldots, D_{n}$, não necessariamente distintos, $\mathrm{R}$ é uma relação entre estes conjuntos se ela for um conjunto de n-tuplas ordenadas

$$
<d_{1}, d_{2}, \ldots, d_{n}>
$$

tais que $d_{1}$ pertença a $D_{1}, d_{2}$ pertença a $D_{2}, \ldots, d_{n}$ pertença a $D_{n}$. Os conjuntos $D_{1}, D_{2}, \ldots, D_{n}$ são os domínios de R. A relação $\mathrm{R}$ pode ser definida também como um subconjunto do produto cartesiano dos domínios, ou seja, $R$ está contido ou é igual a $<D_{1} X D 2 X \ldots X D_{n}>$.

No modelo relacional näo é feita distinção alguma entre entidades e atributos, pois os elos são implícitos, então pode-se ter domínios de fornecedores, peças, etc. - que seriam entidades - como de quantidades, cores, etc. - que seriam atributos.

Pode-se notar facilmente a correspondência entre a terminologia do modelo relacional e a de computação: 


\begin{tabular}{||l|l||}
\hline modelo relacional & computação \\
\hline relaçáa & arquivo \\
tupla & registro \\
valores de domínios & valores de ítens \\
\hline
\end{tabular}

A base de dados pode ser vista como um conjunto de tabelas, cada uma representando uma relação. Cada coluna contém elementos de um domínio e cada linha. é considerada um membro da relação. A Tabela 5.1 mostra a representação das relações F, cujos domínios são Número do Fornecedor (F\#), Nome do Fornecedor (NF), Nome do Representante (NR) e Código da Peça (CP), e a relação $P$, cujos domínios são Número da Peça (P\#), Nome da Peça (NP), Cor (C) e Peso (P).

\begin{tabular}{|c|c|c|c|}
\hline \multicolumn{4}{|c|}{ Relação F } \\
\hline $\mathrm{F} \#$ & $\mathrm{NF}$ & NR & $\mathrm{CP}$ \\
\hline 12 & $a$ & $p$ & 109 \\
\hline 17 & $c$ & $q$ & 018 \\
\hline 12 & $a$ & $p$ & 007 \\
\hline 20 & 6 & $p$ & 018 \\
\hline 17 & $c$ & $q$ & 007 \\
\hline \multicolumn{4}{|c|}{ Relação P } \\
\hline $\mathrm{P} \#$ & $\mathrm{NP}$ & $\mathrm{C}$ & $\mathrm{P}$ \\
\hline 007 & $t$ & $x$ & 29 \\
\hline 018 & $u$ & $z$ & 28 \\
\hline 109 & $u$ & $y$ & 29 \\
\hline
\end{tabular}

Tabela 5.1: Representação do Modelo Relacional

Existem duas maneiras de se encontrar os relacionamentos entre entidades:

- as entidades aparecem juntas em tuplas da mesma relação, como em $F$ do exemplo da Tabela 5.1, o fornecedor $a$ e o representante $p$;

- existência de un elo (implícito) através de ocorrência de valores comparáveis nos domínios de duas relaçóes, como o relacionamento do fornecedor a e peça $u$, associando a primeira tupla de $F$ com a última de $P$ através do valor comum 109, no exemplo da Tabela 5.1 .

No modelo relacional evita-se entrar em detalhes sobre possiveis técnicas de implementação e também evita-se fixar uma interpretação semântica, mantendo 
uma abordagem puramente abstrata. A intenção é isolar, dentre os vários níveis de descrição de uma base de dados, um nível abstrato compatível com uma formalização simples e precisa [Furtado 88 ].

\subsection{Conteúdo da Base de Dados}

Nesta seção é apresentado o conteúdo da base de dados escolhida para a aplicação prática do que é proposto neste trabalho. Poderia ter sido escolhida uma aplicação aleatória, mas se escolheu o Sistema de Colegiados e Comissões - SCC - uma aplicação interna do Instituto de Ciências Matemáticas de São Carlos - ICMSCUSP - de interesse no auxílio ao corpo acadêmico deste instituto. Este sistema visa facilitar o trabalho de seus usuários nas consultas e relatórios relativos aos colegiados e comissões do ICMSC, gerenciando informações sobre a composição, cargos e sobre os elementos destes colegiados e comissões.

$O$ interesse do SCC é possibilitar através de consultas, pelo SGBD ou pela interface em LN, a obtenção de informações sobre a composição dos colegiados e comissões em cada mandato; ou como é a participação de professores, alunos e funcionários, durante sua carreira ou período de estudo, em colegiados ou comissões; ou ainda informações mais específicas sobre a carreira dos professores do ICMSC. Para isso, o sistema gerencia informações sobre a composição dos colegiados e comissões, informações elementares sobre estes componentes e informações complementares sobre professores.

\subsubsection{Colegiados e Comissões}

No ICMSC, assim como em muitos institutos, existem vários colegiados e comissões, cada um sendo responsável pela organização e tomada de decisões de algum setor ou departamento do Instituto, e alguns sendo responsáveis pela união de representantes de mais de um destes colegiados e comissões. O SCC gerencia as informações sobre estes colegiados e comissões, que são apresentados a seguir.

- Congregaçĩo;

- Conselho Técnico Administrativo - C'TA;

- Comissão de Graduação - CG;

- Comissão de Pós-Craduação - CPG;

- Comissão de Pesquisa - CPq; 
- Comissão de Cultura e Extensão Universitária - CCEx;

- Conselho do Departamento de Ciências da Computação e Estatística $\mathrm{SCE}$;

- Conselho do Departamento de Matemática - SMA;

- Comissão Coordenadora de Biblioteca - CCB;

- Comissão Supervisora do Laboratório Didático-Científico de Computa- ção - CS-LDCC.

Devido às regras de composição dos colegiados e comissões, existem elementos que participam de mais de um deles ao mesmo tempo, como por exemplo o diretor do ICMSC, que também é presidente da Congregação e do C'TA. Percebe-se, então, que existe duplicação de dados e, consequentemente, é necessário algum mecanismo que garanta a integridade dos dados.

$\mathrm{Na}$ Tabela 5.2 são apresentados os casos de duplicação de dados descritos acima. $\mathrm{Na}$ coluna da esquerda são apresentados dois colegiados ou comissões, separados por uma linha, que contêm um elemento duplicado - apresentado na coluna da direita. Algumas das informações contidas na coluna da direita, como por exemplo o chefe do SCE, não são diretamente armazenadas na base de dados, mas pode-se obtê-las através de uma consulta simples.

\subsubsection{Composição dos Colegiados e Comissões}

Os participantes de colegiados e comissões pertencem a cinco grupos distintos, que são:

- Professores;

- Alunos;

- Servidores;

- Professores do IFQSC;

- Elementos da Comunidade. 


\begin{tabular}{|c|c|}
\hline Colegiados e Comissões & Elementos \\
\hline Congregação & \multirow{2}{*}{$\begin{array}{l}\text { diretor e vice- } \\
\text { diretor do } \\
\text { ICMSC }\end{array}$} \\
\hline $\mathrm{C}^{\prime} \mathrm{I} \Lambda$ & \\
\hline Congregação & \multirow{2}{*}{$\begin{array}{c}\text { chefe do } \\
\text { SCE e seu } \\
\text { suplente }\end{array}$} \\
\hline CTA & \\
\hline Congregação & \multirow{2}{*}{$\begin{array}{c}\text { chefe do } \\
\text { SMA e seu } \\
\text { suplente }\end{array}$} \\
\hline C'IA & \\
\hline Congregação & \multirow{2}{*}{$\begin{array}{c}\text { presidente da } \\
\text { CG e seu } \\
\text { suplente }\end{array}$} \\
\hline CG & \\
\hline Congregação & \multirow{2}{*}{$\begin{array}{l}\text { presidente da } \\
\text { CPG e seu } \\
\text { suplente }\end{array}$} \\
\hline $\mathrm{CPG}$ & \\
\hline Congregação & \multirow{2}{*}{$\begin{array}{c}\text { presidente da } \\
\text { CPq e seu } \\
\text { suplente }\end{array}$} \\
\hline $\mathrm{CPq}$ & \\
\hline Congregação & \multirow{2}{*}{$\begin{array}{l}\text { presidente da } \\
\text { CCEx e seu } \\
\text { suplente }\end{array}$} \\
\hline CCEx & \\
\hline Congregação & \multirow{2}{*}{$\begin{array}{c}\text { chole do } \\
\text { SCE e seu } \\
\text { suplente }\end{array}$} \\
\hline SCE & \\
\hline Congregação & \multirow{2}{*}{$\begin{array}{c}\text { chefe do } \\
\text { SMA e seu } \\
\text { suplente }\end{array}$} \\
\hline SMA & \\
\hline $\mathrm{CTA}$ & \multirow{2}{*}{$\begin{array}{l}\text { chefe do } \\
\text { SCE e seu } \\
\text { suplente }\end{array}$} \\
\hline SCE & \\
\hline CTA & \multirow{2}{*}{$\begin{array}{l}\text { chefe do } \\
\text { SMA e seu } \\
\text { suplente }\end{array}$} \\
\hline SMA & \\
\hline
\end{tabular}

Tabela 5.2: Casos de Duplicação de Dados no SCC 
Cada elemento é eleito para participar de um colegiado ou comissão pelos indivíduos que fazem parte do mesmo grupo a que ele pertence e representa, ou é designado pelo diretor ou chefe de departamento correspondente. Devido às regras de composição, existem alguns colegiados e comissôes nos quais alguns elementos não exercem nenhum cargo. Em outros, todos os elementos exercem cargos - de presidência, de representação, e outros.

Com base no que foi descrito nesta seção e na Seção 5.4, conclui-se que as relações da base de dados do SCC dizem respeito aos grupos de participantes citados acima e à composição dos colegiados e comissões. Nas seções seguintes é apresentada uma descrição mais detalhada sobre o conteúdo das relações da base de dados do SCC.

\subsection{Descrição da Base de Dados}

Na Figura 5.2 é apresentada uma visão global do SCC, através do diagrama entidade-relacionamento ${ }^{1}$, onde foram omitidos os atributos, visando simplificar a figura. Nela são apresentadas todas as entidades e relacionamentos entre estas entidades que fazem parte do Sistema SCC. O fato de um relacionamento ser definido sobre dois conjuntos de entidades é representado pelas linhas que conectam os dois retângulos que representam estes conjuntos. Por exemplo, o relacionamento pertence é definido sobre os conjuntos de entidades professor e categoria. Neste caso a entidade categoria é uma entidade fraca, isto é, se um professor for excluído da base de dados todas as informações sobre categoria deste professor também têm que ser excluidas. Além disso, a entidade comissão pode dizer respeito a uma das dez comissões do ICMSC; quando o elemento for professor externo ou elemento da comunidade, a comissão só pode dizer respeito à $\mathrm{CG}$ ou à CCEx, respectivamente.

Nas seções seguintes são apresentadas as relações da base de dados referentes a cada um dos participantes dos colegiados e comissões e a cada um destes colegiados e comissões.

\footnotetext{
${ }^{1} \mathrm{O}$ modelo entidade-relacionamento é um método utilizado para descrever os aspectos do mundo que são modelados por uma base de dados. Nele o mundo real é constituído por um grupo básico de objetos chamados entidades e por relacionamentos entre estes objetos [Chen 76].
} 


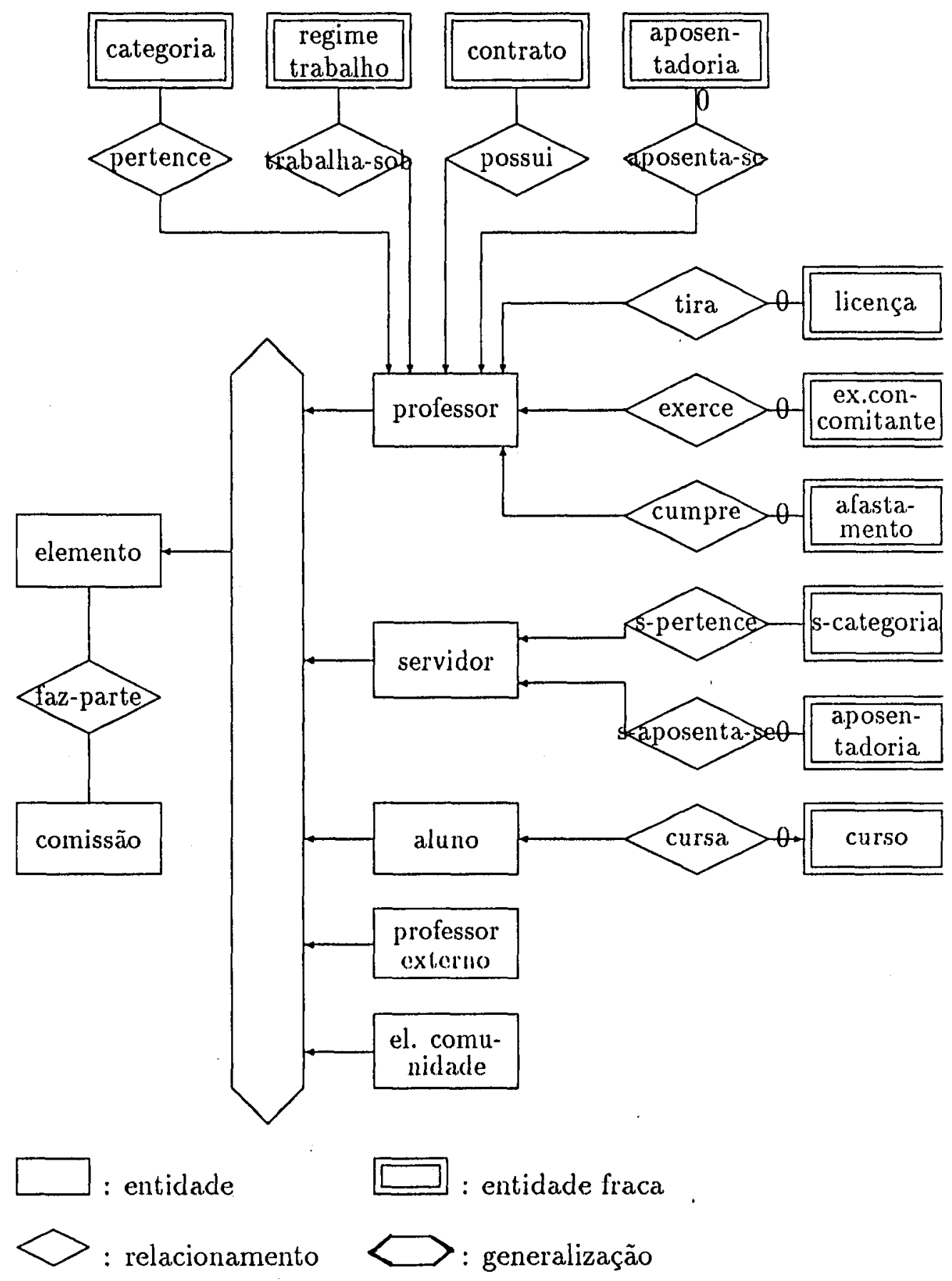

Figura 5.2: Diagrama E-R do SCC 


\subsubsection{Professores}

Os futuros usuários do sistema, servidores da Assistência Acadêmica do ICMSC, acharam interessante que se mantenha sobre os professores do Instituto, além de informações elementares, algumas informações complementares como data de contratação, regime de trabalho, afastamentos, exercícios concomitantes, licenças, etc. A existência de duas datas de ingresso - na USP e no ICMSC - se deve ao fato de um professor poder ingressar em outro instituto da USP antes de ingressar no ICMSC, e um critério de desempate em uma eleição pode ser o candidato com mais tempo na USP.

As relações com informações referentes a Professores são:

- profpes - informações elementares

\begin{tabular}{|c|c|c|c|c|c|}
\hline chavepro & nome & sexo & $\begin{array}{c}\text { depar- } \\
\text { tamento }\end{array}$ & $\begin{array}{c}\text { data ingresso } \\
\text { no ICMSC }\end{array}$ & $\begin{array}{c}\text { data ingresso } \\
\text { na USP }\end{array}$ \\
\hline
\end{tabular}

O domínio chavepro contém o valor do número funcional do professor, que é único.

- categpro - informações sobre a carreira dos professores, que contém informações dos períodos que cada professor pertenceu à categoria

\begin{tabular}{|c|c|c|c|}
\hline chavepro & $\begin{array}{c}\text { data início } \\
\text { na categoria }\end{array}$ & $\begin{array}{c}\text { data término } \\
\text { na categoria }\end{array}$ & categoria \\
\hline
\end{tabular}

O domínio categoria pode assumir os valores: MS1, MS2, MS3, MS4, MS5, MS6.

- contrpro - informações sobre contrato dos professores

\begin{tabular}{|c|c|c|c|}
\hline chavepro & $\begin{array}{c}\text { data início } \\
\text { do contrato }\end{array}$ & $\begin{array}{c}\text { data término } \\
\text { do contrato }\end{array}$ & $\begin{array}{c}\text { condição } \\
\text { do contrato }\end{array}$ \\
\hline
\end{tabular}

O domínio condição do contrato pode assumir os valores: efetivo ou não concursado. 
- regtrab - informações sobre regime de trabalho dos professores

\begin{tabular}{|c|c|c|c|}
\hline chavepro & $\begin{array}{c}\text { data início } \\
\text { do regime }\end{array}$ & $\begin{array}{c}\text { data término } \\
\text { do regime }\end{array}$ & $\begin{array}{c}\text { regime de } \\
\text { trabalho }\end{array}$ \\
\hline
\end{tabular}

O dominio regime de traballio pode assumir os valores: RTP Ou RDIDP.

- apospro - informações sobre aposentadoria dos professores

\begin{tabular}{|l|l|}
\hline chavepro & data da aposentadoria \\
\hline
\end{tabular}

- afastpro - informações sobre afastamento de professores para estudo ou aperfeiçoamento

\begin{tabular}{|c|c|c|c|c|c|}
\hline chavepro & $\begin{array}{c}\text { data início } \\
\text { afastamento }\end{array}$ & $\begin{array}{c}\text { data término } \\
\text { afastamento }\end{array}$ & $\begin{array}{c}\text { tipo de } \\
\text { afastamento }\end{array}$ & país & $\begin{array}{c}\text { univer- } \\
\text { sidade }\end{array}$ \\
\hline
\end{tabular}

Alguns valores que o domínio tipo de afastamento pode assumir são: doutorado, pós-doutorado.

- exerconc - informações sobre o exercício de função concomitante de professores do ICMSC em outros institutos ou universidades

\begin{tabular}{|c|c|c|c|c|}
\hline chavepro & $\begin{array}{c}\text { data início } \\
\text { ex. concomitante }\end{array}$ & $\begin{array}{c}\text { data término } \\
\text { ex. concomitante }\end{array}$ & local & função \\
\hline
\end{tabular}

O domínio função representa a função exercida pelo professor do ICMSC no outro estabelecimento.

- licenca - informações sobre licença de professores por motivos pessoais

\begin{tabular}{|c|c|c|c|}
\hline chavepro & $\begin{array}{c}\text { data início } \\
\text { da licença }\end{array}$ & $\begin{array}{c}\text { data término } \\
\text { da licença }\end{array}$ & motivo \\
\hline
\end{tabular}

O domínio motivo pode assumir os valores: particular ou saúde. 


\subsubsection{Alunos}

$\mathrm{Na}$ base de dados do SCC são armazenadas informações somente de alunos que participam ou participaram de algum colegiado ou comissão.

As relações com informações referentes aos Alunos são:

- alunopes - informações elementares

\begin{tabular}{|l|l|l|}
\hline chavealu & nome & sexo \\
\hline
\end{tabular}

O domínio chavealu contém o número de matrícula do aluno, que é único.

- cursoalu - informaçóes sobre o curso a que pertence o aluno

\begin{tabular}{|c|c|c|c|c|}
\hline chavealu & $\begin{array}{c}\text { data início } \\
\text { do curso }\end{array}$ & $\begin{array}{c}\text { data término } \\
\text { do curso }\end{array}$ & departamento & $\begin{array}{c}\text { nível do } \\
\text { curso }\end{array}$ \\
\hline
\end{tabular}

O domínio nível do curso pode assumir os valores: licenciatura, bacharelado, mestrado ou doutorado.

\subsubsection{Servidores}

Os tipos de relações com informações sobre servidores armazenam os dados de todos os servidores do ICMSC.

As relações com informações referentes aos Servidores são:

- servpes - informações elementares

\begin{tabular}{|l|l|l|l|}
\hline chaveser & nome & sexo & data ingresso \\
\hline
\end{tabular}

O domínio chaveser contém o número funcional do servidor, que é único.

- categser - informações sobre categoria dos servidores 


\begin{tabular}{|c|c|c|c|}
\hline chaveser & $\begin{array}{c}\text { data início } \\
\text { na categoria }\end{array}$ & $\begin{array}{c}\text { data término } \\
\text { na categoria }\end{array}$ & categoria \\
\hline
\end{tabular}

O domínio categoria pode assumir os valores: técnico especializado, administrativo ou operacional.

- aposer - informações sobre aposentadoria de servidores

\begin{tabular}{|l|l|}
\hline chaveser & data da aposentadoria. \\
\hline
\end{tabular}

\subsubsection{Professores Externos}

As informações sobre professores externos são apenas os dados mais elementares de professores do IFQSC que participam ou participaram da CG.

A relação com informações referentes aos Professores Externos é:

- profext

\begin{tabular}{|l|l|l|}
\hline chavepex & nome & sexo \\
\hline
\end{tabular}

O domínio chavepex contém o número funcional do professor externo, que é único.

\subsubsection{Elementos da Comunidade}

As informações sobre elementos da comunidade são apenas os dados mais elementares de indivíduos que participam ou participaram da CCEx.

A relação com informações referentes aos Elementos da Comunidade é:

- elemcomu

\begin{tabular}{|l|l|l|}
\hline chavecom & nome & sexo \\
\hline
\end{tabular}

O domínio chavecom contém o número do elemento da comunidade, que é único - para indexaçâo do arquivo. 


\subsubsection{Colegiados e Comissões}

A composição dos colegiados e comissões e seus cargos são representados em relações que contêm informações sobre o mandato de cada um de seus participantes. As informações relativas aos participantes de cada colegiado ou comissão são armazenadas em relações com a mesma estrutura, e seus nomes são:

- cacongr - cargos da Congregação;

- cacta - cargos do CTA;

- cacg - cargos da $\mathrm{CG}$;

- cacpg - cargos da CPG;

- cacpq - cargos da CPq;

- caccex - cargos da CCEx;

- casce - cargos do SCE;

- casma - cargos do SMA;

- caccb - cargos da CCB;

- cacsldec - cargos da CSLDCC.

\begin{tabular}{|c|c|c|c|c|c|}
\hline chave & $\begin{array}{c}\text { tipo do } \\
\text { elemento }\end{array}$ & $\begin{array}{c}\text { data início } \\
\text { na comissão }\end{array}$ & $\begin{array}{c}\text { data término } \\
\text { na comissão }\end{array}$ & cargo & condição \\
\hline
\end{tabular}

Alguns domínios dos registros apresentados acima são:

- tipo do elemento - pode assumir os valores: $\mathrm{P} \rightarrow>$ professor, $\mathrm{A}->$ aluno, $\mathrm{S}$ -> servidor, $\mathrm{PE}->$ professor externo ou EC -> elemento da comunidade;

- chave - é uma instância de chavepro, chavealu, chaveser, chavepex ou chavecom, dependendo do valor do tipo do elemento;

- cargo - o valor do domínio depende do colegiado ou comissão, alguns valores que pode assumir são: presidente, vice-presidente, representante discente, representante dos professores associados, etc;

- condição - pode assumir os valores: titular ou suplente. 


\subsection{Tipos de Consultas do SCC}

Como já mencionado, o usuário do SCC poderá obter informações de duas maneiras:

- Relatórios gerados no SGBD;

- Requisições em LN.

Alguns relatórios gerados são:

- Professores em Ordem Alfabética;

- Professores em Ordem Alfabética por Departamento;

- Professores em Ordem Cronológica - Ingresso na USP;

- Servidores em Ordem Alfabética;

- Professores de um Departamento;

- Professores com Ingresso no ICMSC em um Período;

- Servidores com Ingresso no ICMSC em um Período;

- Professores de uma Categoria em uma Data;

- Prolessores com um Tipo de Contrato em uma Data;

- Professores com um Regime de Trabalho em uma Data;

- Professores com Afastamento em uma Data;

- Professores em Licença em uma Data;

- Servidores de uma Categoria em uma Data;

- Todos os Professores que Exerceram um Cargo de uma Comissão;

- 'Todos os Servidores que Exerceram um Cargo de uma Comissão;

- Todos os Alunos que Exerceram um Cargo de uma Comissão;

- Professor que Exerceu um Cargo de uma Comissão em uma Data;

- Servidor que Exerceu um Cargo de uma Comissão em uma Data; 
- Aluno que Exerceu um Cargo de uma Comissão em uma Data;

- Professores em Ordem Cronológica de Titulação;

- Histórico de um Prolessor;

- Composição de uma Comissão em uma Data.

Como se pode perceber, os relatórios citados acima dizem respeilo a listas de vários elementos em alguma ordem ou que satisfazem alguma condição. Em contraste, as consultas feitas pela interface em LN, são realizadas para obter respostas em que apenas uma ou um pequeno número de informações satisfaz alguma condição. Alguns exemplos destas consultas podem ser:

- Qual o tipo de contrato de "Fulano"?

- Qual o período do exercício concomitante de "Fulano"?

- Qual a data de término do afastamento de "Fulano"?

- Que elemento exerce o cargo de vice-presidente na CCEx?

- Quais os professores que cumprem afastamento na Inglaterra?

- Quais os servidores técnico-administralivos?

- Qual o professor externo que participa da CG?

- Qual elemento da comunidade participa da CCEx?

\subsection{Considerações Finais}

Neste capítulo foi apresentada a proposta da arquitetura de um sistema que integra um SGBD com uma interface em LN. Além da arquitetura deste sistema, foram apresentadas a base de dados utilizada como aplicação desta proposta (que contém dados sobre os colegiados e comissões do ICMSC-USP), o modelo de dados utilizado e alguns dos tipos de consultas que podem ser realizadas. 


\section{Capítulo 6}

\section{Descrição dos Módulos do SGBD do Sistema SCC}

A interface do SGBD do sistema SCC com o usuário é baseada em menus de opções, através de telas que contém os seguintes elementos:

- Na terceira linha da tela é apresentado o menu de opções, que estará constantemente na tela, permitindo que o usuário saiba a operação que está sendo realizada. A escolha de uma opção é realizada pela movimentação do cursor através das teclas de setas (direita e esquerda) e da tecla <Enter $>$ sobre a opção desejada.

- A quinta linha da tela é de orientação e contém uma mensagem explicativa da opção selecionada pelo cursor.

- Da linha 7 à 22 é apresentada a janela de dados, através da qual são realizadas as operações de inclusão, alteração, exclusão e listagem dos dados.

- Na última linha da tela são apresentadas mensagens ao usuário, que podem ser informativas, de advertência ou de solicitação.

$\mathrm{Na}$ descrição dos módulos do sistema, contida nas próximas seções, são apresentadas algumas telas da interface do SGBD do sistema SCC.

\subsection{O Módulo Principal (SCC)}

Após ativar o sistema é apresentada a tela inicial - Figura 6.1 -, o módulo principal é ativado e a tela da Figura 6.2 é apresentada. 


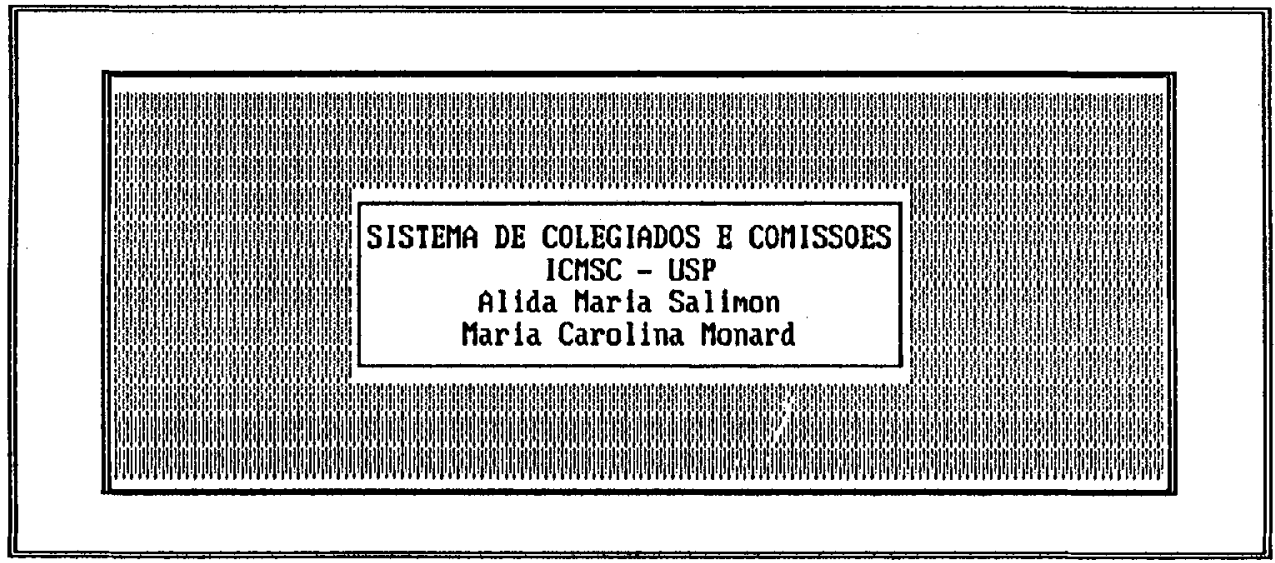

Pressione Alguma Iecla,

Figura 6.1: Tela Inicial do Sistema

SISTEMA DE COLEGIADOS E COMISSOES - ICMSC

B8/82/93

Professores Sisuidores outros Comissoes Relatorios Utilltarios Fim

Manutencao de Dados de Professores

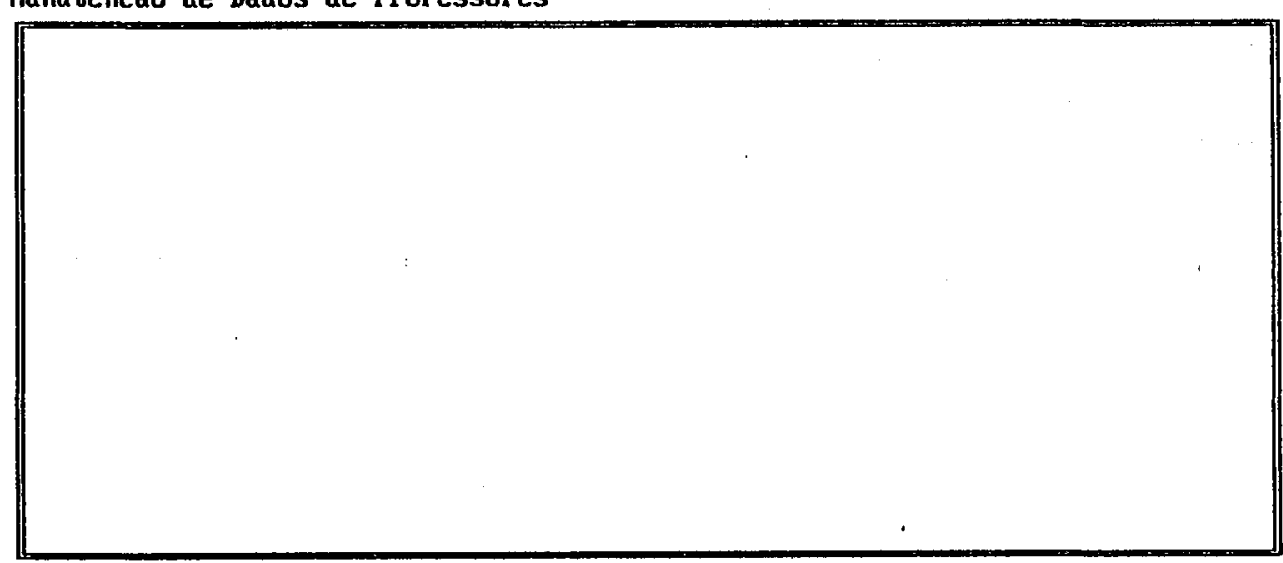

Figura 6.2: Tela do Módulo Principal 
Este módulo é composto por seis submódulos como mostrado na Figura $6.3^{1}$. Nele é apresentado um menu - Figura 6.2 - onde cada opção ativa un dos submódulos, como mostrado na Tabela 6.1.

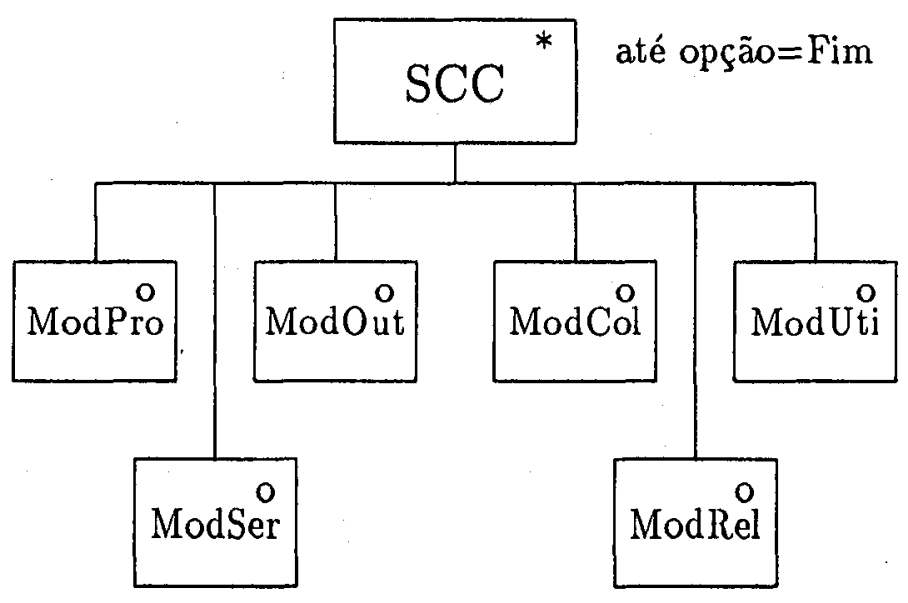

Figura 6.3: Diagrana do Módulo Principal SCC

\begin{tabular}{|l|lc|}
\hline \multicolumn{1}{|c|}{ Opção } & \multicolumn{1}{c|}{ Módulo Ativado } \\
\hline Professores & ModPro & - dados sobre professores \\
Servidores & ModSer & - dados sobre servidores \\
Outros & ModOut & - dados sobre alunos, professores externos \\
& & e elementos da comunidade \\
Comissoes & ModCol & - dados sobre comissões \\
Relatorios & ModRel & - geração de relatórios \\
Utilitarios & ModUti & - utilitários do sistema \\
\hline
\end{tabular}

Tabela 6.1: Tabela de Opções e Submódulos do Módulo Principal

Para finalizar a operação do sistema, basta escolher a opção Fim deste menu e é apresentada a tela de finalização e o pedido de confirmação do final da operação - Figura 6.4.

Nas seções seguintes são apresentadas as descrições dos submódulos do módulo principal - SCC.

\footnotetext{
${ }^{1}$ Nos diagramas o simbolo ${ }^{*}$ significa que o módulo representado no retângulo pode ativar repetidamente qualquer um dos módulos que aparecem nos niveis inferiores do diagrama. A saída desse módulo é realizada através da opção do menu correspondente, indicada no lado direito do retângulo que representa este módulo. O símbolo ${ }^{\circ}$ significa que apenas um dos módulos, cujo retángulo contérn este sínıbolo no nesmo nível do diagrama, scrá ativado.
} 


\begin{tabular}{|c|c|c|c|c|}
\hline & SISTEMA DE COLEGIADOS & COMISSOES & ICMSC & $08 / 82 / 93$ \\
\hline sores & Seruidores Outros & Comissoes & Relatorios & Utilltarios It \\
\hline
\end{tabular}

Fin das Operacoes

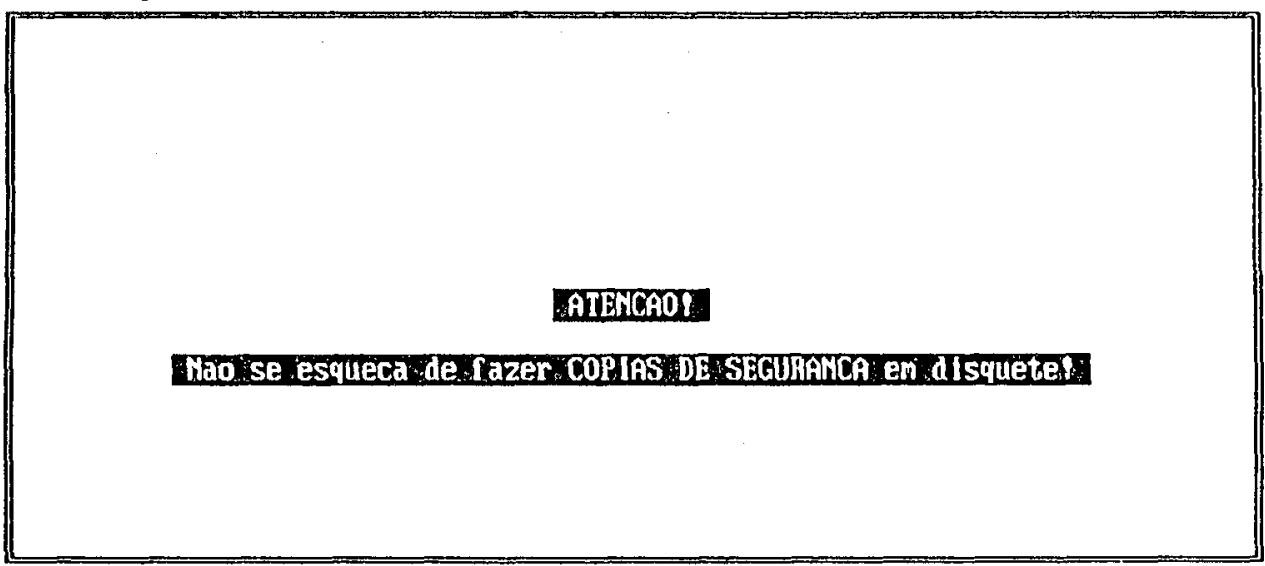

CONIITME FIM DAS OPERACOES, (S/N) i]

Figura 6.4: Tela de Finalização do Sistema

\subsection{Módulo de Manipulação de Dados dos Pro- fessores (ModPro)}

Este módulo é composto por oito submódulos como mostrado na Figura 6.5. Nele são abertos os arquivos necessários para a realização das operações e é apresentado um menu - Figura 6.6 - onde cada opção ativa um dos submódulos como mostrado na Tabela 6.2. Cada submódulo realiza as operações de inclusão, alteração, exclusão e listagem dos dados. A Figura 6.7 mostra a operação de inclusão de dados pessoais de professores.

\begin{tabular}{|l|ll|}
\hline \multicolumn{1}{|c|}{ Op̧̧ão } & \multicolumn{1}{c|}{ Módulo Ativado } \\
\hline Pessoal & ModPpes & - dados pessoais dos professores \\
Categoria & ModPcat & - dados sobre categoria dos professores \\
Contrato & ModPcon & - dados sobre tipo de contrato dos professores \\
Regime & ModPreg & - dados sobre regime de traballıo dos professores \\
Aposent & ModApos & - dados sobre aposentadoria \\
Afastam & ModPexer & - dados sobre exercício concomitante dos professores \\
ExConcom & ModPafa & - dados sobre afastamento dos professores \\
Licenca & ModPlic & - dados sobre licença dos professores \\
\hline
\end{tabular}

Tabela 6.2: Tabela de Opções e Submódulos do Módulo ModPro 


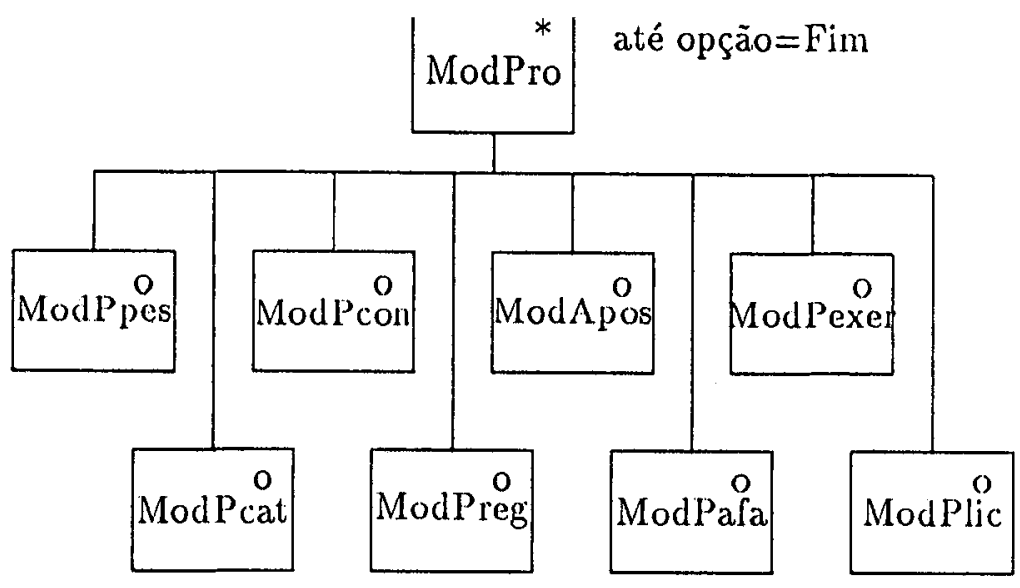

Figura 6.5: Diagrama do Módulo ModPro

[Pessad Categaria Contrato Regime Aposent afastam ExConcom Licenca Fim

Manipulacao de Dados Pessoais dos Professores

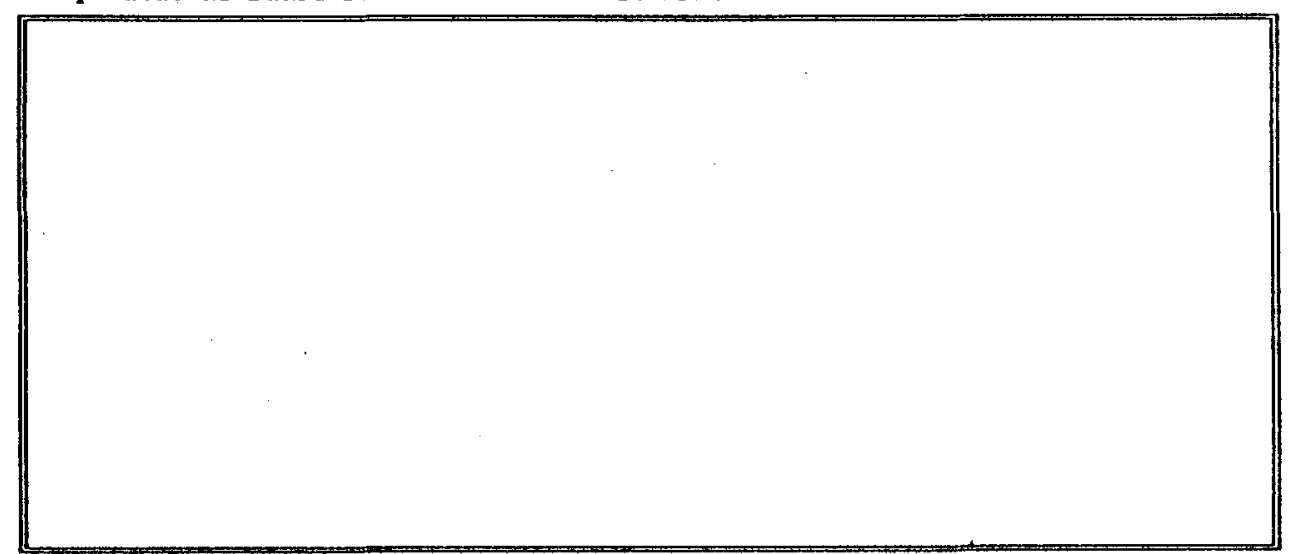

Figura 6.6: Tela do Módulo ModPro 


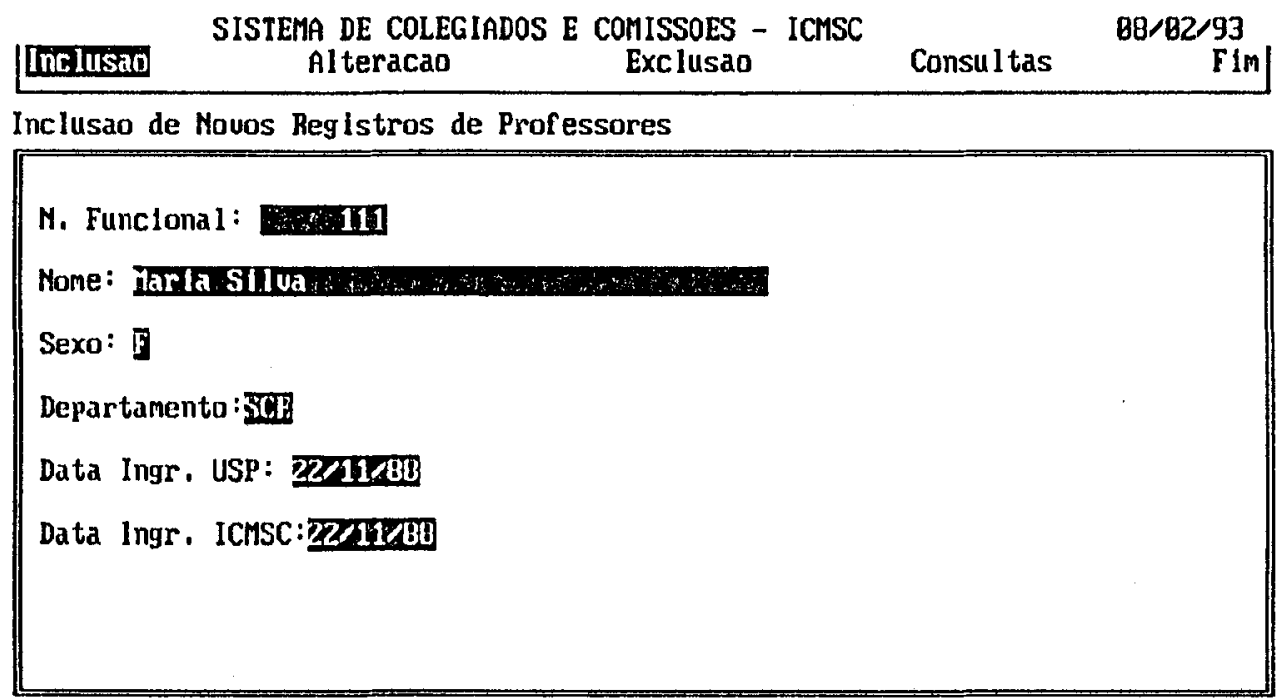

Conf irme Dados DIgltados , (S/N) \$

Figura 6.7: Tela de Inclusão de Dados do Módulo ModPpes 


\subsection{Módulo de Gerenciamento de Dados dos Servidores (ModSer)}

Este módulo é composto por três submódulos como mostrado na Figura 6.8. Nele são abertos os arquivos necessários para realização das operações e é apresentado um menu - Figura 6.9 - onde cada opção ativa um dos submódulos como mostrado na Tabela 6.3. Cada submódulo realiza as operações de inserção, alteração, exclusão e listagem dos dados correspondentes. A Figura 6.10 mostra a operação de alteração de dados do módulo ModScat.

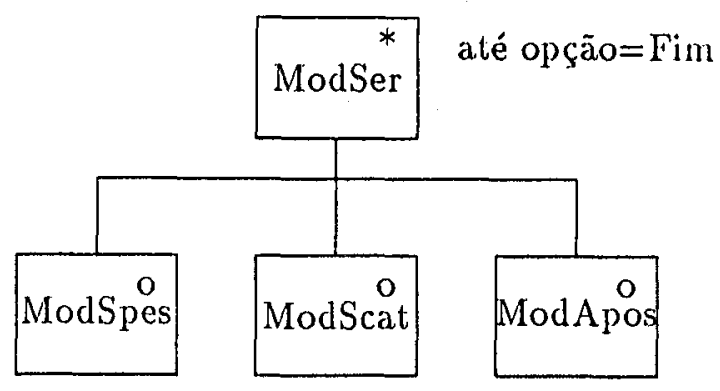

Figura 6.8: Diagrama do Módulo ModSer

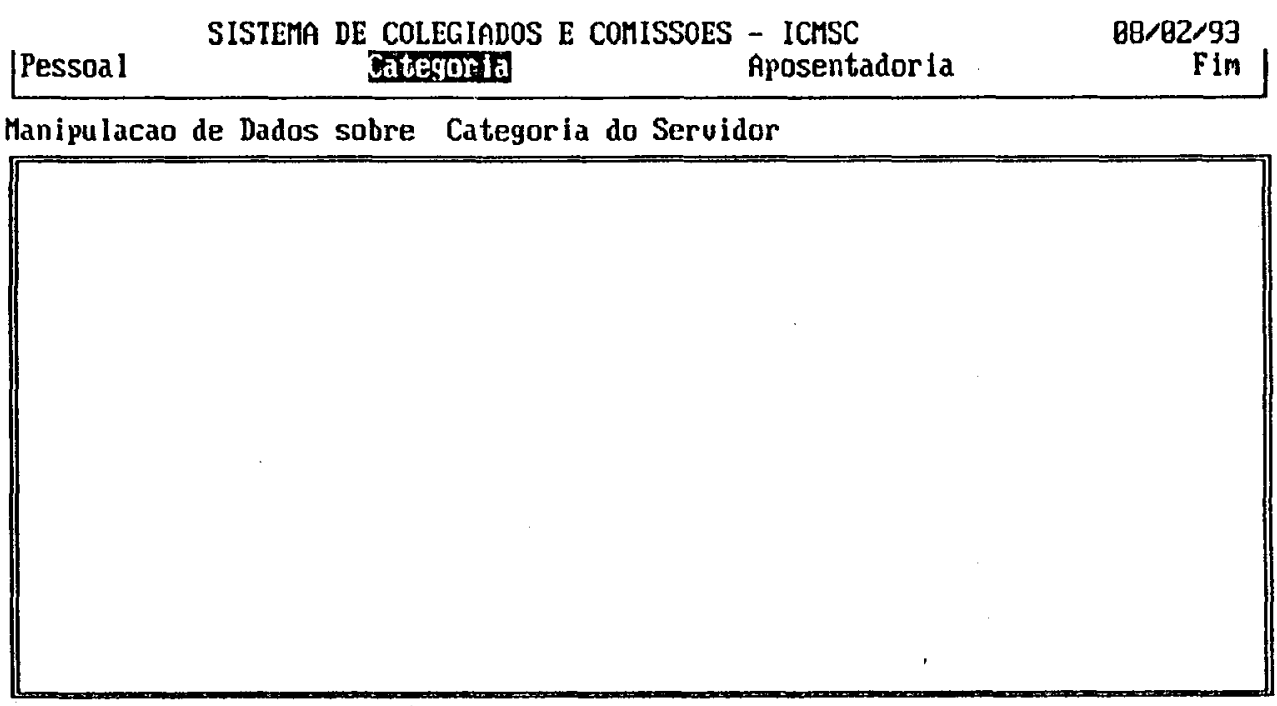

Figura 6.9: Tela do Módulo ModSer 


\begin{tabular}{|l|l|}
\hline Opção & Módulo Ativado \\
\hline Pessoal & ModSpes - dados pessoais dos servidores \\
Categoria & ModPcat - dados sobre categoria dos servidores \\
Aposentadoria & ModApos - dados sobre aposentadoria \\
\hline
\end{tabular}

Tabela 6.3: Tabela de Opções e Submódulos do Módulo ModSer

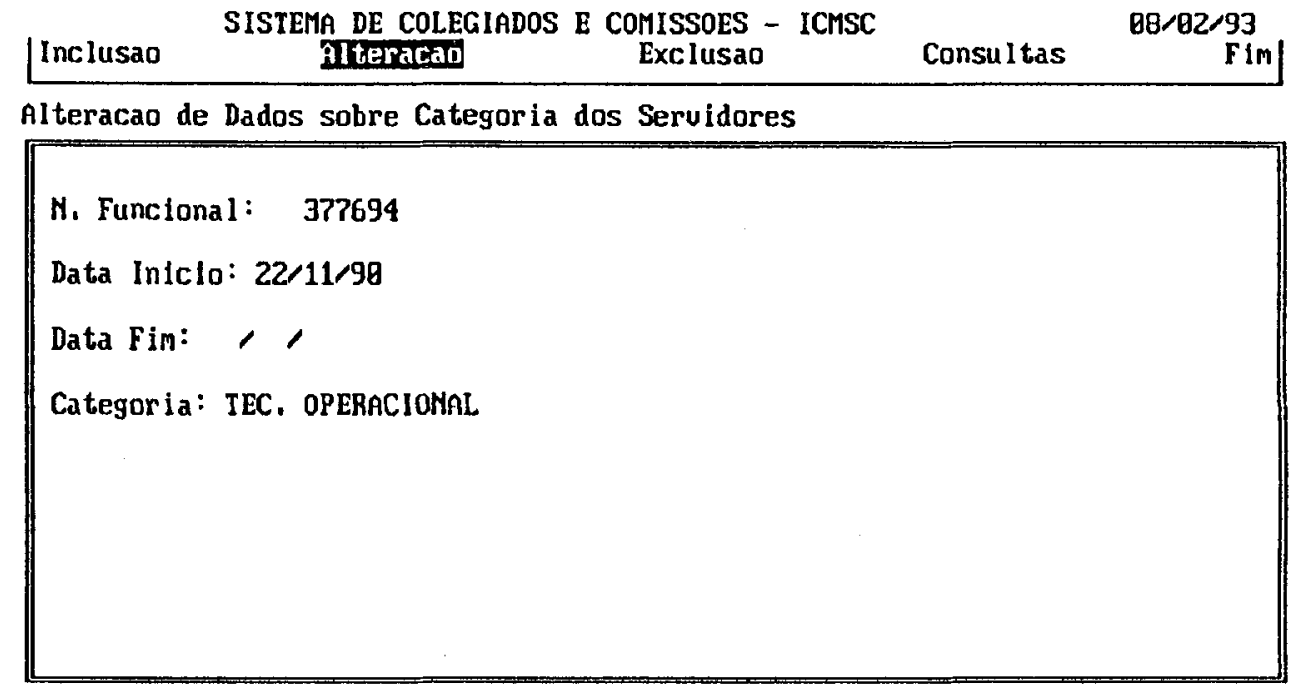

Conf Irme se Este e o Reglstro a Ser Alterado , (S/N) I

Figura 6.10: Tela de Alteração de Dados do Módulo ModScat 


\subsection{Módulo de Manipulação de Dados dos Alu- nos, Professores Externos e Elementos da Comunidade (ModOut)}

Este módulo é composto por quatro submódulos como mostrado na Figura 6.11. Nele são abertos os arquivos necessários para a realização das operações e é apresentado um menu - Figura 6.12 - onde cada opção ativa um dos submódulos como mostrado na Tabela 6.4. Cada submódulo realiza as operações de inclusão, alteração, exclusão e listagem dos dados correspondentes.

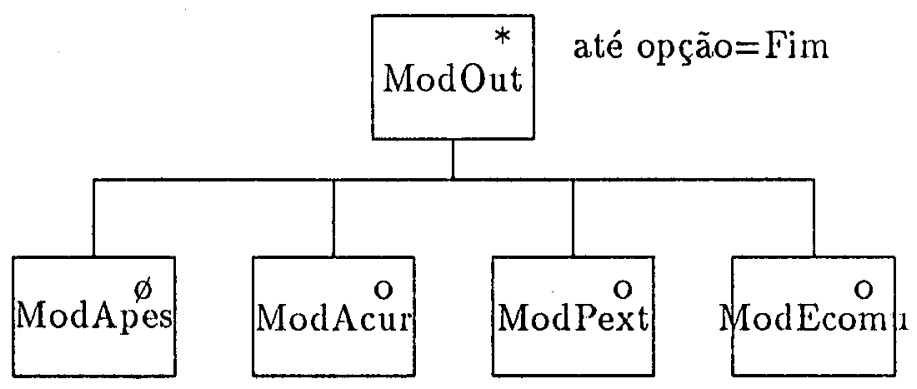

Figura 6.11: Diagrama do Módulo ModOut 


\begin{tabular}{|l|ll|}
\hline \multicolumn{1}{|c|}{ Opção } & \multicolumn{1}{c|}{ Módulo Ativado } \\
\hline Aluno Pessoal & ModApes & - dados pessoais dos alunos \\
Curso Aluno & ModAcur & - dados sobre curso dos alunos \\
Prof. Externo & ModPext & - dados sobre professores externos \\
El Comunidade & ModLcomu & - dados sobre clementos da communidade \\
\hline
\end{tabular}

Tabela 6.4: Tabela de Opções e Submódulos do Módulo ModOut

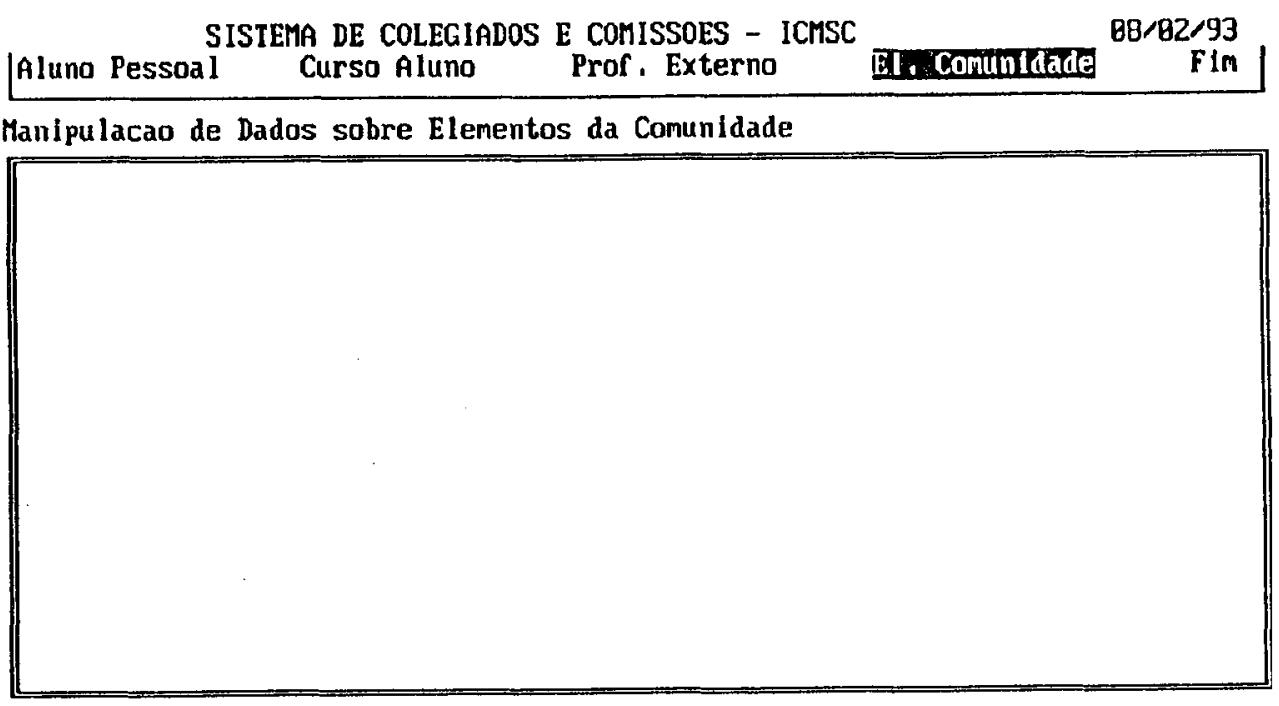

Figura 6.12: Tela do Módulo ModOut 


\subsection{Módulo de Comissões e Colegiados (Mod- Col)}

Neste módulo são abertos os arquivos necessários para a realização das operações e é apresentado um menu - Figura 6.13 - onde cada opção ativa o módulo para a comissão correspondente. Nele são realizadas as operaçóes de inclusão, alteração, exclusĩo e listagem dos dados. A Figura 6.14 mostra a operação de inclusão de dados do módulo ModCol para a Congregação.

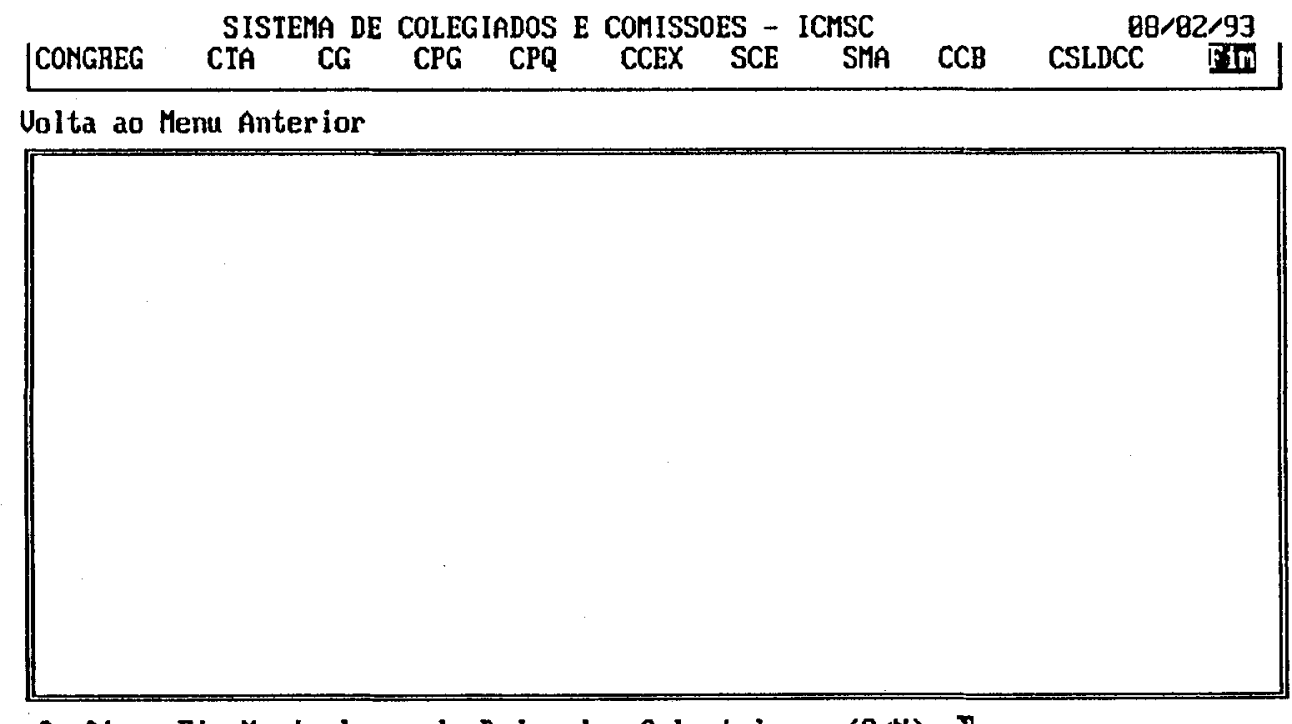

Conf Irme FIm ManIpulacao de Dados dos Coleglados . (S/H) i]

Figura 6.13: Tela do Módulo ModCol

Este módulo, assim como os descritos nas seções seguintes, não possui submódulos.

\subsection{Módulo de Relatórios (ModRel)}

Neste módulo são abertos os arquivos necessários para a geração dos relatórios e é apresentado um menu com as opções de relatórios do sistema - Figura 6.15.

\subsection{Módulo de Utilitários (ModUti)}

Neste módulo é apresentado um menu cujas opções ativam a execução do utilitário selecionado. 
SISTEMA DE COLEGIADOS E COMISSOES - ICMSC

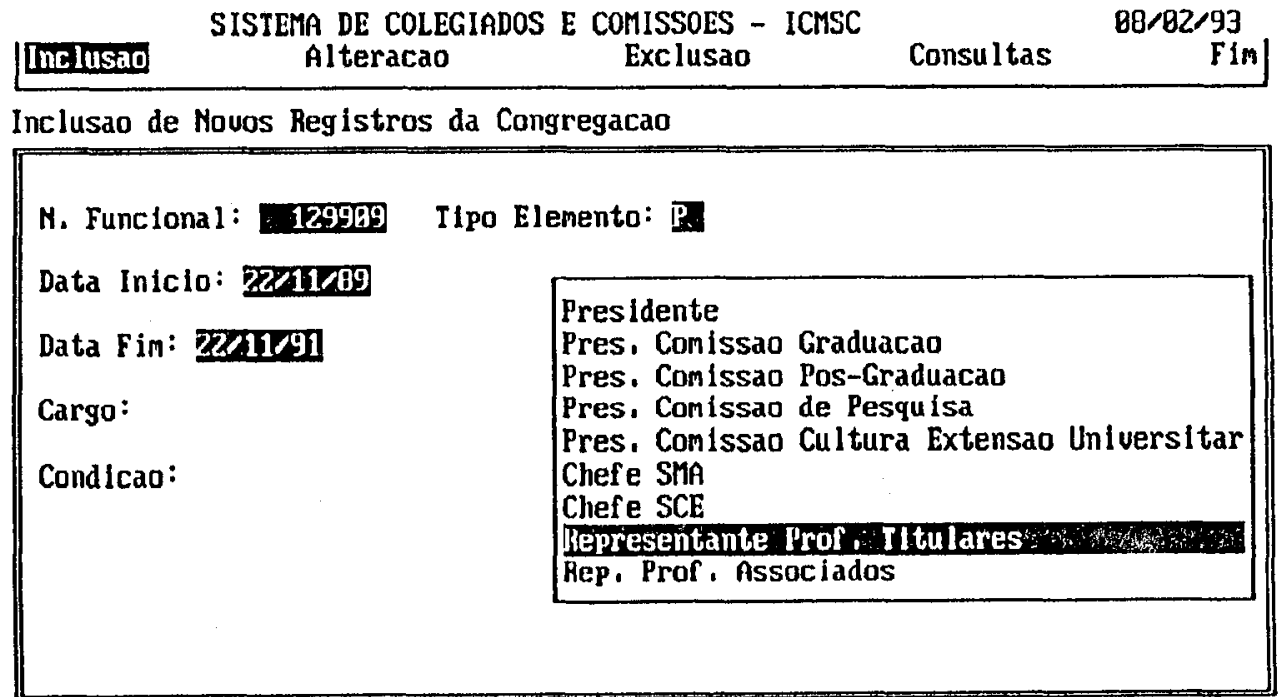

Digite Dados do Professor

Figura 6.14: T'ela de Inclusão de Dados do Módulo ModCol

\begin{tabular}{|c|c|c|c|c|}
\hline & SISTEMA DE COLEGIADOS & COMISSOES & ICMSC & 88/82/93 \\
\hline Professores & Seruldores Outros & Comissoes & Relatorios & Utllitarios Fin \\
\hline
\end{tabular}

Menu de Relatorios

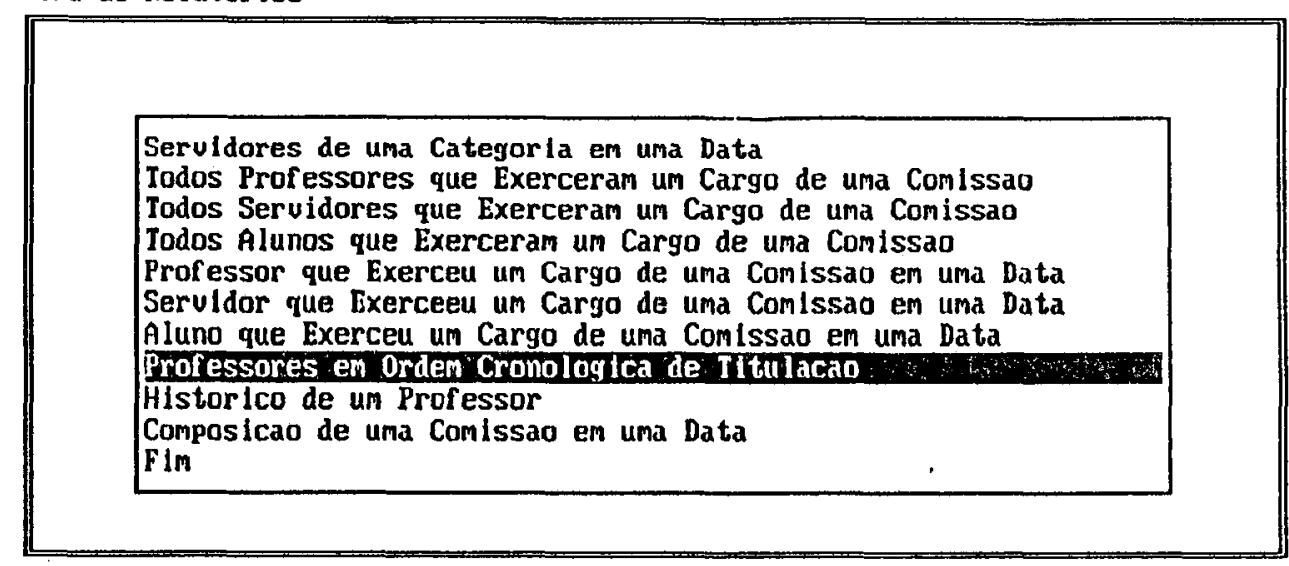

Figura 6.15: Tela do Módulo ModRel 


\section{Capítulo 7}

\section{Descrição da Interface em Linguagem Natural}

\subsection{Considerações Iniciais}

O objetivo desta interface - implementada na linguagem de programação Prolog [Arity 90] - é permitir que o usuário final do sistema realize consultas à base de dados Prolog em linguagem natural. As consultas são realizadas através de sentenças interrogativas do tipo $Q u$ (quando, qual, etc). A interface trabalha com uma sentença por vez e sua função é entender as requisições do usuário e respondê-las.

A representação das informações na base de dados é declarativa. O sistema procura as informações para responder às requisições do usuário utilizando o procedimeno de prova do motor de inferência do Prolog. Caso a prova não seja bem sucedida, o sistema responde ao usuário que não existe resposta para sua requisição.

A arquitetura proposta é modular e tem como objetivo permitir que o sistema possa ser adaptado para novos domínios de aplicação. Cada domínio de aplicação contém informações, bem como vocabulário de interação, especificas, o que restringe o tipo de requisiçôes que podem ser processadas com sucesso. A aplicação desenvolvida neste trabalho contém informações sobre os colegiados e comissões do ICMSC-USP, atualmente em vigor, descritas no Capítulo 5. Esta interface é dividida em módulos, como descrito na Seção 3.3 e detalhados nas próximas seções. 


\subsection{Análise de Sentenças}

A função deste módulo é interpretar uma requisição em linguagem natural, gerando uma interpretação da sentença que será utilizada para realizar o acesso à base de dados em busca da resposta à requisição. A análise da sentença envolve o conhecimento do vocabulário e a gramática, que realiza a análise sintática e semântica. Como descrito na Seção 4.4, existem vários níveis de interação entre sintaxe e semântica. No sistema proposto neste trabalho, cada vez que a análise sintática reconhece um constituinte maior da sentença - sintagma nominal, sintagma preposicional, etc - este constituinte é submetido à análise semântica para verificar se as relações entre seus ítens léxicos são válidas. Esta interação entre sintaxe e semântica permite que o sistema rejeite imediatamente sentenças sintaticamente corretas mas semanticamente anômalas, diminuindo consideravelmente o tempo de análise.

Nas seções seguintes são apresentadas a representação do vocabulário e as fases da análise da sentença: análise léxica, análise sintática, análise semântica e análise pragmática.

\subsubsection{Representação do Vocabulário}

Como mencionado anteriormente, as palavras podem ser divididas em duas classes:

- classe fechada, que contém as palavras que não variam com o domínio de aplicação da base de dados;

- classe aberta, que contém palavras que variam com o domínio.

As palavras do vocabulário de interação, tanto da classe fechada como da classe aberta do sistema proposto, são armazenadas segundo sua classe gramatical em diversos arquivos.

As palavras da classe fechada são armazenadas em um único arquivo, cujo nome "default" é lexicon.ari. A seguir são apresentadas as classes gramaticais das palavras que pertencen à classe fechada, a sua estrutura e um exemplo de representação.

- preposições

$\begin{array}{ll}\text { Estrutura } & \text { preposicao(Prep, RepSem). } \\ \text { Exemplo } & \text { preposicao(de,de). }\end{array}$




\section{- combinações de preposição e artigo}

Estrutura combinacao(Prep, Artigo, Comb).
Exemplo combinacao(em,a,na).

Neste caso, depois de reconhecida a combinação, a análise prossegue como se tivesse sido encontrada apenas a preposição na sentença.

\section{- determinantes}

\begin{tabular}{ll}
\hline Estrutura & $\operatorname{determ}(\operatorname{Det}, A, \operatorname{existe}(A, v))$ \\
Exemplo & $\operatorname{determ}(a, A, \operatorname{existe}(A, v))$
\end{tabular}

A representação semântica fornecida neste caso - o terceiro argumento será explicada posteriormente.

- expressões interrogativas

\begin{tabular}{|ll|}
\hline Estrutura & expr_inter(Inter, RepSem). \\
& expr_inter(Inter, RepSem, InfImplicita). \\
Exemplos & expr_inter(qual, q). \\
& expr_inter(quando, q, [a,data,em,que]).
\end{tabular}

A segunda estrutura apresentada é utilizada nos casos em que um ítem léxico possui um significado implícito. Por exemplo, quem pode significar em algum domínio qual o professor. No caso da aplicação desenvolvida, isto só ocorre com o item quando e, neste caso, ele é transformado em outros itens para permitir uma busca mais direta da interpretação. Por exemplo, a sentença

Quando a Licença de José termina?

será transformada na sentença

Qual a Data em que a licenga de José termina?

- pronomes relativos

\begin{tabular}{|ll|}
\hline Estrutura & pron_rel(Pron). \\
Exemplo & pron_rel(que). \\
\hline
\end{tabular}




\begin{tabular}{|l|l|}
\hline Arquivo & Connteúdo \\
\hline $\begin{array}{l}\text { Substantivos Comuns e } \\
\text { Próprios e Adjetivos }\end{array}$ & $\begin{array}{l}\text { terminal na forma canônica } \\
\text { e sua representação semântica }\end{array}$ \\
\hline Verbos & $\begin{array}{l}\text { infinitivo, transitividade, } \\
\text { conjugação, regularidade } \\
\text { e flexão do verbo no caso } \\
\text { de verbos irregulares }\end{array}$ \\
\hline Semântica de Verbos & $\begin{array}{l}\text { representação semântica } \\
\text { do sujeito e do complemento } \\
\text { do verbo caso exista }\end{array}$ \\
\hline Semântica de Preposições & $\begin{array}{l}\text { representação semântica } \\
\text { dos substantivos e verbo ligados } \\
\text { pela preposição e nome } \\
\text { da relação estabelecida } \\
\text { pela preposição }\end{array}$ \\
\hline
\end{tabular}

Tabela 7.1: Conteúdo dos Arquivos Manipulados pelo Sistema GBC

As palavras da classe aberta devem ser definidas cada vez que o sistema for adaptado a um novo domínio. Cada classe gramatical destas palavras é armazenada em um arquivo diferente. Para realizar a tarefa de manipular estes arquivos criar, editar, apagar e imprimir - foi desenvolvido o Sistema GBC [Monteiro 92]. Este sistema é dirigido por menus, através dos quais se escolhe o arquivo que se deseja manipular. Logo após, as informações que serão armazenadas nele são requisitadas pelo sistema através de janelas.

A Tabela 7.1 apresenta as informações contidas nos arquivos manipulados pelo Sistema GBC.

Durante a ativação do sistema, as informações contidas em cada um dos arquivos criados pelo Sistema GBC devem ser armazenados de tal maneira que o acesso posterior a essa informação seja eficiente. São várias as estruturas de dados que permitem um acesso eficiente [Monard 93, Wirth 76]. Neste trabalho é utilizada a estrutura de árvore-B para armazenar essas informações. Uma árvore- $B$ é um método de indexação eficiente para armazenar e buscar um grande número de termos similares de uma base de dados. $\mathrm{Na}$ árvore- $\mathrm{B}$ a estrutura do índice pode ser visualizada como ramos de uma árvore e seus elementos como nós da árvore. A árvore-B é uma estrutura balanceada na qual os termos são armazenados no mesmo nível (o último) da árvore - Figura 7.1. 


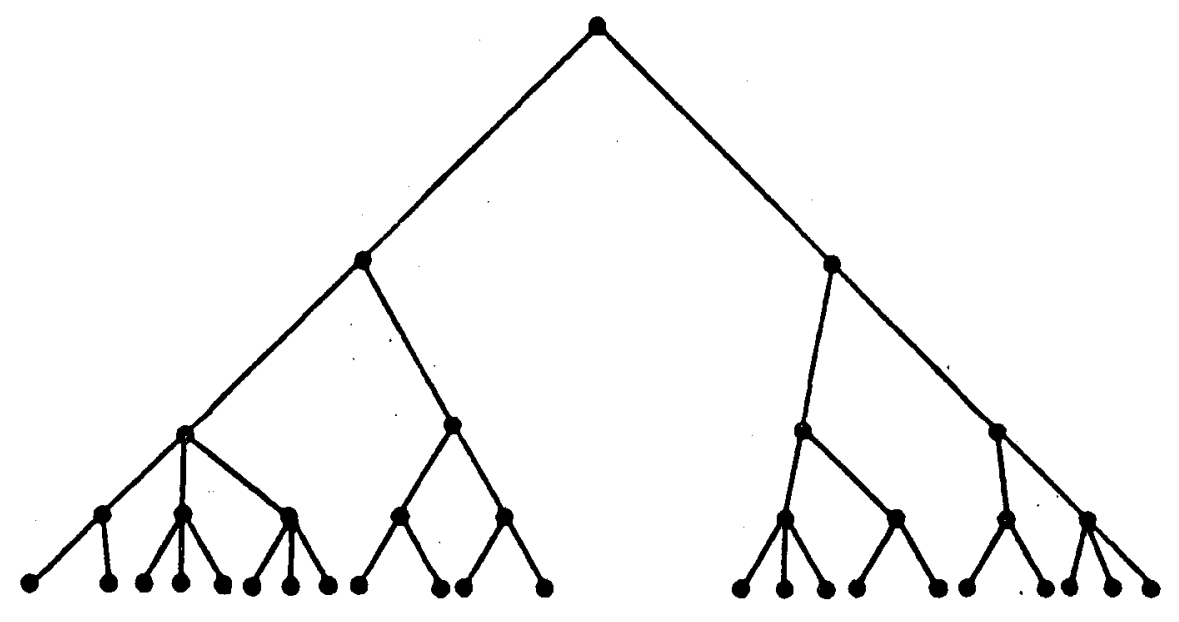

Figura 7.1: Representação Conceitual de uma Árvore-B

O Arity/Prolog possui facilidades para esta técnica de indexação. Conceitualmente, a árvore-B do Arity/Prolog consiste de nós e folhas e a busca na árvore começa no nó pai. Na árvore-B do Arity/Prolog, a menos que seja especificado o contrário, cada nó consiste de até dezessete ramos [Arity 90]. Cada nó contém informação para determinar o ramo da árvore a ser percorrido durante a busca de um termo. Cada ramo da árvore leva a outro nó que continua refinando o caminho de busca, até chegar onde estão armazenados os ternos. Assim, a altura da árvore- $B$ indica o número de acessos necessários para a busca por um dado termo.

O Sistema SCC utiliza, especificamente, uma árvore-B de ordem oito, isto é, cada nó consiste de até dezessete ramos. Portanto, no caso médio, se $n$ é o número de termos armazenados na árvore, deverão ser percorridos $h=\mathcal{O}\left(\log _{8} n\right)$ nós até acessar o termo correspondente, que é bem menos que $\mathcal{O}(n)$ obtida através de uma busca seqüencial.

No Sistema SCC cada ítem léxico é reconhecido durante a análise pelo procedimento term que possui aridade 3,4 ou 5 , dependendo da classe gramatical do ítem sob análise, através do qual é realizada a busca na árvore- $B$ colresponderte ou no arquivo lexicon ari, no caso de palavras da classe fechada. A seguir são apresentadas as classes granaticais, o nome "default" dos arquivos, as informações armazenadas e as árvores-B que são criadas.

\section{- substantivos comuns}




\begin{tabular}{|ll|}
\hline Arquivo & substcom.ari \\
Estrutura & nome(FCanonica, RepSem). \\
Exemplo & nome(categoria, categ-prof). \\
Árvore-B & substcom \\
Chave & FCanonica \\
Termo & nome(FCanonica, RSem). \\
Exemplo & nome(professor, professor:P). \\
\hline
\end{tabular}

As informações requisitadas pelo Sistema GBC são: a forma canônica do substantivo (masculino singular) e sua representação semântica.

$\mathrm{O}$ argumento RSem é obtido através do procedimento

$$
\text { rep_nome(RepSem, RepSem:Tipo). }
$$

onde ele equivale ao segundo argumento. Este procedimento, a partir da informação contida no arquivo substcom.ari, cria a representação semântica que será armazenada na árvore e que vai compor a expresão lógica resultante da análise da sentença. Ti po é uma variável que pode ser instanciada durante o acesso à base de dados.

\section{- subtantivos próprios}

\begin{tabular}{|ll|}
\hline Arquivo & substpro.ari \\
Estrutura & nome_pr(Subst, RepSem). \\
Exemplo & nome_pr('MS2', categ_prof). \\
Árvore-B & substpro \\
Chave & Subst \\
Termo & nome_pr(Subst, RSem). \\
Exemplo & nome_pr('MS2', categ_prof, categ_prof: 'MS2'). \\
\hline
\end{tabular}

As informações requisitadas pelo Sistema GBC são: o substantivo e sua representação semântica, que neste caso é a representação semântica do substantivo comum que representa a classe a que ele pertence.

$\mathrm{O}$ argumento RSem é oblido alravés do procedimento

$$
\text { rep_nome(Subst, RepSem, RepSem:Subst). }
$$

e equivale ao segundo argumento. Este procedimento, a partir da informação contida no arquivo substpro.ari, cria a representação semântica que será armazenada na árvore e que vai compor a expressão lógica resultante da análise da sentença.

É uma exigência do sistema, nesta primeira versão, que nomes próprios começados com letra maiúscula ou compostos por mais de uma palavra sejam fornecidos entre aspas. Por exemplo, 'MS2', 'Joũo Carlos', etc. 
Os substantivos próprios que dependem dos dados da base de dados no caso da aplicação desenvolvida são nomes de professores, de servidores, de alunos, de professores externos, de elementos da comunidade, países e universidades -- e que podem ser incluídos, alterados ou excluídos da base a qualquer momento, não devem ser fornecidos para serem incluídos na árvore-B através do Sistema GBC e sim por procedimentos que os obtenha da base de dados.

\section{- adjetivos}

\begin{tabular}{|ll|}
\hline Arquivo & adjetivari \\
Estrutura & adjetivo(FCanonica, RepSem). \\
Exemplo & adjetivo(efetivo, efetivo). \\
Árvore-B & adjetiv \\
Chave & FCanonica \\
Termo & adjetivo(FCanonica, RepSem). \\
\hline
\end{tabular}

As informações requisitadas pelo Sistema GBC são: forma canônica do adjetivo (masculino singular) e sua representação semântica, que no caso é a própria forma canônica.

- verbos

\begin{tabular}{|ll|}
\hline Arquivo & verbos.ari \\
Estrutura & verb(Trans, Inf, RadFlex, Conj, Reg). \\
Exemplo & verb(trd, cumprir, cumpr, terc_conj, regular). \\
Árvore-B & verbos \\
Chave & chave(Trans, Inf). \\
Termo & verb(Trans, Inf, RadFlex, Conj, Conc, RepSem). \\
Exemplos & verb(trd, cumprir, cumpr, terc_conj, cumprir:C, \\
& cumprir(C, professor:P, afastamento:A)) \\
& verb(intr, aposentar, aposent, prim_conj, \\
& aposentar:C, aposentar(C, servidor:)). \\
\hline
\end{tabular}

As informações requisitadas pelo Sistema GBC são: infinitivo do verbo, transitividade, conjugação, regularidade, e flexão, no caso de verbos irregulares, ou radical, no caso de vebos regulares.

$\mathrm{O}$ argumento RepSem é obtido através do procedimento rep_verb/5, que consulta um arquivo que contém todas as possibilidades de relação de um verbo com sujeito e complemento para caso de verbos transitivos. Este arquivo é criado através do Sistema GBC e será descrito posteriormente. $\mathrm{O}$ procedimento rep_verb/5 descrito a seguir contém três cláusulas para os diversos tipos de transitividade do verbo. 


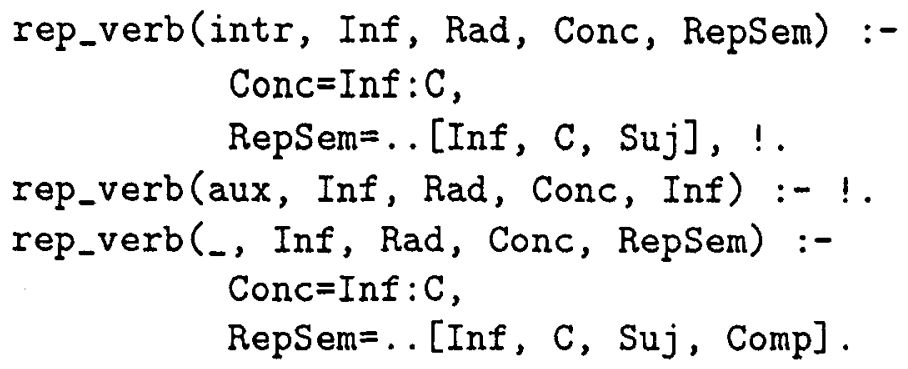

No caso da aplicação desenvolvida não são utilizados verbos irregulares, bem como verbos auxiliares ou transitivos indiretos.

Além dos arquivos com informações sobre as palavras da classe aberta, o Sistema GBC manipula o arquivo com informações sobre semântica de verbos, que é utilizado pelo procedimento rep_verb/5 descrito anteriormente, e sobre semântica de preposições, que é utilizado pelo procedimento ligacao/4 que será descrito posteriormente. A seguir são descritos estes dois arquivos e as informações contidas em cada um deles.

\section{- Semântica de Verbos}

Este arquivo contém informações sobre as possibilidades de construções verbais, ou seja, o relacionamento entre o verbo, o sujeito e o complemento, caso exista.

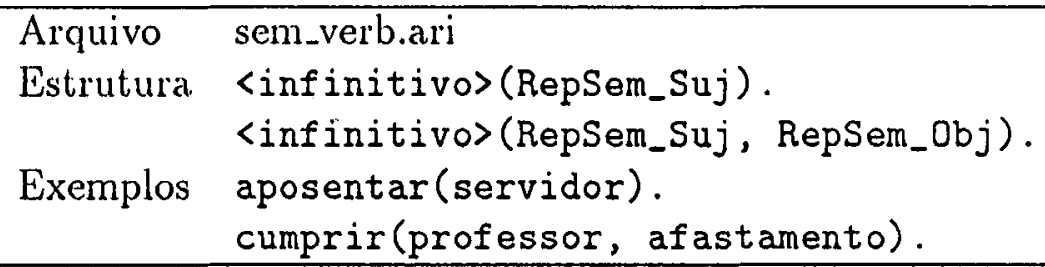

As informações requisistadas pelo Sistema GBC são: infinitivo do verbo, representação semântica do sujeito e, no caso de verbos transitivos, a representação semântica do objeto. Estas representações semânticas são idênticas às requisitadas no caso de substantivos comuns.

\section{- Semântica de Preposições}

As preposições podem modificar um elemento, ou uma idéia. Ela introduz uma relação entre dois constituintes da sentença - entre dois sintagmas nominais ou entre um verbo e um sintagma nominal. Esta relação será descrita mais detalhadamente na Seção 7.2.4. 


\begin{tabular}{|ll|}
\hline Arquivo & sem_prep.ari \\
Estrutura & $\langle$ prep $>$ (RepSem1, RepSem2, NomeRe1). \\
Exemplos & de(categ_prof, professor, prof_cat). \\
& em(cumprir, pais, localizacao).
\end{tabular}

As informações requisitadas pelo Sistema GBC são: a preposição, a representação semântica do primeiro elemento da relação (que é a mesma requisistada no caso de substantivos comuns quando modifica um objeto ou indivíduo e o infinitivo do verbo no caso de modificar uma idéia), a representação semântica do segundo elemento da relagão (que é a mesma requisitada no caso de substantivos comuns) e o nome da relação introduzida pela preposição.

Nos exemplos apresentados, as relações são as introduzidas pelas preposições nas frases

\section{CATEGORIA DO PROFESSOR}

$\mathrm{e}$

CUMPRIR NA INGLATERRA

respectivamente, onde o segundo elemento é a representação semântica do elemento modificado pela preposição. No caso de substantivos próprios, equivale ao substantivo que determina a classe a que o substantivo próprio pertence, no caso do segundo exemplo, Inglaterra é um país.

Percebe-se pelo que foi descrito sobre substantivos comuns, adjetivos e verbos, que apenas suas formas canônicas (masculino singular) e o infinitivo dos verbos são armazenados nas árvores-B correspondentes. Por esta razão, é necessário que se verifique as variações dos terminais (de gênero, número, tempo verbal, etc) através de procedimentos específicos, antes de buscar na árvore- $\mathrm{B}$ correspondente. Por exemplo, o procedimento trata_palavra/2 - apresentado a seguir - é responsável por reconhecer os sufixos de substantivos e adjetivos e retornar sua forma canônica; no caso da palavra professoras a sua forma canônica é professor.

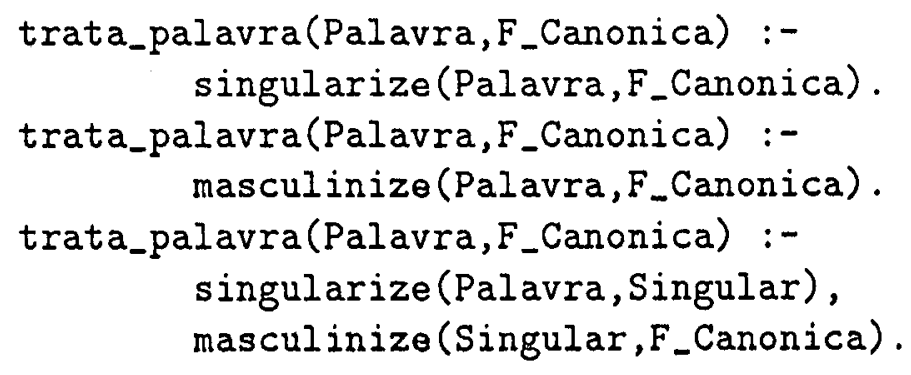




\subsubsection{Análise Léxica}

É função da análise léxica agrupar os caracteres delimitando e separando as palavras das sentenças e reconhecendo-as como ítens léxicos. Neste processo, a sentença introduzida pelo usuário é transformada para o formato de lista, na qual cada elemento é uma palavra da sentença que foi delimitada por um espaço. Por exemplo, a sentença:

\section{'QUAL' O PROFESSOR COM CATEGORIA 'MS2'?}

é transformada na lista

$$
\text { ['Qual',o, professor, com, categoria, 'MS2'] }
$$

\subsubsection{Análise Sintática}

As regras sintáticas - definidas na notação GCD - correspondem a um subconjunto da língua portuguesa, capaz de reconhecer as construçôes das possíveis requisições do domínio de aplicação da base de dados. Este subconjunto se restringe à definição de sentenças interrogativas do tipo $Q u$ e compreende o tratamento de sintagmas preposicionais modificadores de nomes ou frases, bem como o tratamento de sentenças relativas.

À medida que os constituintes maiores da sentença (sintagma nominal, sintagma preposicional, etc) são propostos pela análise sintática, é realizada a análise semântica para verificar se as relações entre seus ítens são válidas.

A seguir são apresentadas duas requisições possíveis no domínio da aplicação desenvolvida, bem como as regras gramaticais utilizadas na análise da sentença.

\section{Setença:}

\section{QUAIS AS PROFESSORAS EFETIVAS?}

Regras gramaticais utilizadas:

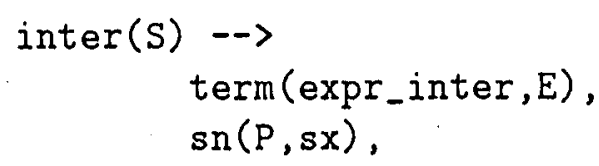




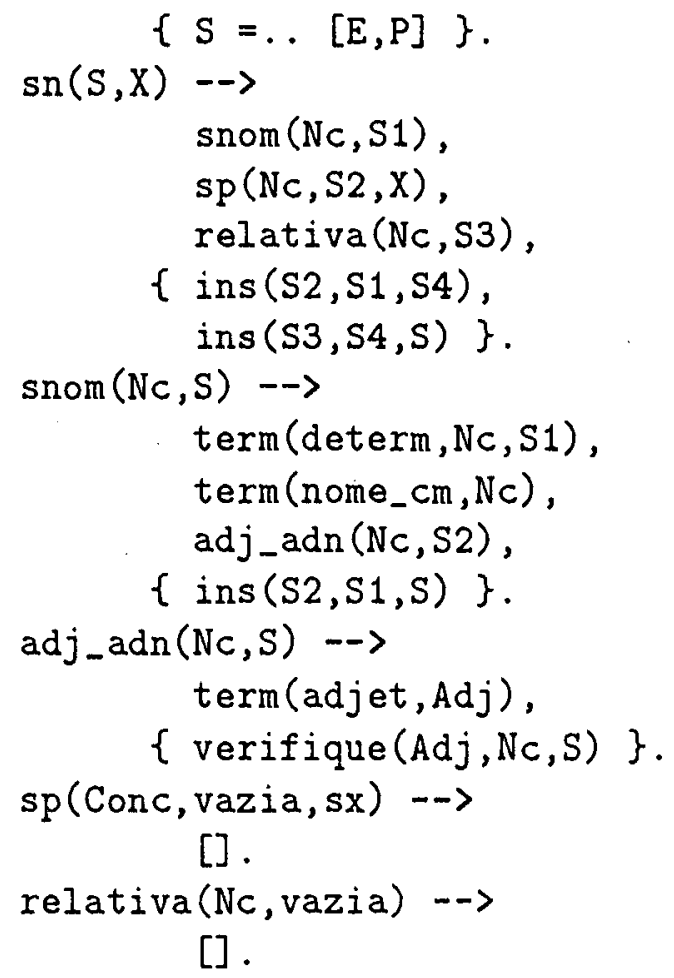

\section{Senteça:}

QUAL O PROFESSOR QUE CUMPRE AFASTAMENTO NA INGLATERRA?

Regras gramaticais utilizadas:

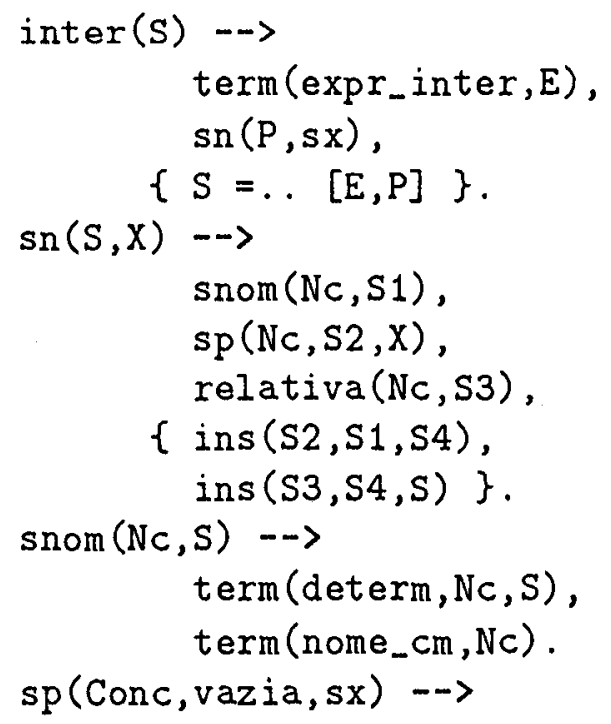




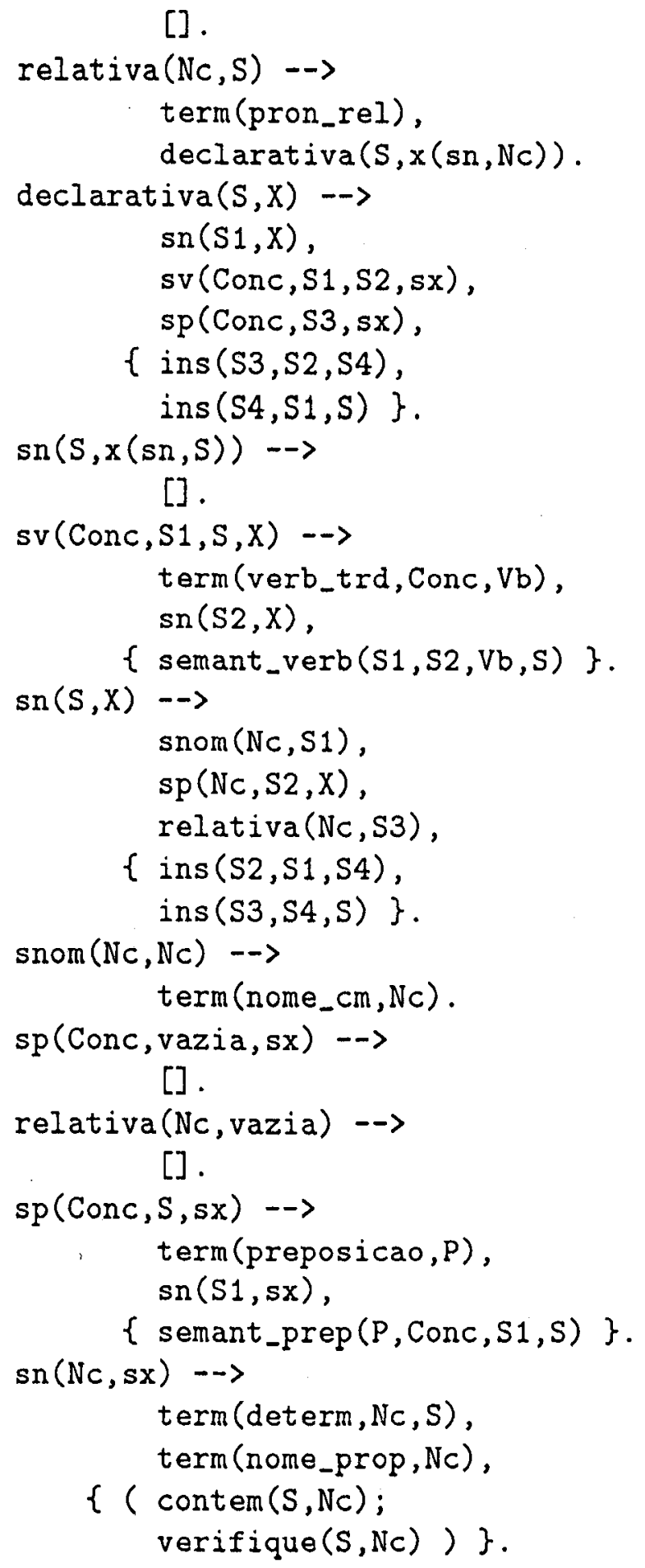

\subsubsection{Análise Semântica}

A interpretação resultante da análise da sentença é uma expressão lógica que possui uma das seguintes formas: 
ou

$$
\text { e(Tipo:X, Y) }
$$

onde X é a parte da sentença que corresponde à informação procurada pelo usuário e Y corresponde às informaçóes explícitas fornecidas pela sentença, dado por uma conjunção da interpretação de cada parte da sentença. A expressão lógica é composta por átomos que correspondem à interpretação semântica dos constituintes da sentença - símbolos terminais ou grupos destes símbolos. É função da análise semântica verificar a relação entre os ítens léxicos e agrupá-los nos átomos que compõem a expressão lógica.

A seguir é descrito cada tipo de átomo que pode compor uma expressão lógica, bem como a parte da análise que produz este átomo.

- existe(Classe:Nome, Conjuncao)

Este átomo é gerado por um determinante que quantifica um substantivo comum na composição de sintagmas nominais. O primeiro argumento é a representação semântica do substantivo, como armazenada na árvore-B substcom. O segundo argumento, Conjuncao, é uma conjunção de propriedades que devem ser satisfeitas por Nome.

Por exemplo, o determinante $o$ em

\section{O PROFESSOR}

vai gerar um átomo que tem a seguinte forma:

$$
\text { existe(professor:P, Conjuncao) }
$$

onde Conjuncao contém as informações da parte restante da sentença.

- Classe:Nome

Estes átomos são gerados pelo reconlecimento de substantivos comuns e próprios, através da busca nas árvores- $\mathrm{B}$ correspondentes. Esta especificação do significado é chamada de tipagem do ítem léxico, ela dá a associação do ítem ao seu domínio. Por exemplo, no caso do substantivo próprio José, que corresponde ao nome de um professor, ele possui como interpretação: 
No caso de substantivos comuns, esta tipagem fornece lacunas ou variáveis que serão instanciadas durante a busca na base de dados. Por exemplo, o substantivo professor possui a seguinte interpretação:

$$
\text { professor : } X
$$

- 〈adjetivo>(Nome).

Lstes átomos são resultado da análise semântica de um adjetivo que introduz alguma qualidade ao objeto ou indivíduo Nome. Esta análise é realizada pelo seguinte procedimento:

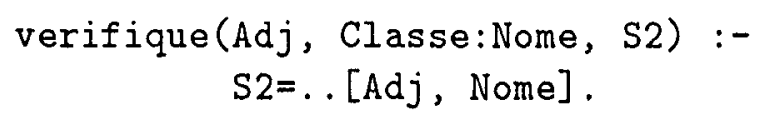

onde $\mathrm{Cl}$ asse:Nome é a representação semântica do substantivo, armazenada na árvore-B, que o adjetivo qualifica. S2 é o átomo resultante da análise.

Por exemplo, o adjetivo efetivo na frase

\section{QUAIS OS PROFESSORES EFETIVOS?}

fornece o átomo

$$
\text { efetivo(P) }
$$

onde P é a variável que será instanciada com o nome dos professores que são efetivos, durante a busca na base de dados. Este átomo vai compor a expressão lógica resultante da análise da sentença.

- 〈nome_relacao>(Conc, Nc1)

As preposições podem modificar um sintagma nominal ou uma frase. Elas introduzem, então, relações entre dois sintagmas nominais ou entre um verbo e um sintagma nominal. Este tipo de átomo é gerado pela análise semântica de preposições. Conc é a representaçãó semântica armazenada na árvore-B correspondente ao verbo - ou ao núcleo do sintagma nominal modificado pela preposição - e E é a representação semântica do núcleo do sintagma nominal que modifica o primeiro elemento da relação.

O procedimento responsável por verificar as relações introduzidas por preposições, construir a expressão lógica relacionada a esta relação e inseri-la na expressão lógica da sentença é 
sement_prep ( $P$, Conc, $S 1, S)$ :-

nucleo(S1, Nc1),

ligacao (P, Conc, Nc1, L),

$\mathrm{E} \ldots=[\mathrm{L}, \mathrm{Conc}, \mathrm{Nc1}]$,

ins $(E, S 1, S)$.

onde P é a preposição, Conc é o constituinte modificado pela preposição, S1 é o sintagma nominal (cujo núcleo é $\mathrm{Nc1}$, que modifica o primeiro elemento da relação) e E é o átomo resultante da relação semântica introduzida pela preposição. O procedimcuto ligacao/4 é responsável por verificar se existe no arquivo sem_prep.ari - criado através do sistema $\mathrm{GBC}$, que contém todas as relações semânticas introduzidas por preposições - a relação existente na requisição do usuário e retornar nome_relacao que é o funtor do átomo.

Por exemplo, a preposição em (no caso combinada com o artigo a) pode modificar o verbo cumprir, como na seguinte parte de sentença:

\section{CUMPRIR NA INGLATERRA}

cuja análise semântica fornece o átomo

$$
\text { localizacao(cumprir:C, pais: Inglaterra) }
$$

- 〈infinitivo>(C, Sujeito) e <infinitivo> (C, Sujeito, Objeto)

Estes átomos são resultantes da análise das construções verbais. Seu funtor é o infinitivo do verbo. Os argumentos correspondem ao conceito do verbo e à representação semântica armazenada na árvore-B do substantivo que é o núcleo do sujeito. No caso de verbos transitivos o terceiro argumento é a representação semântica do substantivo, que é o núcleo do objeto.

O conceito do verbo aparece em todo átomo da expressão lógica relacionado ao verbo (por exemplo, o átomo obtido pela modificação da preposição em apresentado anteriormente) e serve para estabelecer a dependência contextual entre as informaçòes da scntença.

O procedimento semant_verb, de aridade três ou quatro, determinada pela transitividade do verbo, definido a seguir, possui uma cláusula para verbos transitivos e outra para verbos intransitivos. Assim como semant_prep/4, ele é responsável pela verificação da validade da relação entre verbo, sujeito e complemento, caso exista. Ele é também responsável pela construção da expressão lógica desta relação e pela inserção na expressão lógica da sentença. 


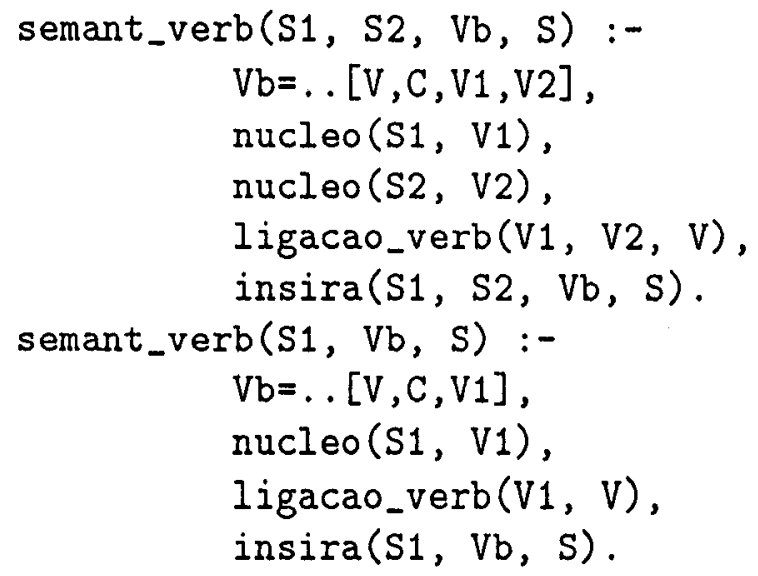

onde S1 e S2 são os sintagmas nominais que correspondem ao sujeito e ao objeto, respectivamente, Vb é o átomo gerado, V1 e V2 são Suj ei to e Objeto na definição do átomo e $S$ é a expressão lógica resultante da análise. $O$ procedimento ligacao_verb, que possui aridade dois ou três, é responsável pela verificação da existência, no arquivo sem_verb.ari, da relação entre o verbo, sujeito e objeto que aparece na requisição do usuário.

Por exemplo, a seguinte parte de sentença:

\section{PROFESSOR QUE CUMPRE AFASTAMENTO}

tem como expressão lógica da análise semântica o átomo

$$
\text { cumprir(C, professor:X, afastamento:A) }
$$

Estes átomos são compostos em conjunções, que vão representar as informações contidas na requisição do usuário. Como exemplo, a interpretação fornecida pela análise da requisição:

\section{QUAL O PROFESSOR QUE CUMPRE AFASTAMENTO NA INGLA- TERRA?}

é a seguinte expressão lógica

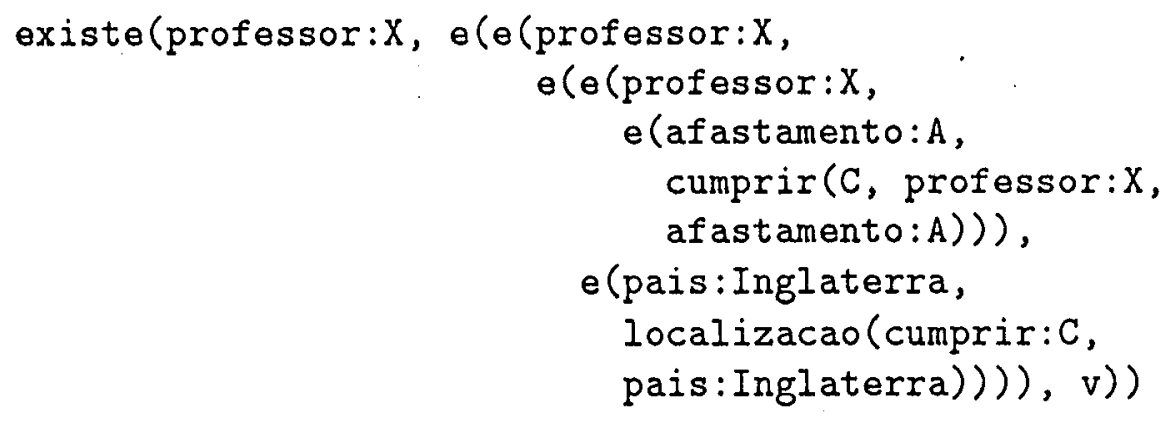




\subsubsection{Análise Pragmática}

O processo de análise no sistẹma proposto não engloba o tratamento pragmático profundo, no sentido de prever o uso das palavras de acordo com as intenções do usuário a cada momento. É tomado o sentido bastante simplificado de pragmática, mencionado na Seção 2.3.3, que é um processamento que faça uso da representação do significado.

\subsection{Acesso ao Conhecimento Específico}

A função deste módulo é realizar o acesso à base de dados utilizando a expressão lógica resultante da análise da requisição do usuário. Este processo consiste em procurar na base de dados os elementos - informações procuradas pelo usuário - que satisfazem as informações explícitas sobre estes elementos fornecidas na requisição.

Neste processo, cada átomo, resultante da análise semântica, que constitui a expressão lógica é utilizado no procedimento de prova, determinando em qual relação ou qual atributo deve ser procurado, ou que satisfaça uma informação contida na requisição. Cada classe gramatical de palavras produz um tipo de átomo como resultado da análise semântica. Alguns destes átomos determinam a ordem do procedimento de prova e outros determinam qual parte da base de dados deve ser consultada. A seguir é apresentada a função de cada tipo de átomo.

- $\operatorname{existe}(X, Y)$ e e $(X, Y)$

Estes átomos determinam que $Y$ será utilizado primeiro e a seguir $X$ no procedimento de prova. Isto porque as informações contidas nos átomos que compõem $Y$ restrigem os elementos que satisfazem $X$. Por exemplo, na conjunção:

$$
\text { e(professor:P, categprofessor(professor:P,categ_prof: 'MS2')) }
$$

que é o átomo resultante da relação introduzida pela preposição com na sentença:

\section{QUAIS OS PROFESSORES COM CATEGORIA MS2?}

o segundo elemento restringe o conjunto de professores. 


\section{- Classe:Nome}

Estes átomos, que são resultantes da análise de substantivos, determinam um atributo de uma relação. Por exemplo, o substantivo professor determina o atributo nome na relação profpes.

- 〈adjetivo>(Nome)

Estes átomos determinam, assim como os resultantes da análise de substantivos, um atributo de uma relação. No caso da aplicação desenvolvida, como as informações de um elemento podem estar armazenadas em registros distintos, é utilizada uma chave para relacionar estas informações e não o nome deste elemento. Assim, pode ser necessário procurar atributos em dois registros para realizar a prova. Por exemplo, o adjetivo efetivo que produz o átomo:

\section{efetivo(NomeProf)}

determina que se procure o atributo condicao, que deve ter o valor efetivo, e o atributo chave na relação contrpro e os atributos chave e nome na relação profpes para se obter NomeProf.

- 〈nome_relacao〉 (Conc,Nc1)

Os argumentos dos átomos resultantes da análise das relações introduzidas por preposições determinam o atributo e a relação a que este atributo pertence. Por exemplo, no átomo:

$$
\text { motivo_lic(motivo:M,Iicenca:L) }
$$

o primeiro argumento determina o atributo motivo e o segundo determina a relação licenca.

No caso em que a preposição introduz uma relação envolvendo um indivíduo - professor, aluno, servidor, professor externo ou elemento da comunidade - pelo mesmo motivo apresentado no caso de adjetivos, o átomo pode determinar o acesso a duas relações da base de dados.

- 〈infinitivo>(C,Sujeito) e 〈infinitivo>(C,Sujeito,Objeto)

No caso dos átomos resultantes de construções verbais, o verbo, juntamente com o sujeito e, no caso de existir, o objeto, determinam uma ou duas relações que devem ser consultadas, bern como scus atributos. Por exemplo, - verbo aposenlar tendo como sujeito um servidor, determina a relação aposer, o atributo chave e a relação servpes para se obter o nome do servidor. 
Como cada átomo é submetido ao meta-interpretador separadamente, é necessário que exista uma maneira de verificar que os dados obtidos no procedimento de prova da expressão lógica para obtenção de cada resposta possível a uma requisição estejam relacionados a um mesmo elemento. Para isto, em cada procedimento relacionado a um átomo existe um argumento cujo valor é a chave do elemento que está sendo consultado. Este argumento deve assumir o mesmo valor para todos os átomos de uma mesma expressão lógica.

Além disso, existem átomos que podem determinar uma busca em várias relações distintas. Por exemplo, átomos que dizem respeito a informações sobre comissões podem determinar até dez relações, uma de cada comissão. Por este motivo, é necessário que se certifique que as informações sejam procuradas apenas nas relações que sejam relacionadas à requisição. No caso da aplicação desenvolvida, cada requisição envolve, no máximo, acesso a duas relações da base de dados: uma com dados pessoais de um elemento e, no caso de envolver duas relações, a segunda contém informações específicas sobre este elemento -- curso de um aluno, categoria de um servidor, participação em um comissão, etc. Assim, a maneira utilizada para validar uma resposta é verificar o número de relações consultadas para encontrar esta resposta.

Como exemplo do que foi descrito, são apresentados a seguir os procedimentos determinados pelos átomos que compõem a expressão lógica (apresentada anteriormente) da sentença

\section{QUAL O PROFESSOR QUE CUMPRE AFASTAMENTO NA INGLA- TERRA?}

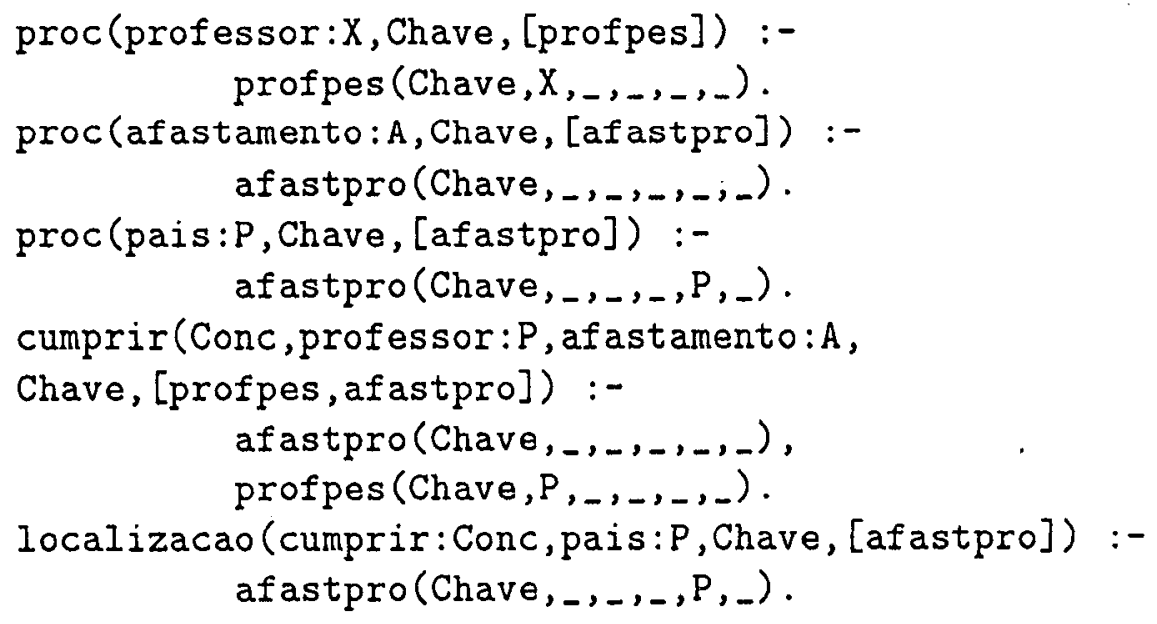

A expressão lógica resultante da análise da requisição do usuário é submetida a uma interpretação. Esta interpretação apenas acrescenta condições à expressão 
para realizar a busca e para que a resposta seja dada ao usuário de uma maneira conveniente. Esta interpretação é realizada pelo procedimento interprete/2 que retorna uma lista de metas que são provadas pelo meta-interpretador Prolog, execute/1 [Franco 92].

Por exemplo, para a sentença:

\section{QuAIS OS PROFESSORES MS2?}

o resultado da interpretação da expressão lógica é a seguinte lista de metas:

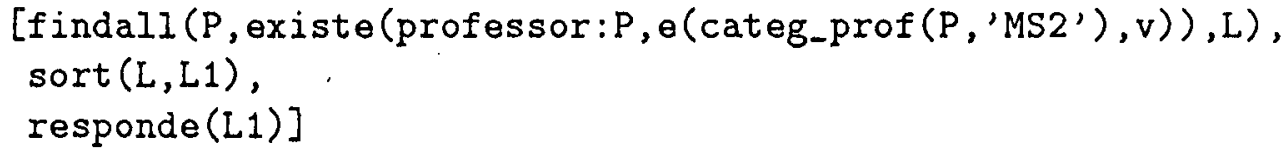

O meta-interpretador execute/1 é responsável pela prova da conjunção dessas metas.

A cada átomo que pode compor uma expressão lógica está associado um procedimento responsável por procurar na base de dados as relações e os atributos determinados por estes átomos. O resultado da execução desses procedimentos fornece as respostas à requisição do usuário. O predicado pré-definido findall/3 encontra uma lista com todas respostas. Respostas idênticas são retiradas dessa lista pelo predicado pré-definido sort/2. Finalmente, as respostas são mostradas ao usuário através do procedimento responde/1.

Como visto, uma possivel forma da expressão lógica é:

$$
\operatorname{existe}(P, Q)
$$

que cletermina a ordem para execular a prova. O procedimento relacionado a cste átomo é o seguinte:

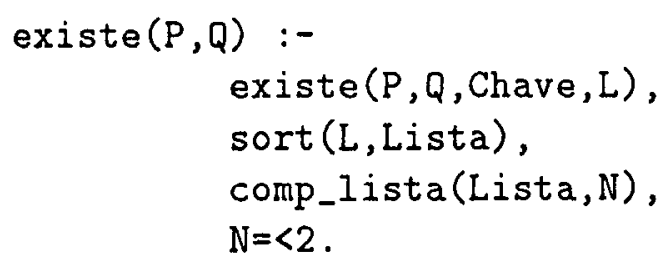


existe $(P, Q$, Chave, Lista) :-

$\operatorname{exec}(Q$, Chave, L1),

$\operatorname{exec}(P$, Chave, L2),

concatena(L1,L2, Lista).

onde o argumento Chave liga os elementos da prova de cada átomo e Lista contém as relações consultadas durante o procedimento de prova.

\subsection{Geração de Respostas}

No sistema proposto, as respostas às requisições do usuário não são apresentadas através de sentenças em linguagem natural, isto é, não é utilizado um processamento de linguagem natural para gerar as respostas. Os dados obtidos pela consulta à base de dados são apresentados diretamente.

\subsection{Interação com Usuário}

Este módulo é simples e tem como objetivo fornecer recursos para que o usuário introduza suas requisições e ativar os outros módulos do sistema, que são responsáveis basicamente pela análise da requisição e acesso ao conhecimento específico.

As Figuras 7.2, 7.3, 7.4 ilustram a realização de requisições através da Interface em Linguagem Natural. 


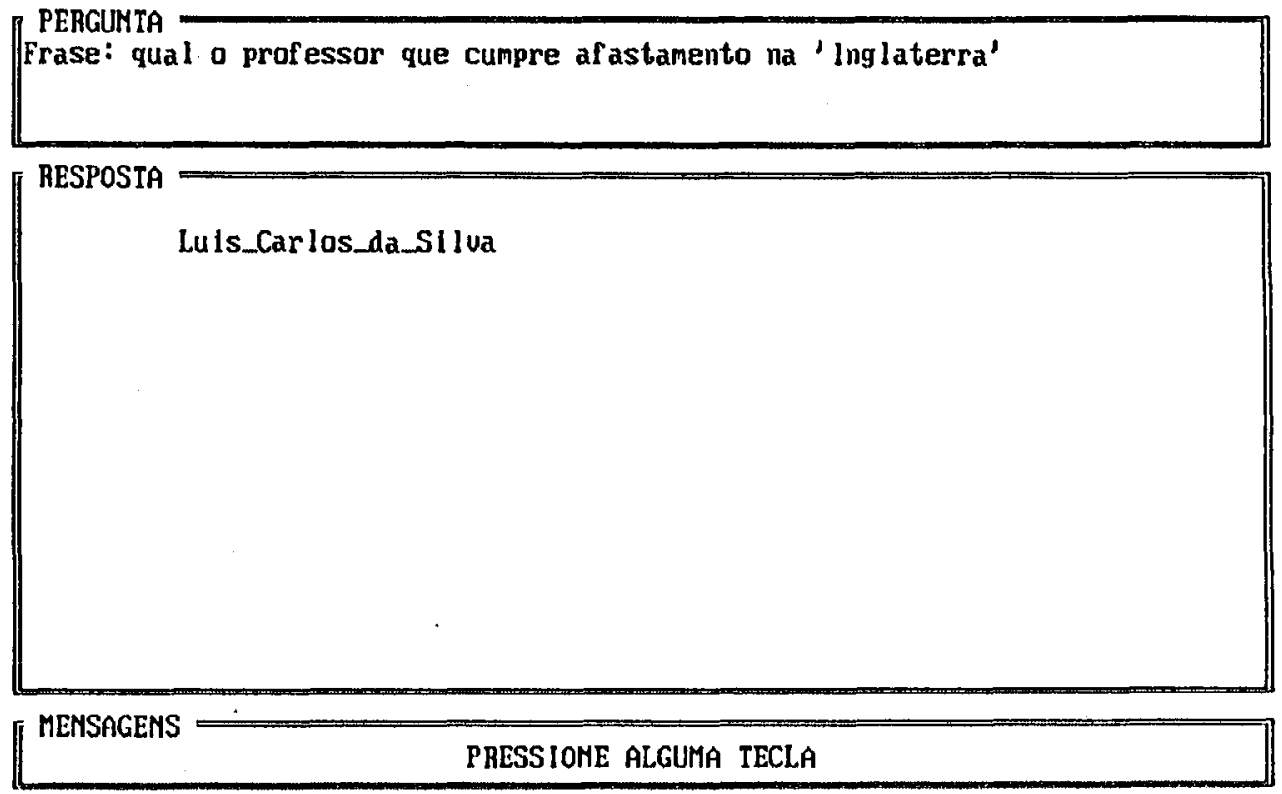

Figura 7.2: Exemplo de Utilização da Interface em Linguagem Natural

PERGUMTA

Frase: qual o professor con categoria ms1

RESPOSTA

MENSHGENS

MAO EXISTE RESPOSTA CONHECIDA

Figura 7.3: Exemplo de Utilização da Interface em Linguagem Natural 
PERGUNTA

Frase: qual e a categoria de 'Jose'

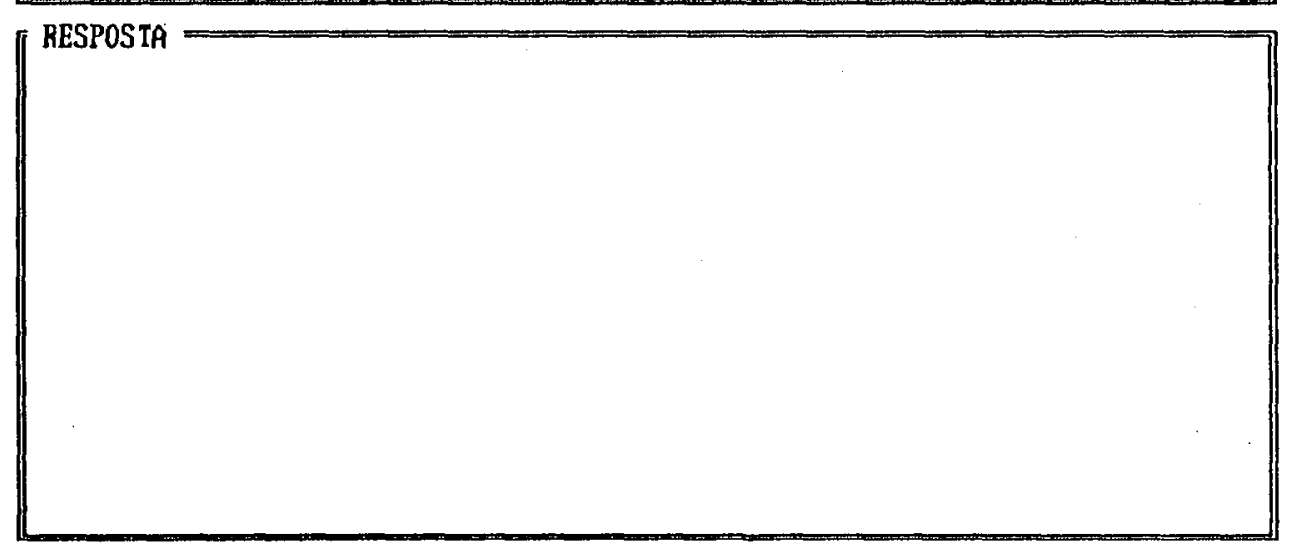

[f MENSAGENS

FRASE MAO RECONHECIDA

Figura 7.4: Exemplo de Utilização da Interface em Linguagem Natural 


\subsection{Adaptação do Sistema Proposto a Novos Domínios de Aplicação}

Para adaptar o sistema a um novo domínio, é necessário que sejam realizadas modificações nos módulos que são dependentes do domínio escolhido. Estas modificações podem ser divididas em três fases:

- a adaptação (ou implementação no caso da base de dados ser implementadada em outro SGBD) do Tradutor;

- a aquisição do vocabulário de interação dependente do domínio de aplicação, bem como todas as possibilidades de relacionamento das palavras do vocabulário através de preposições ou construções verbais - o que é realizado através do Sistema GBC - pelo usuário especialista;

- a implementação, pelo usuário especialista, do módulo de acesso à base de dados, ou seja, procedimentos relacionados a cada átomo que possa compor as expressões lógicas no domínio de aplicação escolhido.

\subsection{Considerações Finais}

Neste capítulo foi apresentada a estrutura da Interface em Linguagem Natural do sistema proposto. A interface possui módulos para realizar a leitura da requisição do usuário, realizar a análise desta requisição produzindo uma expressão lógica que é a representação do significado, executar a consulta à base de dados a partir da expressão lógica para obter a resposta e apresentar a resposta ao usuário. Foram apresentadas também algumas estruturas da representação da informação e alguns procedimentos que fazem parte destes módulos. 


\section{Capítulo 8}

\section{Conclusões}

O objetivo principal deste trabalho foi desenvolver uma interface em linguagem natural para acesso a bases de clados de pequeno porte. Esta área de pesquisa é polênica, embora base de dados tenha sido um dos primeiros ambientes de pesquisa em linguagem natural. Muitos pesquisadores debatem sobre a validade ou não da continuidade destes estudos. Alguns aspectos importantes e difíceis doprocessamento de linguagem natural podem não ocorrer no contexto de consultas a bases de dados, o que pode ser uma característica favorável, uma vez que o sucesso de uma interface não depende da solução de todos os problemas de linguagem. Além disso, as bases de dados são um bom ambiente para testes, já que o sucesso do processamento é avaliado através da consulta gerada [Jones 84].

Considerando-se a utilização destes sistemas no cotidiano, uma pesquisa recente realizada por Sap e McGregor [Sap 92] concluiu que, apesar da existência de alguns sistemas comerciais, seu uso não é muito difundido. Isto ocorre devido, principalmente, à dificuldade do sistema em lidar com ambigüidade, em adaptá-lo a novas bases de dados e à sua limitação com relação à abrangência.

A proposta deste trabalho teve como origern o sistema proposto em [Rino 87]. Este sistema permitia realizar requisições em linguagem natural sobre um conjunto de referências bibliográficas. Foi realizado o estudo e adequação do sistema original para o domínio de aplicação escolhido. Esta adequação envolveu, entre outras atividades, a escollia das regras gramaticais utilizadas, modificaçóes em algumas regras para verificaşão semântica e a troca do modo de armazenamento dos ítens léxicos, que neste trabalho é realizado através de árvores-B que melhora o tempo de acesso às informações. Foi desenvolvido o sistema GBC por Monteiro, que permite maior facilidade na aquisição do vocabulário específico no caso de adaptação do sistema a um novo domínio.

Além destas atividades, foi implementado o módulo de acesso ao conhecimento 
específico, que apresenta características diferentes para cada aplicação escolhida. No caso do sistema apresentado neste trabalho, o que o diferencia do sistema original é o número de tipos de registros diferentes:

- no sistema original todas as informações estavam contidas em um único tipo de registros, o que facilita muito o acesso a estas informações;

- no sistema proposto neste trabalho existem vários - vinte e cinco - tipos diferentes de registros, o que determinou detalhes especificos na implementação do módulo de acesso, como citado na Seção 7.3 .

O sistema proposto realiza as consultas em uma base de dados em Prolog que contém informações atuais sobre os colegiados e comissões do ICMSC - USP. Esta base de dados em Prolog é obtida a partir de arquivos que contêm informações atuais, além de informaçôes sobre o histórico da vida profissional de alguns dos elementos que participam dos colegidos e comissões, manipulados através de um SGBD - o Clipper.

Algumas considerações devem ser feitas com relação às escolhas para a implementação. Neste trabalho foi utilizado o Clipper - não por ser o sistema mais apropriado para o desenvolvimento do trabalho, mas por estar disponivel. O ideal seria ter um SGBD Prolog, evitando assim a duplicação de informações. Devese considerar que a base de dados da aplicação desenvolvida não possui grande volume de dados e nem todas as informações contidas na base são duplicadas apenas as que dizem respeito a fatos atuais - não prejudicando a utilização do sistema com relação à capacidade de memória. Além disso, não são realizadas alterações com freqüência na base de dados proposta, não exigindo que o Tradutor para Prolog seja ativado constantemente. Percebe-se assim, que o sistema, como proposto, é mais adequado a domínios que não possuam grande massa de dados e que suas informações não sejam constanternente atualizadas. A escolha da linguagem Prolog para implementar a interface em linguagem natural para esta base de dados restrita, deve-se à especial aplicabilidade desta linguagem no processamento de linguagem natural.

O sistema desenvolvido utiliza a linguagem natural como meio de comunicação entre o usuário e o computador, através de requisições. As requisições que o sistema reconhece são do tipo $Q u$ (qual, quando, etc). Entretanto, existem várias maneiras de se expressar uma requisição e, para que o sistema possa reconhecer outros tipos de construções de sentenças, é necessário que sejam incluídas novas regras para reconhecer essas novas construções sintáticas.

O processamento sintático não verifica dependência contextual quanto a gênero e número ou conjugação de verbos, o que pode ser facilmente introduziclo. As 
regras gramaticais reconhecem construções verbais para verbos transitivos diretos e indiretos, intransitivos e auxiliares, mas no dominio escolhido não ocorreram construções com verbos transitivos indiretos e os programas para tratamento semântico de verbos auxiliares não foram implementados. Entretanto, as requisições que envolvem verbos auxiliares podem ser expressas de outras maneiras, através de outras construções sintáticas. Por exemplo, a requisição

\section{Qual é a Categonia de José?}

não pode ser realizada através da Interface em Linguagem Natural implementada neste trabalho, mas pode ser expressa da seguinte maneira:

\section{Qual a CATEgonia de José?}

Alguns dos aspectos do processamento de linguagem natural abordados neste sistema são:

- tratamento de sinônimos;

- ligações semânticas introduzidas por verbos e preposições;

- transformação de símbolos terminais, introduzindo ítens equivalentes com maior poder explicativo;

- tratamento de sentenças relativas com termos extrapostos.

O sistema não lida com alguns aspectos do processamento de linguagem natural, entre eles:

- negação;

- conjunção;

- diálogo;

- elipses;

- preposições temporais.

A aplicação escolhida apresenta caracteristicas que foram favoráveis ao desenvolvimento do sistema, tais como: 
- falta de ambigüidade léxica;

- vocabulário restrito;

- as requisições não são complexas;

- conhecimento sobre o que os usuários desejam saber.

Nesta primeira versão, o usuário introduz suas requisições digitando a sentença. Este método apresenta alguns problemas, pois o usuário está limitado ao subconjunto da linguagem que o sistema reconhece mas ele não conhece, a princípio, este limite. Uma solução seria a utilização de menus, que associam o poder de expressão da lingugem natural com a facilidade de uso. As interfaces que utilizam menus podem usar a gramática para selecionar a cada passo da construção da requisição as possibilidades de palavras ou frases de acordo com os ítens selecionados anteriormente. Assim, a requisição é analisada enquanto é construída eliminando os problemas de erros de digitação ou construção de sentenças inválidas, além de estar explícita a capacidade do sistema.

Um aspecto importante do sistema proposto é que ele foi desenvolvido com o objetivo de facilitar sua adaptação a novos domínios, tentando apresentar um modelo de aplicação de processamento de linguagem natural.

São várias as sugestões para trabalhos futuros a firn de dar continuidade ao estudo realizado neste trabalho, entre elas:

- adaptação da gramática para realizar a interface através de menus;

- adaptação do sistema a um novo domínio de aplicação;

- tratamento de alguns aspectos do processamento de linguagem natural que não foram abordados neste trabalho;

- inclusão de regras gramaticais para que o sistema reconheça outras construções sintáticas - para requisições com respostas do tipo confirmação / recusa, por exemplo;

- estudo de uma nova expressão lógica resultante da análise da requisição do usuário, que facilite e otimize a acesso às informações da base de dados. 


\section{Bibliografia}

[Allen 88] Allen, J. Natural Language Understanding. The Benjamin/Cummings Publishing Company, Inc., 1988.

[Arias 92] Arias, C.I.S. Um Assistcule Especialista para Especificaşuão de Requisitos. Dissertação de Mestrado, IMEC-UNICAMP, MAio, 1992.

[Arity 90] Arity Corporation The Arity/Prolog Programming Language., 1990.

[Ballard 86] Ballard, B.; Stumberger, D. Semmantic Acquisition in TELI. Proceedings of the 24th Annual Meeting of the ACL, pp. 20-9, New York, 1986.

[Ballard 87] BAllard, B.; Jones, M. Computational Linguistics. Encyclopedia of Artificial Intelligence, New York, Wiley Interscience, pp. 133,151, 1987.

[Bates 86] Bates, M.; Moser, M.G.; Stallard, D. The IRUS Transportable Natural Language Database Interface. Expert Database Systems, Menlo Park, L. Kerschberg (editor), pp. 617-630, 1986.

[Bates 87] Bates, M. Natural Language Interfaces. Encyclopedia of Artificial Intelligence, New York, Wiley Interscience, pp. 655-660, 1987.

[Binot 88] Binot, J.L. et al. LOKI: A Logic Oriented Approach to Data and Knowledge Bases Supporting Natural Language Interaction. London, Scicon Ltd, 1988.

[Branco 87] Branco, A.C.S. Semântica para Processamento de Linguagem Natural. Dissertação de Mestrado, IME-RJ, 1987.

[Bratko 90] Bratko, I. Prolog Programming for Artificial Intelligence. Addison Wesley, 1990.

[Bronnenberg 80] Bronnenberg, W.J.H.J. The Question Answering System PIILIQA1. Natural Language Question Answering Systems, London, L. Bolc (editor), pp. 217-305, 1980. 
[Byte 86] Integrated Software with Macros and an Intelligent Assistant. Byte, Vol. 11, № 1, pp. 120-128, January, 1986.

[Chen 76] Chen, P.P.S. The Entity-Relationship Model - Toward a Unified View of Data. ACM Transactions on Database Systems, Vol. 1, № 1, pp. 9-36, March, 1976.

[Clocksin 81] Clocksin, W.F.; Mellish, C.S. Programming in Prolog. New York, Springer-Verlag, 1981.

[Cood 74] Cood, E.; Arnold, R.; Cadiou, J.; Chang, C.; Roussopoulos, N. Seven Steps to RENDEZVOUS with Casual User. Database Management, North-Holland, pp. 179-200, 1974.

[Copestake 90] Copestake, A.; Jones, K.S. Natural Language Interfaces to Databases. The Knowledge Engineering Review, Vol. 5, № 4, pp. 225-49, 1990.

[Date 84] Date, C.J. A Guide to DB2. Addison-Wesley, 1984.

[Date 88] Date, C.J. Introdução a Sistemas de Bancos de Dados. Rio de Janeiro, Campus, 1988.

[Franco 92] Franco, J.L.; Monard, M.C. Meta Interpretadores Prolog. Notas Didáticas do ICMSC-USP, № 6, Novembro, 1992.

[Furtado 88] Furtado, A.L.; Santos, C.S. Organização de Bancos de Dados. Rio de Janeiro, Campus, 1988.

[Garavaglia 87] Garavaglia, S. Prolog Programming T'echniques and Applicalions. New York, Harper \& Row, 1987.

[Geetha 90] Geetha, T.V.; Subramanian, R.K. Representing Natural Language With Prolog. IEEE Software, Vol. 7, № 2, pp. 85-92, March, 1990.

[Ginsparg 83] Ginsparg, J. A Robust Portable Natural Language Database Interface. Proceedings of the Conference on Applied Natural Language Processing, Santa Monica, pp. 25-31, 1983.

[Green 61] Green, B. et al. BASEBALL: An Automatic Question Answer. Proceedings of the Western Joint Computer Conference, Vol. 19, pp. 545-9, 1961 .

[Grosz 87] Grosz, B.J.; Appelt, D.E.; Martin, P.A.; Pereira, F.C.N. TEAM: An Experiment in the Design of Transportable Natural-Language Interfaces. Artificial Intelligence, Vol. 32, № 2, pp. 173-243, 1987. 
[Haas 83] Haas, N.; Hendrix, G.G. Learning Without Beeing Told: Acquiring Knowledge for Information Management. Machine Learning, Palo Alto, R. S. Michalski, J. G. Carbonell and T. M. Mitchel (editores), pp. 405$27,1983$.

[Harris 77] Harris, L.R. User Oriented Database Query with the ROBOT Natural Language Query System. International Journal of Man-Machine Studies, № 9, pp. 697-713, 1977.

[Harris 80] Harris, L.R. ROBOT : A High Performance Natural Language Interface for Database Query. Natural Language Based Computer Systems, London, Carl Hanser Verlag, pp. 285-318, 1980.

[Harris 84] Harris, L.R. Expirience with INTELLECT: Artificial Intelligence Technology Transfer. The AI Magazine, Vol. 5, № 2, pp. 43-50, 1984.

[Hendrix 78] Hendrix, G.G.; Sacerdoti, E.D.; Sagalowicz, D.; Slocum, J. Developing a Natural Language Interface to Complex Dala. ACM Transactions on Database Systems, Vol. 3, № 2, pp. 105-47, June, 1978.

[Hendrix 82] Hendrix, G.G. Natural-Language Interface. American Journal of Computational Linguistics, Vol. 8, № 2, pp. 56-61, April-June, 1982.

[James 80] James,E.B. The User Interface. The Computer Journal, Vol. 23, № 1, pp. 25-8, 1980.

[Jones 84] Jones, K.S. et al. Panel: Natural Language and Databases, Again. Proceedings of the 22nd Annual Meeting of the ACL, Stanford, CA, pp. 182-93, 1984.

[Kaplan 82a] Kaplan, S.J. Cooperative Responses from a Natural Language Query System. Artificial Intelligence, Vol. 19, № 2, pp. 165-87, 1982.

[Kaplan 82b] Kaplan, S.J.; Ferris, D. Natural Language in the DP World. Datamation, Vol. 28, №9, pp. 114-20, August, 1982.

[Kasik 90] Kasik, T.; Lusk, E.; Olson, R.; Overbeek, R.; Tuecke, S. Prototyping Databases in Prolog. The MIT Press, pp. 1-30, 1990.

[Leite 91] Leite, J.C. A Interaçào entre Usuários e Sislemas de Compuladores em Linguagem Natural Orientada por Menus. Dissertação de Mestrado, Departamento de Informática, Pontifícia Universidade Católica do Rio de Janeiro, Rio de Janeiro, 1991.

[Marcus 87] Marcus, C. Prolog Programming - Applications for Database Systems, Expert Systems, and Natural Language Systems. Addison Wesley, 1987. 
[McCord 87] McCord, M. Natural Language Processing in Prolog. Knowledge Systems and Prolog - A Logical Approach to Expert Systems and Natural Language Processing, Addison-Wesley, pp. 291-402, 1987.

[Miranda 86] Miranda, C.S. Processamento de Linguagem Natural. Dissertação de Mestrado, IME-RJ, 1986.

[Monard 93] Monard, M.C.; Nicoletti, M.C. Técnicas Avançadas de Programação Prolog para Tratamento de Árvores. Notas Didáticas do ICMSC-USP, № 8 , Fevereiro, 1993.

[Monteiro 92] Monteiro, J.; Rino, L.H.M. Adequamento de um Sistema de Linguagem Natural para Interpretação de Perguntas. Relatório Técnico, 1992.

[Pereira 83] Pereira, F. Logic for Natural Language Analysis. Phd Thesis, 1983.

[Rino 87] Rino, L.H.M. Uma Interface em Linguagem Natural para Recuperação de Conhecimento. Dissertação de Mestrado, ICMSC-USP, 1987.

[Sap 92] Sap, M.N.M.; McGregor,D.R. Natural Language Interfaces to Databases : The State of the Art. Research Report - IKBS-7-92, University of Strathclyde, May, 1992.

[Savadovsky 88] Savadovsky, P. Introdução ao Projeto de Interfaces em Linguagem Natural. São Paulo, Edição SID, 1988.

[Scha 83] Scha, R.J.H. Logical Foundations for Question Answering. Phd Thesis, 1983.

[Sgall 89] Sgall, P. The Tasks of Semantics and the Perspectives of Computers. Computers and Artificial Intelligence, Vol. 8, № 5, pp. 403-21, 1989.

[Shapiro 75] Shapiro, S.C.; Rwasny, S.C.. Interactive Consulting Via Natural Language. CACM, Vol. 18, № 8, pp. 459-62, August, 1975.

[Spiegler 83] Spiegler, I. Modelling Man-machine Interface in a Dala Base Environment. International Journal in Man-Machine Studies, Vol. 18, pp. 55-70, 1983.

[Templeton 79] Templeton, M. EUFID: A Friendly and Filcxible fronlend for Data Management Systems. Proceedings of the Seventeenth Annual Meeting of the ACL, pp. 91-93, 1979.

[Tennant 87] Tennant, H. Menu-Based Natural Language. Encyclopedia of Artificial Intelligence, New York, Wiley Intercience, pp. 594-597, 1987. 
[Vidal 90] Vidal, A.G.R. CLIPPER - Versão Summer 87. Rio de Janeiro, Livros Técnicos e Científicos Editora Ltda, Vol. 1 e 2, 1990.

[Wallace 84] Wallace, M. Communicating with Databases in Natural Language. Ellis Horwood Limited, 1984.

[Waltz 78] Waltz, D.L. An English Language Question Answering System for a Large Relational Dalabase. CACM, Vol. 21, №7, pp. 526-39, July, 1978.

[Weischedel 89] Weischedel, R.M. A Hybrid Approach to Representation in the JANUS Natural Language Processor. Proceedings of the 27th ACL, pp. 193-202, Vancouver, 1989.

[Wirth 76] Wirth, N. Algorithms + Data Structures = Programs. Prentice-Hall, 1976.

[Woods 72] Woods, W. The LUNAR Sciences Natural Language Information System. Final Report, Beranek and Newman, Cambridge, MA, 1972. 